Daniela Aparecida de Brito Cervilha

\title{
Estudo da resposta imunológica em modelo experimental da DPOC por exposição à fumaça de cigarro e exacerbação por instilação de LPS
}

Tese apresentada à Faculdade de Medicina da Universidade de São Paulo para obtenção do título de Doutor em Ciências

Programa em Fisiopatologia Experimental Orientadora: Prof. ${ }^{\mathrm{a}}$ Dr. $^{\mathrm{a}}$ Fernanda Degobbi Tenorio Quirino dos Santos Lopes

São Paulo 
Daniela Aparecida de Brito Cervilha

\title{
Estudo da resposta imunológica em modelo experimental da DPOC por exposição à fumaça de cigarro e exacerbação por instilação de LPS
}

\author{
Tese apresentada à Faculdade de Medicina da \\ Universidade de São Paulo para obtenção do título de \\ Doutor em Ciências \\ Programa em Fisiopatologia Experimental \\ Orientadora: Prof. ${ }^{a}$ Dr. $^{\mathrm{a}}$ Fernanda Degobbi Tenorio \\ Quirino dos Santos Lopes
}

(Versão corrigida. Resolução CoPGr6018, de 03 de outubro de 2011.

A versão original está disponível na Biblioteca FMUSP)

São Paulo 


\section{Dados Internacionais de Catalogação na Publicação (CIP)}

Preparada pela Biblioteca da

Faculdade de Medicina da Universidade de São Paulo

Oreprodução autorizada pelo autor

Cervilha, Daniela Aparecida de Brito

Estudo da resposta imunológica em modelo

experimental da DPOC por exposição à fumaça de cigarro

e exacerbação por instilação de LPS / Daniela

Aparecida de Brito Cervilha. -- São Paulo, 2018.

Tese (doutorado)--Faculdade de Medicina da

Universidade de São Paulo.

Programa de Fisiopatologia Experimental.

Orientadora: Fernanda Degobbi Tenorio Quirino

dos Santos Lopes.

Descritores: 1.Doença pulmonar obstrutiva crônica 2. Fumaça 3. Cigarro 4.Exacerbação 5.Lipopolissacarídeo 6.Interleucina-10 7.Resposta Th17 8.Células T regulatórias

$\mathrm{USP} / \mathrm{FM} / \mathrm{DBD}-292 / 18$

Responsável: Eidi Raquel Franco Abdalla - CRB-8/4901 


\section{Dedicatória}

Dedico

a minha família, pois vocês são meu alicerce, tudo que consegui até agora só foi possível graças ao amor, apoio e incentivo de vocês. Obrigada por sempre estarem ao meu lado me incentivando a correr atrás dos meus sonhos com respeito, humildade, honestidade e amor. Graças a todos vocês, tive força para superar os obstáculos e conquistar mais um sonho. Minha eterna gratidão por ter vocês na minha vida! 


\section{Agradecimentos}

Agradeço à DEUS, pois sem sua permissão nada seria possível. Obrigada meu DEUS pelas oportunidades, gratidão sempre!!! Agradeço todas as dificuldades e alegrias durante essa caminhada. Tudo é possível quando se acredita NELE!

Meu agradecimento em forma de gratidão ao Prof. Dr. Milton de Arruda Martins. Prof. muito obrigada por ter aberto as portas do seu laboratório e ter me dado a oportunidade de realizar esse sonho.

Agradeço de forma imensurável a minha orientadora Prof. ${ }^{\text {a }}$ Dra. Fernanda Degobbi Tenorio Quirino dos Santos Lopes. Fê, obrigada por acreditar em meu potencial, pela confiança, profissionalismo, paciência, ensinamentos, pelos momentos de amizade, conselhos, apoio e compreensão. Você é uma pessoa iluminada, admirável e fez a diferença na minha vida! Só tenho que agradecer á Deus por nossos caminhos terem se cruzado!

Ao meu marido Guilherme, que sempre me apoiou e me incentivou na busca desse sonho. Obrigada por me fazer uma pessoa melhor a cada dia, pela paciência, compreensão e amor. Gui, sou grata à Deus por ter você do meu lado. Obrigada por tudo!!!

Aos meus pais agradeço por tudo que fizeram e fazem por mim até hoje. Tenho muito orgulho de ter vocês como pais! Que sorte a minha Deus ter me permitido caminhar ao lado de vocês. Vocês são exemplos de vida, minha inspiração! Muito obrigada meus queridos pais!

Ao meu irmão Fábio, obrigada pelo apoio, incentivo e por estar sempre presente na minha vida. Aos irmãos Wagner e Wander, agradeço pela confiança e incentivo. Obrigada por estarem ao meu lado, mesmo distantes. Ao irmão de coração Elton, obrigada por acreditar no meu potencial e sempre me apoiar e incentivar.

A minha Melzinha não poderia ficar de fora. Obrigada minha "filhinha" dog por fazer parte da minha família e me distrair nos momentos de estresse com suas brincadeiras, deixando a minha trajetória mais leve.

Aos demais familiares e amigos muito obrigada pelo incentivo e apoio sempre!

Agradeço a família LIM-20: A minha "Best" Tiyaki (minha companheira de tese) por tornar minha jornada mais leve, feliz e divertida, esse doutorado não teria sido tão bom se não fosse você, Ty. Passamos por tantas coisas juntas e só tenho que agradecer por você ter participado desse ciclo, amizade, respeito e gratidão são algumas 
palavras que podem definir tudo que vivenciamos, obrigada por tudo! As amigas, Camila e Isabella, que fizeram na maioria das vezes um show nos bastidores, me apoiando e me guiando sempre. Meninas, obrigada por caminharem comigo e deixarem essa caminhada doce e leve. Ao "Team Fê Lopes": Juliana, Julia, Larissa e Alyne. Meninas, agradeço a paciência, a amizade, a boa vontade em ajudar sempre e os ensinamentos da prática laboratorial. Aos amigos, Jader e Kaique que apareceram no finalzinho, mas que também tiveram sua contribuição, obrigada pelos momentos de descontração e risadas.

Agradeço também aos demais colegas de pós-graduação pelo apoio e por terem compartilhado tantas expectativas, angústias e conhecimentos. Obrigada!

Ao Prof. Dr. Rodolfo de Paula Vieira, obrigada por todo ensinamento e paciência. Ao Manoel e Alana, vocês foram muito solícitos e receptivos, obrigada pela ajuda durante os experimentos. Ao Prof. Dr. Rildo, obrigada por toda paciência e disponibilidade que dedicou para que pudéssemos finalizar este trabalho.

Aos membros da banca de qualificação Prof. ${ }^{a}$ Dra. Edna, Prof. ${ }^{a}$ Dra. Carla, Prof. ${ }^{a}$ Dra. Elnara, Prof. ${ }^{\text {a }}$ Dra. Iolanda, Prof. Dr. Rogério, obrigada pelas sugestões e críticas que foram de extrema importância para o aprimoramento deste trabalho.

Aos membros da banca examinadora Prof. Dr. Renato, Prof. ${ }^{a}$ Dra. Cláudia, Prof. a Dra. Ana Paula, Prof. Dr. Celso, obrigada pela disponibilidade, pelo tempo gasto na leitura deste trabalho e pelas contribuições pessoais e científicas acerca desta tese.

Aos demais professores e seus respectivos alunos e também os funcionários da FMUSP (Davi, Profa. Dra. Beatriz, Dra. Francine, Prof. Dra. Clarice, Rosana, Sara, Profa. Dra. Fernanda Arantes, Profa. Dra. Thais Mauad), que mesmo indiretamente estavam engajados e contribuíram de alguma forma para minha formação pessoal e acadêmica. Obrigada pela ajuda e momentos de descontração.

Ao Biotério Central da FMUSP, em especial ao Luiz Afonso, por terem fornecido os animais que foram essenciais para a execução deste trabalho.

Pessoas, eu agradeço a DEUS por vocês existirem na minha vida. Vocês são essenciais e estarão sempre no meu coração! Como diz Charles Chaplin: "Cada pessoa que passa em nossa vida, passa sozinha, é porque cada pessoa é única e nenhuma substitui a outra! Cada pessoa que passa em nossa vida passa sozinha e não nos deixa só porque deixa um pouco de si e leva um pouquinho de nós. Essa é a mais bela responsabilidade da vida e a prova de que as pessoas não se encontram por acaso". E assim foi com todos vocês! Obrigada, obrigada e obrigada! 
À CAPES, pelo apoio financeiro.

À FMUSP por toda infra estrutura e por permitir a realização deste trabalho, me proporcionando a cada dia um novo conhecimento.

E por fim, mas não menos importante do que qualquer um citado neste trabalho o meu sincero e eterno agradecimento aos animais. Muito Obrigada!

E se me perguntarem se valeu a pena... Sim, faria tudo de novo, pois valeu muito a pena! 


\section{Epígrafe}

"If you can dream it, you can do it" ("Se você pode sonhar, você pode fazer").

Walt Disney 
Esta tese está de acordo com as seguintes normas, em vigor no momento desta publicação:

Referências: adaptado de International Committee of Medical Journals Editors (Vancouver).

Universidade de São Paulo. Faculdade de Medicina. Divisão de Biblioteca e Documentação. Guia de apresentação de dissertações, teses e monografias. Elaborado por Anneliese Carneiro da Cunha, Maria Julia de A. L. Freddi, Maria F. Crestana, Marinalva de Souza Aragão, Suely Campos Cardoso, Valéria Vilhena. 3a ed. São Paulo: Divisão de Biblioteca e Documentação; 2011.

Abreviaturas dos títulos dos periódicos de acordo com List of Journals Indexed in Index Medicus. 


\section{SUMÁRIO}

Lista de abreviaturas, símbolos e siglas

Lista de figuras

Lista de tabelas

Resumo

Abstract

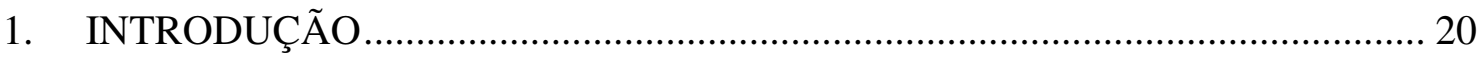

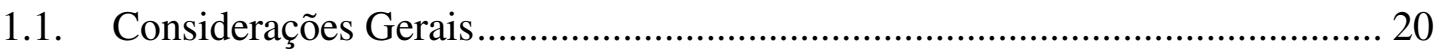

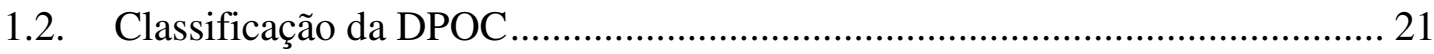

1.3. Mecanismos fisiopatológicos envolvidos no desenvolvimento da DPOC ...... 23

1.3.1. Desequilíbrio protease - antiprotease .............................................. 23

1.3.2. Estresse Oxidativo ......................................................................... 24

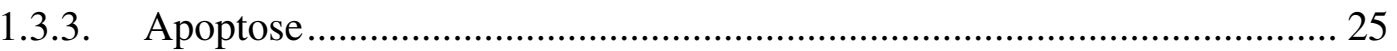

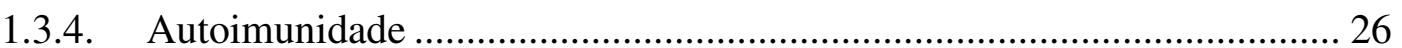

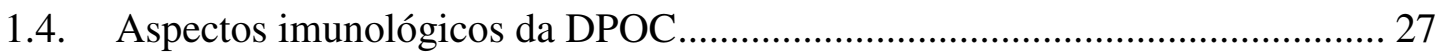

1.4.1. Imunidade inata: Tipos celulares e mediadores inflamatórios ................ 27

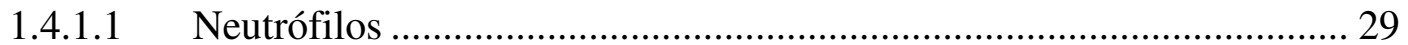

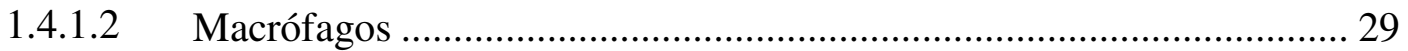

1.4.2. Imunidade adaptativa: Tipos celulares e mediadores inflamatórios......... 30

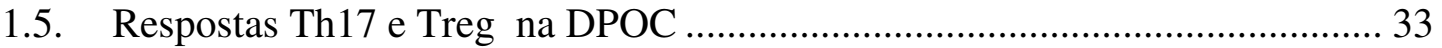

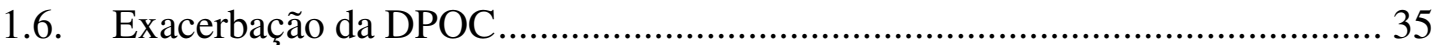




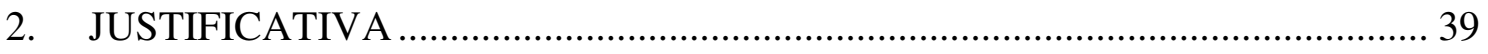

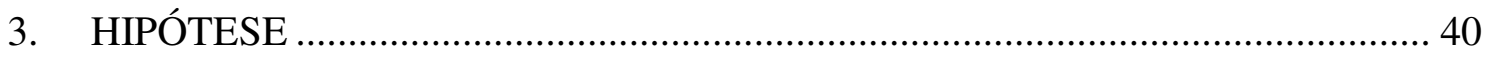

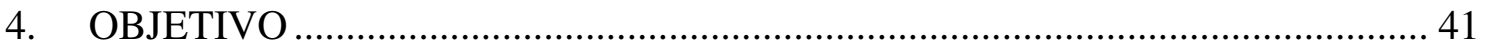

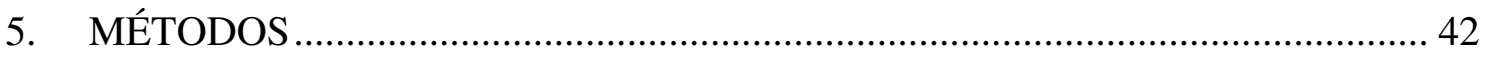

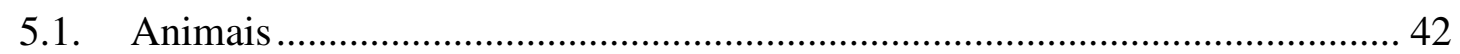

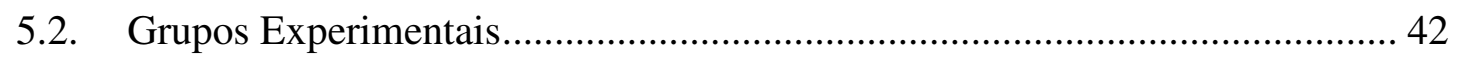

5.3. Indução do enfisema pulmonar por exposição à fumaça de cigarro ................. 45

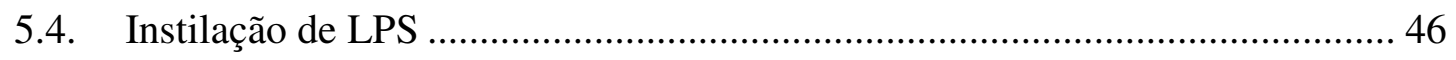

5.5. Avaliação da Mecânica do Sistema Respiratório............................................ 46

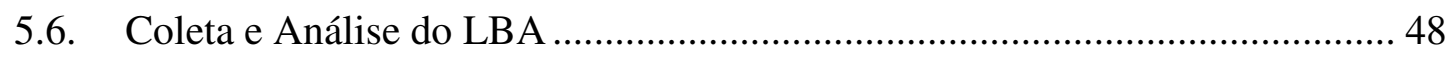

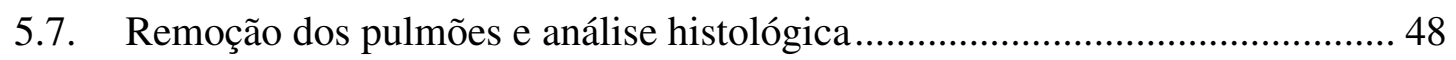

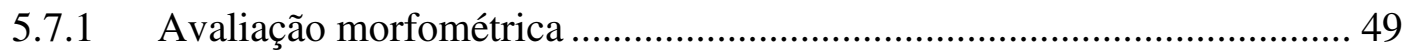

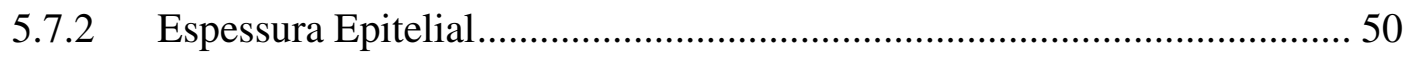

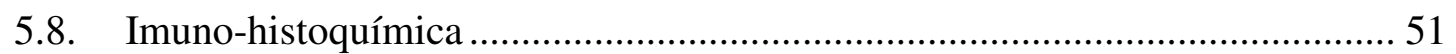

5.8.1. Contagem de células positivas por área de parênquima .......................... 53

5.9. Dupla marcação por imuno-histoquímica.................................................... 54

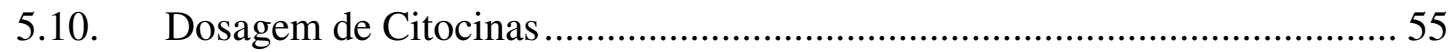

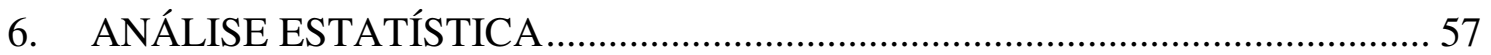

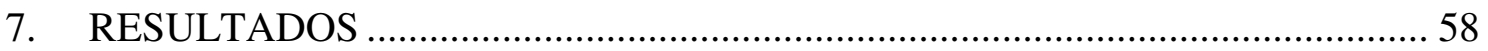

7.1. Avaliação da mecânica do sistema respiratório ............................................. 58

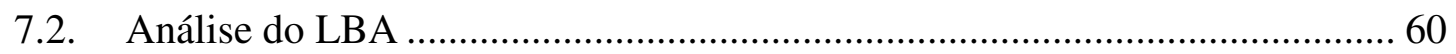


7.3. Avaliação morfométrica

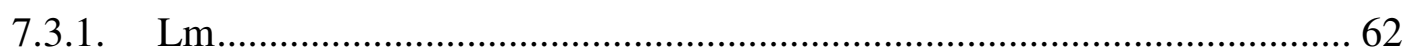

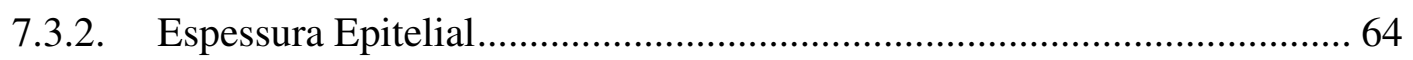

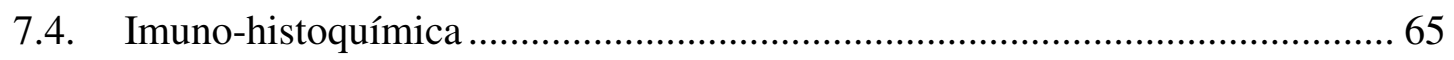

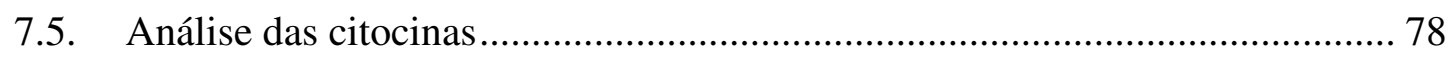

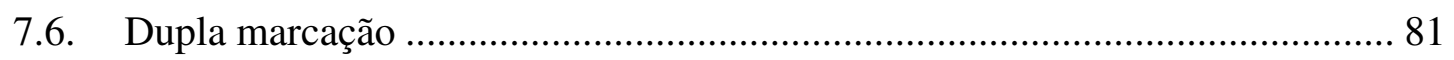

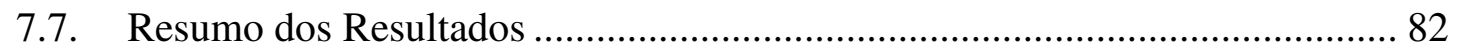

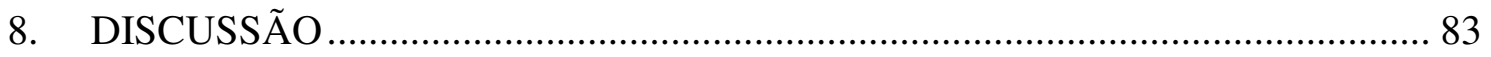

9. CONCLUSÃO

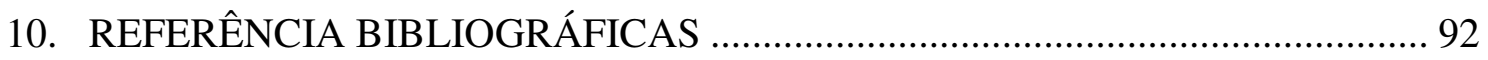




\section{LISTA DE ABREVIATURAS, SÍMBOLOS E SIGLAS}

\begin{tabular}{|c|c|}
\hline $\mathrm{cmH}_{2} \mathrm{O}$ & - Centímetros de água \\
\hline $\mathrm{CO}$ & - Monóxido de carbono \\
\hline CLPS & - Grupo controle lipopolissacarídeo \\
\hline CSAL & - Grupo controle salina \\
\hline CVF & - Capacidade vital forçada \\
\hline CXCL1 & - Quimiocina da família CXC ligante um \\
\hline CXCL2 & - Quimiocina da família CXC ligante dois \\
\hline CXCR2 & - Receptor de quimiocina tipo dois \\
\hline $\mathrm{DAB}$ & - Diaminobenzidina \\
\hline DATASUS & - Departamento de informática do sistema único de saúde \\
\hline DC & - Células dendrítica \\
\hline DPOC & - Doença pulmonar obstrutiva crônica \\
\hline ELISA & $\begin{array}{l}\text { - Ensaio de imunoabsorção enzimática (Enzyme Linked ImmunoSorbent } \\
\text { Assay) }\end{array}$ \\
\hline EP & - Erro padrão \\
\hline ERO & - Espécies reativas de oxigênio \\
\hline et al & - E colaboradores \\
\hline$f$ & - Frequência em Hertz \\
\hline FLPS & - Grupo fumo lipopolissacarídeo \\
\hline FMUSP & - Faculdade de Medicina da Universidade de São Paulo \\
\hline FosfoStat3 & - Transdutor de sinal e ativador de transcrição três fosforilado \\
\hline FosfoStat5 & - Transdutor de sinal e ativador de transcrição cinco fosforilado \\
\hline Foxp3 & - Fator de transcrição para células T regulatória (Forkhead box p3) \\
\hline FSAL & - Grupo fumo salina \\
\hline g & - Gramas \\
\hline G & - Gauge \\
\hline Gtis & - Resistência tecidual do pulmão \\
\hline
\end{tabular}




\begin{tabular}{|c|c|}
\hline GOLD & - Global Initiative for Obstructive Lung Disease \\
\hline $\mathrm{h}$ & - Hora \\
\hline $\mathrm{HE}$ & -Hematoxilina e eosina \\
\hline Htis & - Elastância tecidual do pulmão \\
\hline $\mathrm{Hz}$ & - Hertz \\
\hline$i$ & - Unidade imaginária \\
\hline I $a w$ & - Inertância das vias aéreas \\
\hline IFN- $\gamma$ & - Interferon gama \\
\hline IL & - Interleucina \\
\hline IL-6 & - Interleucina seis \\
\hline IL-8 & - Interleucina oito \\
\hline IL-10 & - Interleucina dez \\
\hline IL-17 & - Interleucina dezessete \\
\hline IL-21 & - Interleucina vinte e um \\
\hline IL-23 & - Interleucina vinte e três \\
\hline i.p & - Intraperitoneal \\
\hline $\mathrm{L}$ & - Litros \\
\hline LBA & - Lavado brônquio alveolar \\
\hline LIM & - Laboratório de investigação médica \\
\hline Lm & - Intercepto linear médio \\
\hline LPS & - Lipopolissacarídeo \\
\hline LTB4 & - Leucotrieno B quatro \\
\hline $\mathrm{KC}$ & $\begin{array}{l}\text { - Quimiocina derivada de queratinócitos (Keratinocyte-derived } \\
\text { chemokine) }\end{array}$ \\
\hline $\mathrm{kg}$ & - Quilograma \\
\hline $\mathrm{mg}$ & - Miligramas \\
\hline MHC-2 & - Complexo de histocompatibilidade classe dois \\
\hline $\min$ & - Minuto \\
\hline MIP-2 & $\begin{array}{l}\text { - Proteínas inflamatórias de macrófagos dois (Macrophage } \\
\text { inflammatory protein-2) }\end{array}$ \\
\hline
\end{tabular}




\begin{tabular}{|c|c|}
\hline $\mathrm{mL}$ & - Mililitros \\
\hline $\mathrm{mm}$ & - Milímetros \\
\hline $\mathrm{mM}$ & - Milimolar \\
\hline MMP & - Metaloproteinase \\
\hline $\mathrm{NaCl}$ & - Cloreto de sódio \\
\hline $\mathrm{NF}-\kappa \mathrm{B}$ & - Fator nuclear kappa B \\
\hline NK & - Células assassinas naturais (Natural killer) \\
\hline $\mathrm{nm}$ & - Nanômetro \\
\hline PBS & - Tampão fosfato \\
\hline $\mathrm{pH}$ & - Potencial hidrogeniônico \\
\hline ppm & - Partículas por milhão \\
\hline Raw & - Resistência de via aérea do pulmão \\
\hline RNAm & - Ácido ribonucléico mensageiro \\
\hline $\mathrm{rpm}$ & - Rotações por minuto \\
\hline SAL & - Solução fisiológica $0,9 \%$ estéril \\
\hline Stats & $\begin{array}{l}\text { - Transdutores de sinal e ativadores de transcrição (Signal transducer } \\
\text { and activator of transcription) }\end{array}$ \\
\hline Stat3 & $\begin{array}{l}\text { - Transdutor de sinal e ativador de transcrição três (Signal transducer } \\
\text { and activator of transcription-3) }\end{array}$ \\
\hline Stat5 & $\begin{array}{l}\text { - Transdutor de sinal e ativador de transcrição cinco (Signal transducer } \\
\text { and activator of transcription-5) }\end{array}$ \\
\hline TGF- $\beta$ & - Fator de crescimento beta \\
\hline Th1 & - Células auxiliares (T helper) um \\
\hline Th2 & - Células auxiliares (T helper) dois \\
\hline Th17 & - Células auxiliares (T helper) dezessete \\
\hline TLR & - Receptor de membrana do tipo "toll" (Toll-like receptors) \\
\hline TLR2 & - Receptor de membrana do tipo "toll" dois \\
\hline TLR4 & - Receptor de membrana do tipo "toll" quatro \\
\hline TNF- $\alpha$ & - Fator de necrose tumoral alfa \\
\hline TPM & - Total de partículas em suspensão \\
\hline Treg & - Células T regulatória \\
\hline
\end{tabular}




\begin{tabular}{|c|c|}
\hline Tregs & - Células T regulatórias \\
\hline $\mathrm{V}$ & - Volume \\
\hline $\mathrm{V}^{\prime}$ & - Fluxo \\
\hline VEF1 & - Volume expirado no primeiro segundo \\
\hline $\mathrm{U}$ & - Unidade \\
\hline $\mathrm{x}$ & - Multiplicação - vezes \\
\hline $\mathrm{Z}(f)$ & - Impedância em função da frequência \\
\hline Zrs & - Impedância do sistema respiratório \\
\hline$\mu \mathrm{g}$ & - Microgramas \\
\hline$\mu \mathrm{L}$ & - Microlitros \\
\hline$\mu \mathrm{m}$ & - Micrômetro \\
\hline$\alpha$ & - Alfa \\
\hline$\alpha-1 \mathrm{AT}$ & - Alfa um antitripsina \\
\hline$\%$ & - Porcentagem \\
\hline${ }^{\circ} \mathrm{C}$ & - Graus Celsius \\
\hline$<$ & - Menor \\
\hline$=$ & - Igual a \\
\hline- & - Menos \\
\hline+ & - Positivo \\
\hline \pm & - Mais ou menos \\
\hline$\pi$ & $-\mathrm{Pi}$ \\
\hline
\end{tabular}




\section{LISTA DE FIGURAS}

Figura 1 - Esquema ilustrativo do desequilíbrio protease - antiprotease...................... 24

Figura 2 - Esquema ilustrativo da ativação da imunidade inata na DPOC ................... 28

Figura 3 - Esquema ilustrativo da diferenciação das células T CD4 naive ................... 33

Figura 4 - Esquema ilustrativo da resposta Th17/Treg na DPOC ............................. 35

Figura 5 - Representação esquemática dos grupos experimentais .............................. 44

Figura 6 - Linha temporal do protocolo experimental ............................................. 44

Figura 7 - Esquema ilustrativo da caixa de exposição à fumaça de cigarro.................. 46

Figura 8 - Retículo com 100 pontos e 50 retas utilizado para quantificação dos parâmetros morfométricos distais (subpleural) no parênquima pulmonar.

Figura 9 - Retículo com 100 pontos e 50 retas utilizado para quantificação dos parâmetros morfométricos proximais (peribronquial) no parênquima pulmonar. ......... 50

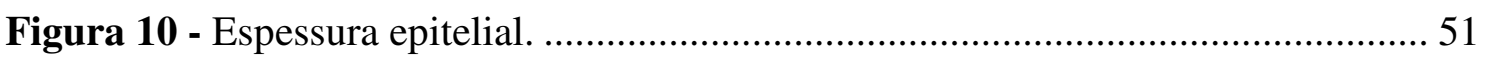

Figura 11 - Foto ilustrativa da contagem da área de parênquima pulmonar. ................ 54

Figura 12 - Avaliação da mecânica do sistema respiratório, Gtis. ................................ 58

Figura 13 - Avaliação da mecânica do sistema respiratório, Htis. ............................... 59

Figura 14 - Avaliação da mecânica do sistema respiratório, Raw. .............................. 59

Figura 15 - Representação gráfica do número de células inflamatórias totais no LBA.60

Figura 16 - Representação gráfica do número de macrófagos no LBA. ....................... 61

Figura 17 - Representação gráfica do número de neutrófilos no LBA.......................... 61

Figura 18 - Representação gráfica do número de linfócitos no LBA............................ 62

Figura 19 - Representação gráfica dos valores do Lm e fotomicrografias.................... 63

Figura 20 - Representação gráfica da espessura epitelial e fotomicrografias. .............. 64

Figura 21 - Representação gráfica do número de células positivas para macrófagos e marcação específica por imuno-histoquímica. 66 
Figura 22 - Representação gráfica do número de células positivas para neutrófilos e marcação específica por imuno-histoquímica.

Figura 23 - Representação gráfica do número de células positivas para CD4 e marcação específica por imuno-histoquímica.

Figura 24 - Representação gráfica do número de células positivas para CD8 e marcação específica por imuno-histoquímica. 70

Figura 25 - Representação gráfica do número de células positivas para Foxp3 e marcação específica por imuno-histoquímica.

Figura 26 - Representação gráfica do número de células positivas para Stat3 e marcação específica por imuno-histoquímica.

Figura 27 - Representação gráfica do número de células positivas para FosfoStat3 e marcação específica por imuno-histoquímica. 74

Figura 28 - Representação gráfica do número de células positivas para Stat5 e marcação específica por imuno-histoquímica.

Figura 29 - Representação gráfica do número de células positivas para FosfoStat5 e marcação específica por imuno-histoquímica. 77

Figura 30 - Quantificação da IL-6 no homogenato pulmonar. 78

Figura 31 - Quantificação da IL-17 no homogenato pulmonar. 79

Figura 32 - Quantificação da IL-10 no homogenato pulmonar. 79

Figura 33 - Quantificação de IFN- $\gamma$ no homogenato pulmonar. 80

Figura 34 - Quantificação da CXCL1 no homogenato pulmonar. 80

Figura 35 - Quantificação da CXCL2 no homogenato pulmonar. 81

Figura 36 - Dupla marcação para Foxp3/IL-10. 82

Figura 37 - Figura ilustrativa com o resumo dos resultados 82 


\section{LISTA DE TABELAS}

Tabela 1 - Especificações das marcações específicas por imuno-histoquímica 53

Tabela 2 - Especificações das dosagens de citocinas e quimiocinas 55 


\section{RESUMO}

Cervilha DAB. Estudo da resposta imunológica em modelo experimental da DPOC por exposição à fumaça de cigarro e exacerbação por instilação de LPS [tese]. São Paulo: Faculdade de Medicina, Universidade de São Paulo; 2018.

O tabagismo é o principal fator de risco para o desenvolvimento da doença pulmonar obstrutiva crônica (DPOC). A importância da imunidade adaptativa para este processo não está totalmente esclarecida, entretanto a inflamação persistente está associada à ocorrência de infecções e exacerbação da DPOC. O nosso objetivo foi desenvolver um modelo experimental de exacerbação da DPOC utilizando a exposição à fumaça de cigarro e instilação de lipopolissacarídeo (LPS), visando investigar os aspectos imunológicos. Camundongos machos (C57BL/6), foram divididos em 4 grupos. Grupo controle salina (CSAL) e grupo controle LPS (CLPS) que foram expostos ao ar filtrado durante 12 semanas e receberam duas instilações intratraqueais $(50 \mu 1)$ de salina ou LPS $(1 \mathrm{mg} / \mathrm{kg})$ com intervalo de 15 dias entre cada instilação e o grupo fumo salina (FSAL) e grupo fumo LPS (FLPS) que foram expostos à fumaça de cigarro e também receberam duas instilações intratraqueais de salina ou LPS com o mesmo intervalo de tempo entre as instilações e a mesma dosagem. Após 3 dias da última instilação os animais foram anestesiados, traqueostomizados e acoplados a um ventilador para pequenos animais para avaliação da mecânica respiratória. Em seguida, fizemos a coleta do lavado broncoalveolar (LBA) para avaliar o perfil inflamatório e posteriormente, os pulmões foram removidos e feitos cortes para análise do intercepto linear médio (Lm) subpleural e peribronquial, além da espessura epitelial. Também avaliamos a densidade de macrófagos, neutrófilos, células $\mathrm{T} \mathrm{CD}^{+}, \mathrm{CD}^{+}$e células $\mathrm{T}$ regulatória (Treg), células positivas para Stat3/5 e FosfoStat3/5 no parênquima pulmonar por imuno-histoquímica. Além disso, foram analisados por ELISA no homogenato pulmonar os fatores quimiotáticos (KC/CXCL1 e MIP-2/CXCL2) e interleucina (IL) (-17, -6, -10) e interferon gama (IFN-y). Observamos alteração da mecânica do sistema respiratório com aumento da resistência tecidual (Gtis) e elastância tecidual (Htis) nos animais expostos á fumaça de cigarro e desafiados com LPS. Nos grupos FSAL e FLPS observamos aumento de Lm (regiões subpleurais), e no grupo FLPS também observamos aumento de Lm nos espaços peribrônquicos e espessamento epitelial. A associação da fumaça de cigarro e o LPS, além de ter causado dano ao parênquima pulmonar mais difuso tanto em regiões subpleurais quanto em espaços peribrônquicos intensificou a resposta inflamatória com aumento de neutrófilos, macrófagos, células $\mathrm{T}$ $\mathrm{CD}^{+}$, células positivas para Stat3, FosfoStat5 e CXCL2. A densidade das células Treg, os níveis de IL-17 e IL-6 aumentaram em ambos os grupos LPS, enquanto o nível de IL-10 aumentou apenas no grupo CLPS. O aumento das células positivas para Stat3 -5, FosfoStat3 -5, corrobora com valores mais elevados para as células IL-17 e Treg. Assim, nosso estudo demonstrou que embora a associação da fumaça de cigarro e o LPS tenha induzido a diferenciação das células Th17 e Treg, não observamos aumento da expressão de IL-10 e sim da expressão de IL-17 sugerindo que uma falha na produção de IL-10 desempenha um papel fundamental na exacerbação do processo inflamatório.

Descritores: doença pulmonar obstrutiva crônica; fumaça; cigarro; exacerbação; lipopolissacarídeo; interleucina-10; resposta Th17; células T regulatórias. 


\begin{abstract}
Cervilha DAB. Study of the immune response in an experimental model of COPD by exposure to cigarette smoke and exacerbation by LPS instillation [thesis]. São Paulo: "Faculdade de Medicina, Universidade de São Paulo"; 2018.

The tobacco smoking is the main risk factor for the development of Chronic Obstructive Pulmonary Disease (COPD). The importance of adaptive immunity for this process is not completely clear, however there are studies attesting the association of infection with COPD exacerbation. We propose an experimental model of COPD exacerbation using a traditional method of cigarette smoke (CS) combining with lipopolysaccharide (LPS) instillations, focusing on the adaptive immunity response. C57BL/6 male mice were exposed to room air or to CS and after 3 months, they received two instillations of saline or LPS (Control/SAL; Control/LPS; CS/SAL and CS/LPS groups). Animals were anesthetized to perform the respiratory mechanics and inflammatory profile in broncho alveolar lavage (BAL) and lungs were removed to evaluate the mean linear intercept $(\mathrm{Lm})$, the density of macrophages, neutrophils, $\mathrm{CD} 4^{+}$and $\mathrm{CD} 8^{+}$cells, regulatory $\mathrm{T}$ cells (Treg), signal transducer and activator of transcription (Stat) 3, 5 and phosphoStat 3, 5. The chemotactic factors (CXCL1 and CXCL2); interleukins (IL): -17, -6, -10 and INF- $\gamma$ were measured in lung using Enzyme Linked ImmunoSorbent Assay (ELISA). We observed a change in the mechanics of the respiratory system with increased tissue resistance (Gtis) and tissue elastance (Htis) in CS/LPS group. In addition, in CS/Sal and CS/LPS groups we observed increase of Lm (subpleural), and in CS/LPS group we observed the increase in Lm in peribronchial spaces. CS exposure and LPS challenge induced an increase in neutrophils, macrophages, $\mathrm{CD}^{+}$and $\mathrm{CD}^{+} \mathrm{T}$ cells. CS/LPS challenge association intensified this response and lung parenchyma damage. Treg density cells, IL-17 and IL-6 levels was increased in both LPS groups, while IL-10 level was increased only in Control/LPS group. The increase of Stat3, -5, PhosphoStat3, -5 positive cells corroborates with higher values for IL-17 and Treg cells. Although the CS/LPS challenge association induced both Th17 and Treg cells differentiation, there is no increase for IL-10 expression, suggesting that a failure in IL-10 production play a pivotal role in the inflammatory process exacerbation.
\end{abstract}

Descriptors: chronic obstructive pulmonary disease, smoke, cigarette, exacerbation; lipopolysaccharide, interleukin-10, Th17 response; regulatory t cells 


\section{INTRODUÇÃO}

\subsection{Considerações Gerais}

A doença pulmonar obstrutiva crônica (DPOC) é definida como uma doença evitável e tratável, caracterizada pela obstrução persistente e progressiva do fluxo aéreo e está associada a resposta inflamatória crônica das vias aéreas e dos pulmões a partículas e/ou gases nocivos ${ }^{1}$.

A limitação do fluxo aéreo na DPOC é resultante da bronquite crônica ou do enfisema pulmonar ${ }^{2}$. A bronquite crônica é definida pela presença de tosse produtiva e hipersecreção mucosa por no mínimo três meses em dois anos consecutivos ${ }^{3}$ e o enfisema pulmonar é caracterizado pela inflamação permanente ${ }^{4}$, destruição do parênquima pulmonar ${ }^{5}$ com alargamento dos espaços aéreos distais e perda gradual da elasticidade tecidual ${ }^{6}$ acarretando a hiperinsuflação pulmonar ${ }^{4}$.

A DPOC é considerada a quarta maior causa de morte no mundo ${ }^{1}$, afetando 210 milhões de pessoas ${ }^{7}$. Ela é um importante e crescente problema de saúde mundial ${ }^{8}$. As estimativas mostram que a DPOC se tornará em 2030 a terceira principal causa de morte no mundo 9 .

No Brasil, cerca de 5-6 milhões de pessoas sofrem com a DPOC. A DPOC é responsável por um custo de 103 milhões de reais ao Sistema Único de Saúde (SUS) ${ }^{10}$. Em 2003, a DPOC foi considerada a quinta maior causa de internações no sistema público de saúde do Brasil, em indivíduos maiores de 40 anos, representando um gasto aproximado de 72 milhões de reais ${ }^{11}$.

A DPOC atualmente configura entre as principais causas de morte no Brasil. O número de óbitos causados por esta doença vem aumentando nos últimos 20 anos. Em 
ambos os sexos, a taxa de mortalidade passou de 7,88 em cada 100.000 habitantes na década de 1980, para 19,04 em cada 100.000 habitantes na década de 1990, com um crescimento de $340 \%{ }^{11}$. Segundo dados do Departamento de Informática do Sistema Único de Saúde (DATASUS) do Brasil, a cada hora morrem três brasileiros em decorrência da DPOC. No país ocorrem aproximadamente 40 mil óbitos a cada ano, causados principalmente pelo tabagismo ${ }^{12}$.

O projeto latino-americano de investigação em obstrução pulmonar, conhecido como PLATINO ${ }^{13}$, demonstrou em um estudo transversal de base populacional na região metropolitana de São Paulo - Brasil com objetivo de avaliar a prevalência da DPOC e os fatores associados a esta doença. Os resultados mostraram que a prevalência da DPOC foi de 15,8\%, correspondendo $18 \%$ nos homens e $14 \%$ nas mulheres. Segundo os autores a DPOC associou-se positivamente com a idade e o tabagismo. São atribuídas à utilização do tabaco mais de 20 doenças fatais ou incapacitantes ${ }^{14}$. O número total de morte causada por consumo de tabaco é mais alto que a soma de mortes por tuberculose, vírus da imunodeficiência adquirida/síndrome de imunodeficiência adquirida e malária ${ }^{15}$.

Cerca de $85 \%$ dos casos da DPOC são causados pelo tabagismo ${ }^{16}$, sendo assim, o tabagismo é considerado o principal fator de risco para o desenvolvimento da doença, mas outros fatores, como a poluição do ar devido à queima de biomassa são importantes causas desta doença em muitos países em desenvolvimento ${ }^{17,18}$.

\subsection{Classificação da DPOC}

A DPOC pode ser classificada de acordo com "Global Initiative for Chronic Obstructive Lung Disease" - GOLD em quatro estágios ${ }^{1}$. Essa classificação é baseada 
nas alterações espirométricas, no estado de saúde do paciente (sintomas), no histórico de exacerbação, no risco de eventos futuros (como exacerbações, internações hospitalares ou morte) e a presença de comorbidades. Entre estes parâmetros, o mais utilizado é o $\mathrm{VEF}_{1}$ : volume expirado forçado no primeiro segundo, bem como a razão entre esta variável e a CVF (capacidade vital forçada): $\mathrm{VEF}_{1} / \mathrm{CVF}$.

No estágio I, a DPOC é considerada leve e é determinada em pacientes cujo padrão espirométrico apresenta uma pequena alteração $\left(\mathrm{VEF}_{1} / \mathrm{CVF}<0,70 ; \mathrm{VEF}_{1} \geq 80 \%\right.$ do valor predito), podendo haver ou não sintomas presentes. Muitos destes pacientes desconhecem que sua função pulmonar é anormal.

No estágio II, a $D P O C$ é classificada como moderada e é caracterizada por uma piora da limitação ao fluxo aéreo $\left(\mathrm{VEF}_{1} / \mathrm{CVF}<0,70 ; 50 \% \leq \mathrm{VEF}_{1}<80 \%\right.$ do valor predito) associada a aparição de sintomas e a busca por atendimento médico.

No estágio III, a DPOC é considerada grave e tem como característica uma limitação importante do fluxo aéreo $\left(\mathrm{VEF}_{1} / \mathrm{CVF}<0,70 ; 30 \% \leq \mathrm{VEF}_{1}<50 \%\right.$ do valor predito), associada ao encurtamento do padrão respiratório, diminuição da tolerância ao exercício, fadiga generalizada e exacerbações constantes do quadro, atingindo de forma direta a qualidade de vida dos pacientes.

Já no estágio IV, a $D P O C$ é considerada muito grave e está relacionada a uma limitação grave ao fluxo aéreo $\left(\mathrm{VEF}_{1} / \mathrm{CVF}<0,70 ; \mathrm{VEF}_{1}<30 \%\right.$ do valor predito), além disso, há presença de insuficiência respiratória associada a sinais clínicos de insuficiência cardíaca direita, com consequente redução da qualidade de vida. Nestes pacientes, qualquer exacerbação do quadro pode representar um risco para a vida. 


\subsection{Mecanismos fisiopatológicos envolvidos no desenvolvimento da DPOC}

A DPOC pode ser considerada uma doença complexa e possui diferentes mecanismos envolvidos em sua fisiopatologia.

\subsubsection{Desequilíbrio protease - antiprotease}

O desequilíbrio protease - antiprotease é o mais aceito e descrito para explicar a patogênese da DPOC. O aumento da atividade proteolítica pode ser consequência do processo inflamatório, no qual ocorre aumento da liberação de proteases por células como neutrófilos e macrófagos. O aumento de proteases também pode estar associada a fatores genéticos, como a deficiência de alfa-1 antitripsina $\left(\alpha-1\right.$ AT) ${ }^{19}$. A $\alpha-1$ AT é uma molécula produzida principalmente no fígado e, atinge os pulmões através da circulação, onde vai realizar sua função de antiprotease ${ }^{20}$, e atuar inativando a elastase neutrofílica e impedindo o dano tecidual ${ }^{21}$ (Figura 1).

O aumento de proteases em relação às antiproteases resulta na destruição das fibras constituintes do parênquima pulmonar, tendo, como consequência a perda de elasticidade tecidual $^{22}$. A perda do recolhimento elástico e a evidência histológica de dano das fibras elásticas sugerem que a degradação de elastina é fator chave na patogênese do enfisema ${ }^{23}$ (Figura 1).

A exposição à fumaça do cigarro potencializa a lesão pulmonar, reduzindo a atividade das antiproteases ${ }^{24}$, sendo um importante fator no desenvolvimento do enfisema pulmonar ${ }^{21}$ (Figura 1). 


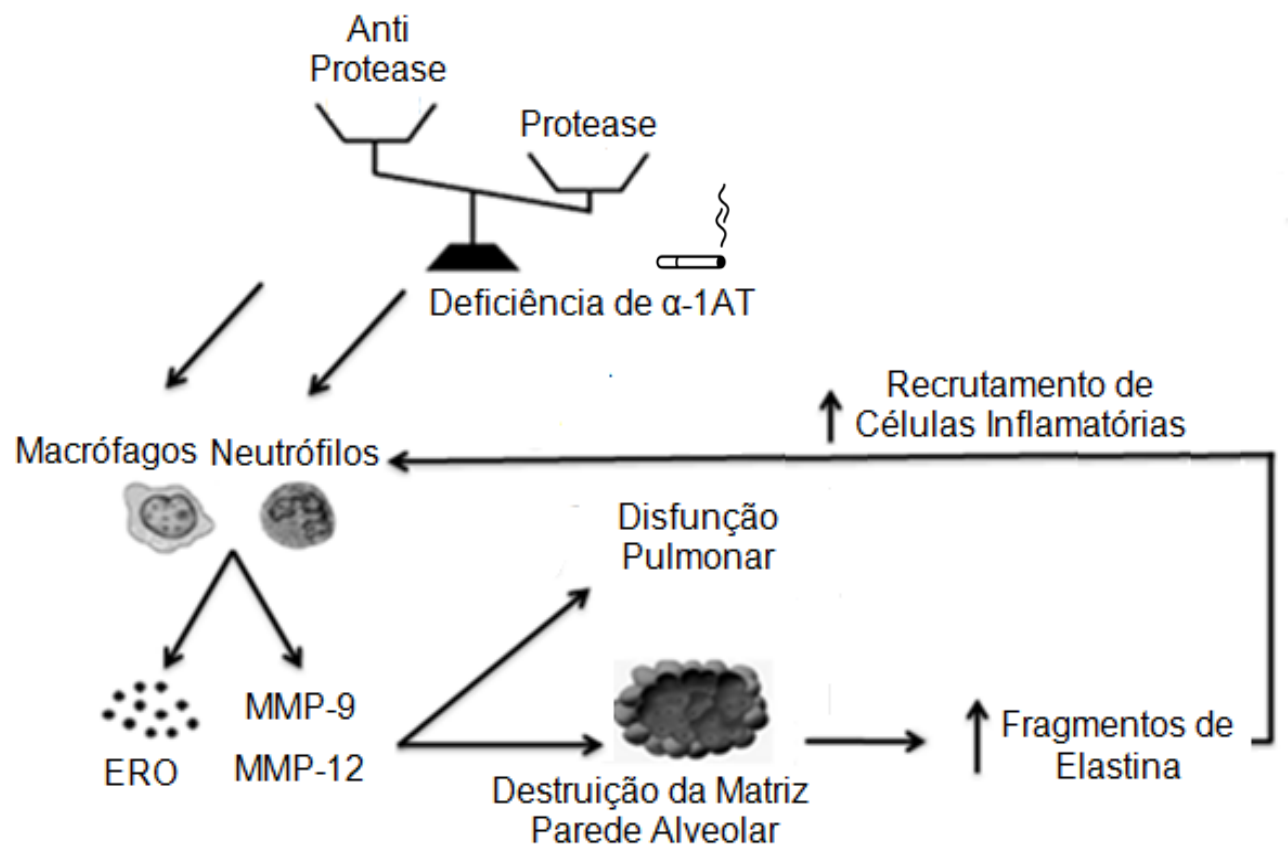

FONTE: Antunes M, $2011^{25}$, adaptado.

Figura 1 - Esquema ilustrativo do desequilíbrio protease - antiprotease

\subsubsection{Estresse Oxidativo}

O estresse oxidativo têm um importante papel na fisiopatologia da DPOC, pois além de provocar danos direto às estruturas pulmonares, amplifica os demais mecanismos fisiopatológicos envolvidos no desenvolvimento da doença ${ }^{26}$.

O estresse oxidativo é caracterizado pelo aumento de espécies reativas de oxigênio (ERO) e nitrogênio e em contrapartida redução da capacidade antioxidante ${ }^{27}$.

A produção de ERO é parte integrante do metabolismo e está presente em condições normais, especialmente nos processos fisiológicos envolvidos na produção de energia, regulação do crescimento celular, fagocitose, sinalização intracelular e síntese de substâncias importantes, tais como hormônios e enzimas ${ }^{28}$.

O organismo humano possuiu um complexo sistema antioxidante que atua neutralizando os radicais livres e as ERO, com o objetivo de manter a homeostase ${ }^{29}$. 
A fumaça de cigarro induz um enorme influxo de células inflamatórias para dentro dos pulmões, o que leva o desequilíbrio de oxidantes e antioxidantes através da liberação de $\mathrm{ERO}^{25}$. O aumento nos níveis de ERO em vias aéreas e pulmões resultam em estresse oxidativo ${ }^{30}$. Estudos revelam um aumento dos níveis de indicadores de estresse oxidativo em condensado de ar exalado em pacientes com DPOC ${ }^{31-33}$. Em fumantes, os macrófagos alveolares liberam mais ERO quando comparado com não fumantes e a capacidade antioxidante do plasma está reduzida ${ }^{34}$. Além disso, o aumento da liberação de ERO traz consequências como aumento da oxidação de antiproteases, como a $\alpha$-1 AT, ativação das metaloproteinases (MMP) que promovem a degradação da matriz extracelular e aumento da proteólise ${ }^{35}$.

Marcadores sistêmicos do estresse oxidativo e níveis plasmáticos elevados de mediadores inflamatórios têm sido relatados em fumantes e em portadores de DPOC $^{36}$. Os neutrófilos periféricos de portadores de DPOC liberam mais ERO que os de indivíduos normais não-fumantes ${ }^{37}$. $\mathrm{O}$ estresse oxidativo e a inflamação crônica estão incluídos entre os fatores envolvidos no mecanismo gerador das manifestações sistêmicas, tais como a perda de peso e a disfunção da musculatura esquelética, observadas em alguns pacientes com DPOC ${ }^{38}$.

\subsubsection{Apoptose}

A apoptose é um mecanismo regulador de morte celular. Esta morte celular programada permite a eliminação das células não desejadas, danificadas ou infectadas ${ }^{39}$. A apoptose, quando ocorre de forma desordenada acarreta repercussões negativas com consequente desenvolvimento de doenças como asma e enfisema. O mecanismo de 
apoptose das células alveolares está envolvido na patogênese do enfisema, sendo determinante na lesão do tecido pulmonar ${ }^{19,40}$.

A DPOC está associada com o aumento do número de eventos apoptóticos quando comparado a pessoas saudáveis ou fumantes sem DPOC, o que tem sido atribuído, especialmente, à combinação de inibição ou defeito no processo apoptótico e/ou ineficiência de remoção de células apoptóticas ${ }^{41,42}$.

Muitos estudos atribuem ao processo acelerado de apoptose das células epiteliais e endoteliais a ocorrência da destruição alveolar presente em pacientes com enfisema ${ }^{43}$, ${ }^{44}$. A apoptose também está relacionada com a liberação de perforinas e granzimas pelas células $\mathrm{T} \mathrm{CD}^{+45}$ e a baixos níveis de fator de crescimento endotelial vascular, como resultado do processo de destruição de células endoteliais ${ }^{46}$.

Segura-Valdez et al. (2000) ${ }^{47}$ encontraram um aumento da apoptose de células endoteliais em pulmões de pacientes com DPOC. Aoshiba et al. $(2003)^{48}$ administraram por via intratraqueal caspase-3 (protease com uma função importante na regulação da apoptose) em camundongos e observaram apoptose de células das paredes alveolares, predominantemente de células epiteliais com posterior alargamento dos espaços aéreos distais, característico do enfisema pulmonar.

\subsubsection{Autoimunidade}

Estudos experimentais e em pacientes sugerem a autoimunidade como um possível mecanismo envolvido no desenvolvimento da DPOC, sendo este um evento que ocorre tardiamente seguindo o curso progressivo da doença ${ }^{49}$. Segundo a teoria da ativação imunológica a fumaça de cigarro e outros gases nocivos provocam uma resposta autoimune que leva ao dano pulmonar $^{50}$. 
Embora o tabagismo seja o principal fator de risco para o desenvolvimento da DPOC, nem todos os fumantes desenvolvem a doença ${ }^{51}$. Cerca de $10-20 \%$ dos fumantes desenvolvem limitação ao fluxo aéreo ${ }^{52}$, isto sugere que há outros fatores intrínsecos ao indivíduo envolvidos na patogênese da DPOC ${ }^{1}$. Além disso, a inflamação persistente em pacientes com DPOC mesmo após cessarem o fumo sugere um processo imunológico de autoperpetuação ${ }^{51}$. Segundo Lee et al. $(2007)^{50}$ na DPOC a degradação da matriz extracelular (elastina) desencadeia a produção de autoanticorpos que atuam contra as fibras elásticas, essa produção de autoanticorpos antielastina caracterizam um possível processo autoimune.

\subsection{Aspectos imunológicos da DPOC}

Na DPOC várias células e seus mediadores, denominados citocinas, atuam durante o processo inflamatório ${ }^{53}$. As citocinas são responsáveis pela comunicação entre as células $^{54}$, desempenhando várias funções, dentre elas podemos destacar a ativação e proliferação celular, quimiotaxia de outros tipos celulares, imunomodulação e liberação de outras citocinas, atuando no crescimento, diferenciação celular e apoptose ${ }^{55}$.

Esses mediadores inflamatórios podem ser classificados de acordo com o seu papel no processo inflamatório em citocinas pró-inflamatórias que são capazes de induzir e liberar outras citocinas, amplificando o processo inflamatório e em citocinas anti-inflamatórias, que são liberadas para controlar o processo inflamatório ${ }^{53}$.

\subsubsection{Imunidade inata: Tipos celulares e mediadores inflamatórios}

O sistema imune inato é a primeira linha de defesa contra as infecções, atuando 
de maneira rápida e pouco específica em resposta aos componentes irritantes da fumaça do cigarro, à lesão tecidual e o estresse celular ${ }^{56}$. Para impedir o dano provocado pela exposição à fumaça de cigarro e na tentativa de manter a homeostase pulmonar, o sistema respiratório possui mecanismos de defesa que incluem a barreira epitelial, a "clearance" mucociliar, fatores humorais (peptídeos antimicrobianos, proteínas do complemento e do surfactante) e mecanismos de respostas imunológicas ${ }^{57}$. Vários fatores humorais e células, como os neutrófilos, macrófagos, células dendríticas (DC dendritic cells), células NK do inglês -“natural killer”), monócitos, e mastócitos participam na imunidade inata e são recrutadas para controlar a invasão do patógeno ${ }^{58}$.

A exposição à fumaça de cigarro causa dano as células epiteliais e consequente liberação de produtos derivados desta destruição, os quais irão se ligar aos receptores de membrana do tipo "toll” (TLR - toll-like receptors), no epitélio (TLR4 e TLR2) acarretando a ativação de fator nuclear kappa $\mathrm{B}(\mathrm{NF}-\kappa \mathrm{B})$ e liberação de mediadores inflamatórios pelas células epiteliais, os quais irão ativar macrófagos e neutrófilos alveolares $^{59}$. A migração de neutrófilos e macrófagos caracteriza o papel da imunidade inata na resposta aos estímulos agressores (Figura 2).

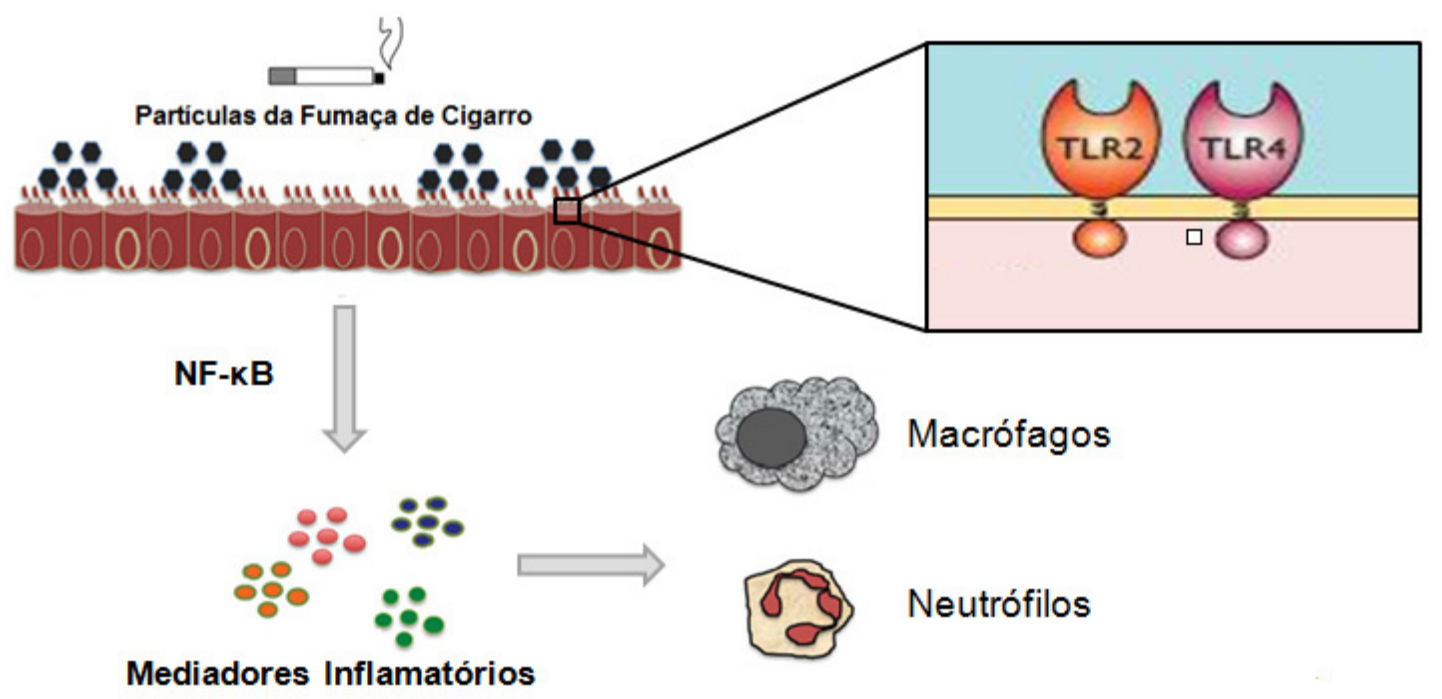

Figura 2 - Esquema ilustrativo da ativação da imunidade inata na DPOC 


\subsubsection{Neutrófilos}

Os neutrófilos são células polimorfonucleares ${ }^{60}$, são as primeiras células a migrarem para os tecidos infectados ${ }^{61}$. O recrutamento neutrofílico é vital tanto para ação direta contra os microorganismos quanto para atrair linfócitos envolvidos na resolução do processo inflamatório. As principais quimiocinas responsáveis pelo recrutamento de neutrófilos em modelo murino são as quimiocinas CXCL1 (quimiocina da família C-X-C ligante 1 ou KC - quimiocina derivada de queratinócitos) e CXCL2 (quimiocina da família C-X-C ligante 2 ou MIP-2 - proteína inflamatória de macrófagos 2) e ambas se ligam ao receptor de quimiocina, CXCR2 (receptor de quimiocina tipo $2)^{62}$

Os neutrófilos são responsáveis pela secreção de proteases, incluindo elastase neutrofílica, catepsina $\mathrm{G}$ e proteinase-3, que estão envolvidas na hipersecreção de muco pelo epitélio das vias aéreas e na destruição das paredes alveolares. Além disso, fatores quimiotáticos incluindo interleucina (IL) -8 e leucotrieno B4 (LTB4) promovem a migração neutrofílica da circulação sistêmica para o trato respiratório. Lacoste et al. $(1993)^{63}$ e Keatings et al. (1996) ${ }^{64}$ demonstraram aumento de neutrófilos ativados em amostras de escarro e no lavado broncoalveolar (LBA) de pacientes com DPOC. O aumento no número de neutrófilos nos brônquios e amostras de escarro está relacionado à gravidade da doença ${ }^{35}$.

\subsubsection{Macrófagos}

Os macrófagos são células mononucleares que desempenham um importante papel na resposta imune. Estas células assumem um papel de defesa do organismo pela 
sua capacidade de realizar o processo de fagocitose ${ }^{65}$.

Entretanto, também apresentam importante função para o desenvolvimento da DPOC, e estão em maior número no parênquima pulmonar, principalmente nos espaços aéreos distais de pacientes portadores desta doença ${ }^{66}$. Os macrófagos alveolares de pacientes com DPOC secretam mais proteínas inflamatórias e têm maior atividade elastolítica quando expostos à fumaça do cigarro comparados aos fumantes que não desenvolvem a doença ${ }^{67}$.

A ativação de macrófagos alveolares também liberam mediadores quimiotáticos que recrutam células inflamatórias adicionais como as células $\mathrm{T} C \mathrm{C} 8^{+}$para os pulmões, perpetuando o estado de inflamação crônica que também é responsável por alterações estruturais, obstrução nas vias aéreas e sintomas respiratórios ${ }^{68}$.

Quando o controle do processo inflamatório pela imunidade inata é ineficaz a resposta imune adaptativa se manifesta de maneira específica e significativa para combater os agentes infecciosos ${ }^{49}$.

\subsubsection{Imunidade adaptativa: Tipos celulares e mediadores inflamatórios}

O controle inadequado do processo inflamatório levará a longo prazo a destruição das fibras constituintes do parênquima pulmonar, necrose e apoptose celular, gerando restos teciduais, que podem ser reconhecidos como antígenos. Este reconhecimento é feito por células T diferenciadas, as DC, as quais são responsáveis pela apresentação destes antígenos para outras células T na região dos órgãos linfóides. As DC são encontradas em grande número em pulmões de fumantes e são reconhecidas pelo seu papel importante na passagem da imunidade inata para a adaptativa ${ }^{69-71}$. Com a intensificação do processo inflamatório, as DC irão expressar altos níveis de proteínas 
como as do complexo-histocompatibilidade classe 2 (MHC-2) e moléculas como CD80 e CD86 e já na região dos folículos linfoídes fazem a apresentação dos antígenos às células $\mathrm{T}^{72}$.

Infiltrados de células $\mathrm{T} \mathrm{CD}^{+}$estão presentes em pulmões de pacientes com DPOC e também em camundongos cronicamente expostos à fumaça do cigarro, esse infiltrado persiste mesmo depois de um longo período de cessação do tabagismo ${ }^{73,74}$. Além disso, alguns estudos demonstraram que infiltrado de células $\mathrm{T} \mathrm{CD}^{+}$está correlacionado com a limitação do fluxo aéreo e progressão da doença ${ }^{75,76}$.

As células $\mathrm{T} \mathrm{CD}^{+}$também são importantes para combater infecções, mas o excessivo recrutamento destas células causa dano ao tecido pulmonar e declínio da função respiratória $^{76,77}$. Alguns estudos demonstraram um papel importante das células $\mathrm{T} \mathrm{CD}^{+}$na manutenção da resposta inflamatória crônica e na piora da obstrução das vias aéreas $^{75,78}$.

Finkelstein et al. (1995) ${ }^{79}$ demonstraram que a progressão da DPOC está correlacionada ao aumento do número de células T em pacientes. Há um aumento no número total de células $\mathrm{T}$ no parênquima pulmonar e nas vias aéreas centrais $\mathrm{e}$ periféricas, principalmente de $\mathrm{CD}^{+}$, o que diferencia o enfisema das demais doenças obstrutivas e explica o aparecimento de mediadores inflamatórios específicos que determinam a lesão estrutural característica do enfisema ${ }^{53,80}$. Embora a função das células $\mathrm{T} \mathrm{CD}^{+}$seja frequentemente destacada nos estudos da DPOC, as células T CD4 ${ }^{+}$ também são importantes no processo da doença. Embora os infiltrados de células $\mathrm{T}$ $\mathrm{CD}^{+}$sejam menos extensos que os infiltrados de células $\mathrm{T} \mathrm{CD}^{+}$, as células $\mathrm{CD}^{+}$ estão aumentadas nos pulmões com enfisema ${ }^{44}$. As células $\mathrm{T} \mathrm{CD}^{+}$também são responsáveis pela adequação dos processos imunológicos, pois liberam citocinas importantes para as respostas inflamatórias ${ }^{45}$. 
As células $\mathrm{T} \mathrm{CD}^{+}$podem ser divididas em subgrupos: as células $\mathrm{Th} 1$, Th2, Th17 e Treg ${ }^{81}$, (Figura 1). As células T de pacientes com enfisema apresentam uma porcentagem maior de $\mathrm{CD}^{+}$Th1 e secretam maiores quantidades de IFN- $\gamma$. Já, as células Th17 estão envolvidas na manutenção do processo inflamatório através da liberação de IL-17A e IL-17F ${ }^{82,83}$ (Figura 3).

As células $\mathrm{T}$ regulatória (Treg) representam uma subpopulação de células $\mathrm{T}$ caracterizados pela expressão da molécula $\mathrm{CD} 25^{+}$e do fator de transcrição para células $\mathrm{T}$ regulatórias (Foxp3 - Forkhead box p3) ${ }^{84}$. As Treg são essenciais para manter a homeostasia do sistema imune ${ }^{85}$, pois possuem funções imuno regulatórias, que inibem a autoimunidade e suprimem a inflamação ${ }^{57}$ de auto-antígenos, alérgenos e microbiotas, além de atuar nas respostas imunes a agentes infecciosos e tumores ${ }^{86}$. Esse efeito imunossupressor ocorre devido à produção de citocinas anti-inflamatórias como a IL-10 e o fator de crescimento $\beta$ (TGF- $\beta)^{87}$ (Figura 3 ).

Cosio et al. (2009) ${ }^{49}$ propõem que a progressão da DPOC e a gravidade desta doença são determinadas tanto pela habilidade das DC em estimularem as células T, quanto pelos mecanismos imunorregulatórios dependentes das Treg. Estes autores sugerem que uma falha grave neste mecanismo resulta nos estágios 3 e 4 da DPOC de acordo com a classificação de GOLD.

Por essa razão, vários estudos têm focado na avaliação do papel das células Treg na DPOC. Sales et al. (2017) ${ }^{88}$ destacaram em seu estudo a importância das células Treg no controle da progressão da DPOC, os resultados mostraram que há diferença na distribuição de células Treg nos compartimentos pulmonares pode levar à obstrução em fumantes. 


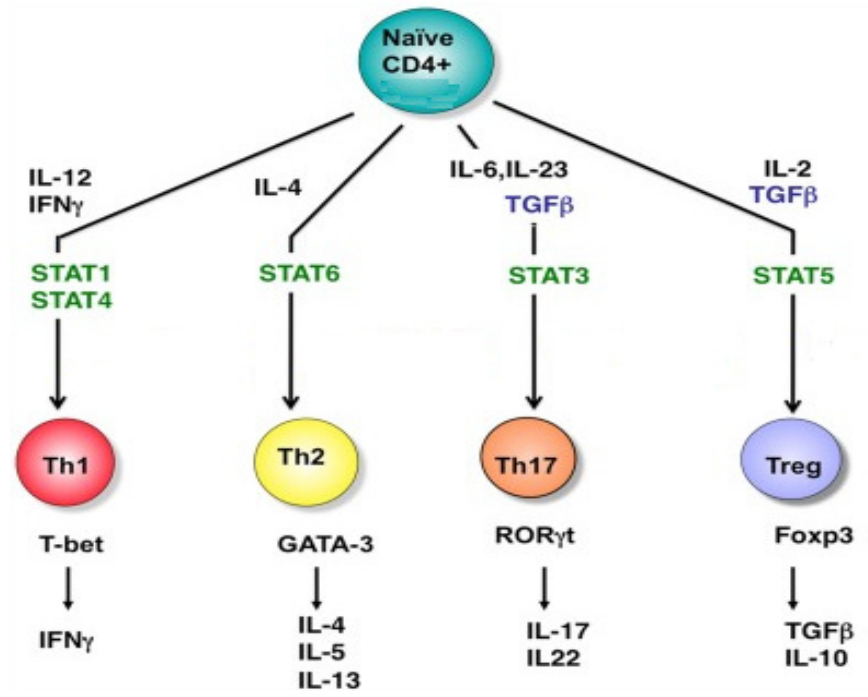

FONTE: Yoshimura A, $2012^{81}$, adaptado.

Figura 3 - Esquema ilustrativo da diferenciação das células T CD4 naive

\subsection{Respostas Th17 e Treg na DPOC}

Estudos mostraram aumento de citocinas pró-inflamatórias, como por exemplo, a IL-6 em escarro de pacientes com DPOC estável ${ }^{64}$. A IL-6 é secretada principalmente por células T e macrófagos ${ }^{89}$. As respostas de sinalização da IL-6 são mediadas pelo transdutor de sinal e ativador de transcrição $3(\text { Stat } 3)^{90}$. Uma vez ativado, o Stat3 induz a expressão de numerosos genes pró-inflamatórios no pulmão ${ }^{91}$. O aumento de Stat3 e aumento de genes associado à expressão de Stat3 tem sido encontrada em tecido pulmonar de pacientes com DPOC ${ }^{92}$. A IL-6 juntamente com a IL-21 e IL-23 via Stat3 regula a diferenciação de células Th17 e consequente aumento na produção de IL-17 $7^{93}$, 94 (Figura 4).

O Stat3 além de ser um fator de transcrição essencial para diferenciação de Th17 ele atua na inibição de Treg. Por outro lado, a ativação do Stat5 é fundamental no que diz respeito à diferenciação e manutenção das células Treg e suprime a diferenciação de 
células Th17 $7^{95,96}$. Animais que foram cronicamente expostos à fumaça de cigarro e desenvolveram enfisema pulmonar apresentaram um maior número de células Th17 e IL-17 ${ }^{97}$. Brandão-Rangel et al. (2017) ${ }^{98}$ demonstraram em seu estudo que camundongos expostos à fumaça de cigarro apresentaram aumento na concentração de IL-17 no LBA e no plasma, podendo estar associado com o aumento da expressão e ativação da Stat3 (FosfoStat3) (Figura 4).

Em relação às citocinas anti-inflamatórias, que são liberadas para controlar o processo inflamatório, podemos destacar a IL-10, que é liberada por monócitos, macrófagos $^{99}$ e principalmente pelas células $\operatorname{Treg}^{100}$, em resposta a estímulos inflamatórios (Figura 4).

$\mathrm{O}$ controle da proliferação e migração de células $\mathrm{T}$ para o trato respiratório é mediado por subtipos de linfócitos CD4+, que são as células Treg, as quais apresentam funções imunorregulatórias devido à produção de citocinas anti-inflamatórias como a IL-10 e o TGF- $\beta^{57}$.

Cosio et al. (2009) ${ }^{49}$ propõem que a progressão da DPOC e a gravidade desta doença são determinadas tanto pela habilidade das células dendríticas em estimularem as células $\mathrm{T}$ quanto pela ineficiência dos mecanismos imunorregulatórios dependentes das Tregs.

Lee et al. $(2007)^{50}$ foram uns dos primeiros autores que propuseram que uma redução nos valores de células Tregs estava associada à progressão da DPOC. Detectaram em tecido de pacientes DPOC uma redução de expressão nos níveis de ácido ribonucleíco mensageiro (RNAm) para Foxp3, bem como menor expressão de IL$10^{57}$

Em estudo anterior desenvolvido por nosso grupo, observamos uma redução da densidade de células Treg e de células positivas para IL-10 em vias aéreas de 
indivíduos fumantes com DPOC, quando comparados aos demais grupos ${ }^{88}$, sugerindo a importância da célula Treg no controle do processo inflamatório através da produção de IL-10.

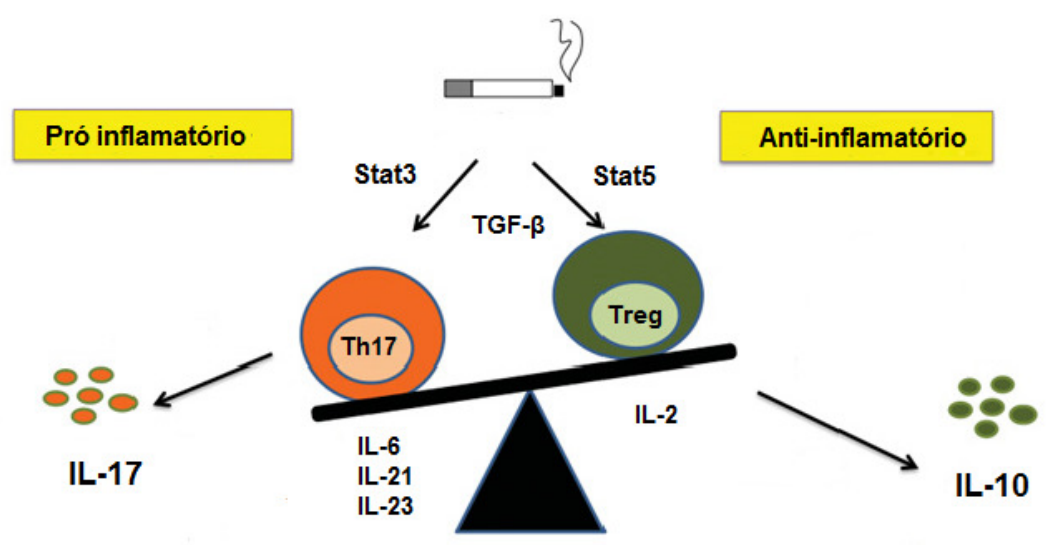

FONTE: Lane N, $2010^{51}$, adaptado.

Figura 4 - Esquema ilustrativo da resposta Th17/Treg na DPOC

\subsection{Exacerbação da DPOC}

A progressão da DPOC é caracterizada por exacerbações, que pode ser definida como a intensificação/piora dos sintomas ${ }^{1,101-103}$. A exacerbação é caracterizada por redução da função pulmonar, diminuição da qualidade de vida e está associada com o aumento de mediadores pró-inflamatórios nos pulmões ${ }^{104}$. Repetidas crises de exacerbação da DPOC promove a piora do prognóstico $^{105}$ e acelera a progressão da doença $^{106}$.

As causas mais comuns de exacerbação estão associadas às infecções por agentes bacterianos e/ou virais ${ }^{107}$. Cerca de metade de todas as exacerbações são causadas por infecções bacterianas ${ }^{108}$. Estes episódios diminuem significativamente a qualidade de vida destes pacientes ${ }^{109}$, devido a intensificação dos sintomas $^{39}$, 
requerendo muitas vezes admissão hospitalar ${ }^{110}$. A exacerbação é a maior causa de morbidade e mortalidade em pacientes com DPOC ${ }^{111}$.

A exposição prolongada à fumaça de cigarro também aumenta a susceptibilidade às infecções e consequentemente a exacerbação da DPOC. Isto pode ser explicado por 3 fatores: o avanço da queda na função pulmonar; maior predisposição para ocorrência de infecções e ao fato de que o efeito somatório da exposição à fumaça do cigarro e a infecção intensificam o processo inflamatório acarretando um aumento na gravidade da doença $^{112}$.

Acredita-se que episódios repetidos de exacerbação e inflamação, contribuam para a lesão do tecido pulmonar e consequentemente a limitação do fluxo aéreo. Embora, a frequiência de exacerbação aumente com a progressão da doença, os mecanismos ainda não estão totalmente esclarecidos ${ }^{113}$.

Já está demonstrado o aumento do número de neutrófilos e produção de interleucinas e quimiocinas como IL-6, IL-8, TNF- $\alpha$ e LTB4 em LBA de pacientes com exacerbação da $\mathrm{DPOC}^{39,114}$. Além disso, os pacientes que apresentam exacerbações frequentes possuem níveis mais elevados de IL-6 $6^{115,116}$ e aumento da ativação de NF-kB nos macrófagos alveolares ${ }^{117}$.

Estudos nas vias aéreas de adultos mostraram que a exacerbação da DPOC por bactéria promoveu a liberação de antígenos, incluindo endotoxinas, fragmentos de peptidoglicano, lipoproteínas, e outras moléculas nas vias aéreas, promovendo a liberação de IL-8 e TNF- $\alpha$ os quais irão promover a ativação de TLR2 e ativação de $\mathrm{NF}-\kappa \mathrm{B}^{118}$.

Entender o papel da imunidade adaptativa na exacerbação da DPOC torna-se importante, uma vez, que alguns estudos têm relatado aumento do número de células Treg em pacientes com exacerbação aguda da DPOC e em pacientes com enfisema, 
sugerindo que essas células podem não ser efetivas para controlar a inflamação desses pacientes $^{119}$.

\subsubsection{Modelos Experimentais de Exacerbação na DPOC}

Estudos prévios mostraram que diferentes modelos experimentais têm sido desenvolvidos para elucidar a fisiopatologia das exacerbações da DPOC. Existem duas principais abordagens experimentais para a indução das exacerbações da DPOC: a instilação intratraqueal de lipopolissacarídeo (LPS) bacteriano e desafio com estirpes bacterianas ou virais específicos ${ }^{120}$.

A maioria dos estudos experimentais utilizam a associação entre os modelos de indução de enfisema por instilação de proteases em conjunto com LPS, devido ao menor tempo requerido para o desenvolvimento da doença, comparado aos modelos de exposição ao fumo. O LPS é um importante componente da membrana externa das bactérias gram-negativas e está presente na fumaça do cigarro em consideráveis quantidades $^{121-123}$.

Vernooy et al. (2002) ${ }^{124}$ demonstraram em camundongos que foram desafiados repetidamente (duas vezes por semana, durante doze semanas) com LPS ( $5 \mu \mathrm{g}$ ) via intratraqueal, inflamação pulmonar caracterizada por agregados linfocitários peribrônquicos e perivasculares $\left(\mathrm{CD}^{+}, \mathrm{CD}^{+}\right.$e $\left.\mathrm{CD} 19^{+}\right)$, acúmulo de macrófagos e células $\mathrm{T} \mathrm{CD}^{+}$no parênquima e alteração da expressão de citocinas, após 5 instilações de LPS. Além disso, alterações nas vias aéreas e alvéolos, tais como metaplasia das células produtoras de muco, espessamento da parede das vias respiratórias e aumento dos espaços alveolares também foram observados. 
Até o momento são poucos os estudos que avaliam o efeito do LPS em modelo experimental de exposição à fumaça de cigarro. Isto decorre do fato de que embora o modelo de fumo seja considerado o que melhor mimetize o enfisema encontrado em humanos, este tipo de exposição requer um tempo bastante prolongado e a lesão tecidual obtida é considerada leve, correspondente a um paciente com DPOC grau I ou II seguindo os critérios do GOLD ${ }^{125}$. 


\section{JUSTIFICATIVA}

Embora já se saiba que o principal fator de risco para o desenvolvimento da DPOC é o tabagismo, e que os episódios recorrentes de exacerbação por infecções em pacientes com DPOC comprometam a qualidade de vida destes indivíduos, podendo acarretar piora e progressão da doença, poucos são os estudos que avaliam o papel da exacerbação em modelos experimentais de exposição à fumaça de cigarro.

Tais estudos seriam de grande importância para um melhor entendimento do papel da imunidade adaptativa envolvido neste processo, em especial das respostas Th17 e Treg.

Uma melhor compreensão dos mecanismos imunológicos envolvidos na exacerbação da DPOC é importante, uma vez que poderia nos levar a abordagens terapêuticas novas e mais eficazes para tratamento desta importante doença. 


\section{HIPÓTESE}

A utilização de um modelo experimental da DPOC por exposição à fumaça de cigarro associada à instilação de LPS em camundongos acarretará exacerbação do processo inflamatório mediado pelo desequilíbrio entre as respostas Th17/Treg. 


\section{OBJETIVO}

O objetivo deste estudo foi desenvolver um modelo de enfisema pulmonar por exposição à fumaça de cigarro e instilação de LPS que mimetize parte dos fenômenos fisiológicos característicos da exacerbação clínica de pacientes com DPOC visando investigar o papel da imunidade adaptativa, em especial o desequilíbrio entre a resposta Th17 e Treg, nesta amostra experimental. 


\section{MÉTODOS}

\subsection{Animais}

Foram utilizados 60 camundongos C57BL/6 machos, com idade 6-8 semanas e peso de 25-30g, provenientes do Biotério Central da Faculdade de Medicina da USP (FMUSP). Os animais foram mantidos em gabinetes com temperatura e ventilação adequadas, acomodados em caixa moradia de polipropileno no biotério do Laboratório de Terapêutica Experimental I (LIM-20) da FMUSP. Durante o período de aclimatização e experimentação os animais receberam água e ração comercial peletizada à vontade e foram mantidos em ciclo claro-escuro de $12 \mathrm{~h}$ em temperatura ambiente de $20 \pm 2{ }^{\circ} \mathrm{C}$, sendo cuidados por profissionais treinados e capacitados durante todo o período do estudo. Este projeto foi aprovado pela Comissão Ética no Uso de Animais em Pesquisa da FMUSP - SP (Protocolo 077/2014). Todos os animais receberam os cuidados necessários de acordo com o "Guia de cuidados e uso de animais de laboratório" (NIH publication 85-23, revisado em 1985) e com a Lei Arouca (Lei 11.794 de 8 de outubro de 2008).

\subsection{Grupos Experimentais}

Os animais foram divididos em 4 grupos experimentais:

Grupo Controle Salina (CSAL): Os animais foram mantidos durante 12 semanas no biotério e expostos ao ar filtrado. Após este período, os animais receberam a primeira instilação intratraqueal de solução salina ( $\mathrm{NaCL}$ 0,9\%, volume $50 \mu \mathrm{l}$ ), e após 15 dias 
receberam a segunda instilação da mesma solução, seguindo os mesmos procedimentos. A eutanásia dos animais foi realizada 3 dias após a última instilação.

Grupo Controle LPS (CLPS): Os animais foram mantidos durante 12 semanas no biotério e expostos ao ar filtrado. Após este período, os animais receberam a primeira instilação intratraqueal de LPS (Escherichia coli, serotipo O26:B6: Sigma Chemical Co.) $(1 \mathrm{mg} / \mathrm{kg})^{113}$, (volume $50 \mu \mathrm{l}$ ), e após 15 dias receberam a segunda instilação da mesma solução, seguindo os mesmos procedimentos. A eutanásia dos animais foi realizada 3 dias após a última instilação.

Grupo Fumo Salina (FSAL): Os animais foram expostos à fumaça de cigarro por um período de 30 min, duas vezes por dia, 5 dias por semana, durante 12 semanas. Após este período, os animais receberam a primeira instilação intratraqueal de solução salina (NaCL 0,9\%, volume $50 \mu \mathrm{l}$ ), e após 15 dias receberam a segunda instilação da mesma solução, seguindo os mesmos procedimentos. A eutanásia dos animais foi realizada 3 dias após a última instilação. Os animais permaneceram expostos à fumaça de cigarro durante todo o protocolo experimental exceto nos dias das instilações e eutanásia.

Grupo Fumo LPS (FLPS): Os animais foram expostos à fumaça de cigarro por um período de $30 \mathrm{~min}$, duas vezes por dia, 5 dias por semana, durante 12 semanas. Após este período, os animais receberam a primeira instilação intratraqueal de LPS (Escherichia coli, serotipo O26:B6: Sigma Chemical Co.) $(1 \mathrm{mg} / \mathrm{kg})^{113}$, (volume $\left.50 \mu \mathrm{l}\right)$, e após 15 dias receberam a segunda instilação da mesma solução, seguindo os mesmos procedimentos. A eutanásia dos animais foi realizada 3 dias após a última instilação. Os 
animais permaneceram expostos à fumaça de cigarro durante todo o protocolo experimental exceto nos dias das instilações e eutanásia.

A representação esquemática dos grupos experimentais estão representados na figura 5 e a linha do tempo do protocolo experimental está representado na figura 6.

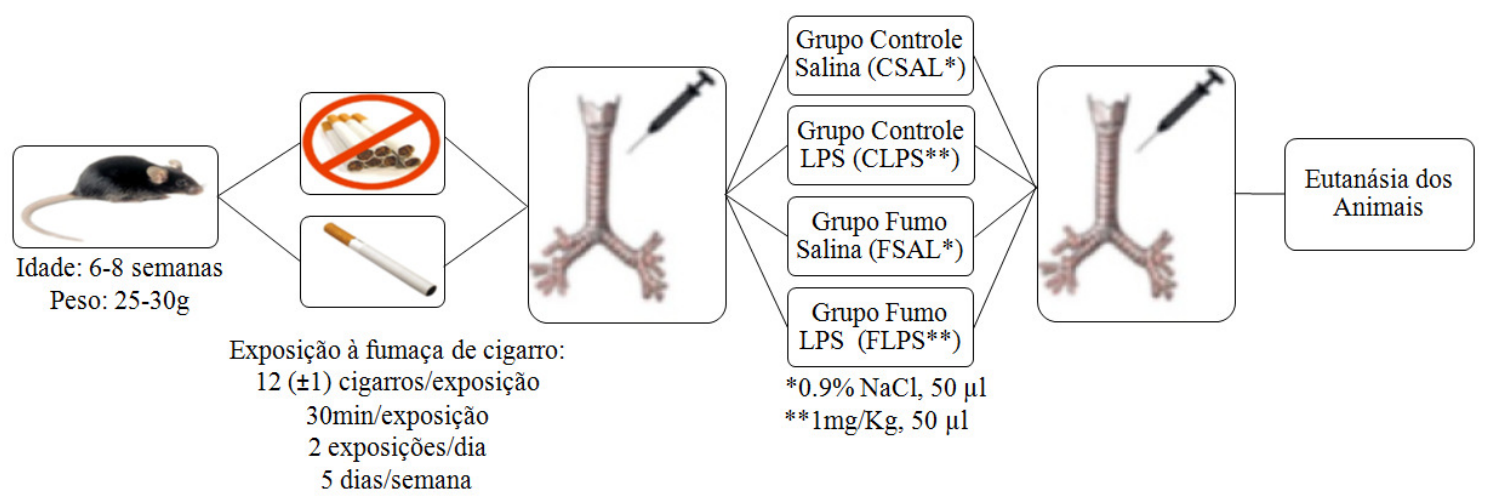

Figura 5 - Representação esquemática dos grupos experimentais

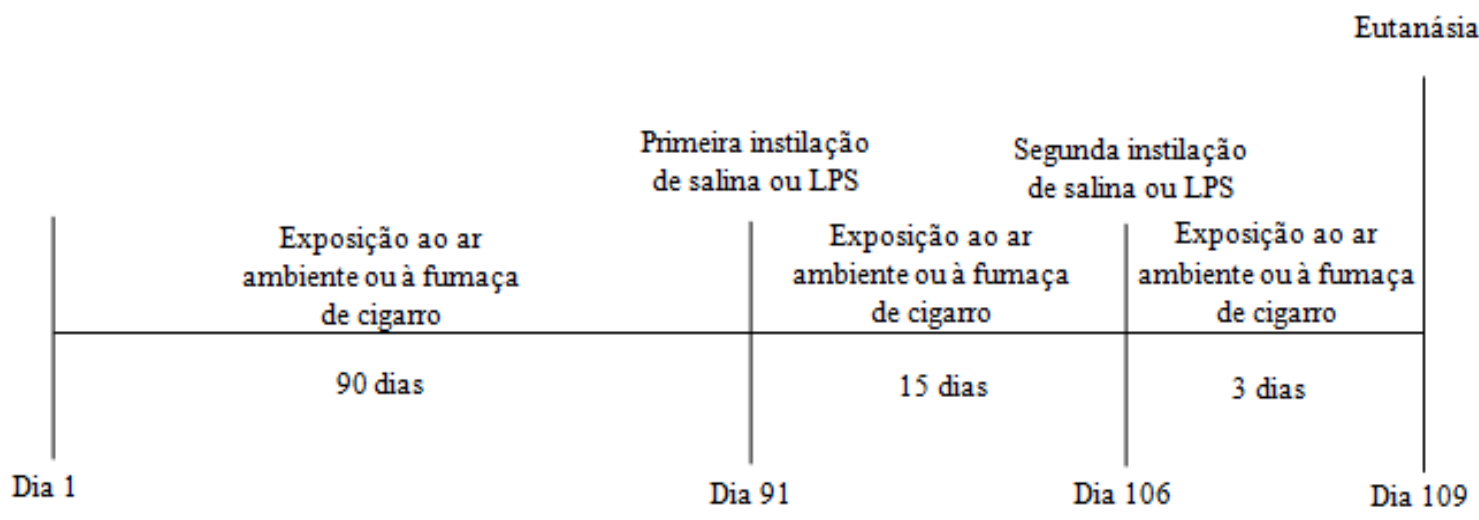

Figura 6 - Linha temporal do protocolo experimental

O protocolo experimental foi realizado em duas etapas: a primeira exposição foi coletado material para análises da mecânica respiratória, LAB, morfometria do tecido pulmonar e imuno-histoquímica. A segunda exposição, o material coletado foi utilizado para dosagens de quimiocinas e citocinas. 


\subsection{Indução do enfisema pulmonar por exposição à fumaça de cigarro}

Para indução do enfisema pulmonar, os animais foram expostos à fumaça de cigarro como descrito previamente por Toledo et al. $(2012)^{126}$. Para tanto foi utilizada uma câmara de inalação ( 28 L), com duas entradas (ar e fumo), uma saída e um ventilador, para aumentar a mistura entre o ar e a fumaça dentro da caixa. O fluxo de ar sintético na primeira entrada foi de $2 \mathrm{~L} / \mathrm{min}$, e a segunda entrada recebeu um fluxo de ar sintético, que passou através de um Sistema Venturi ligado a um cigarro aceso, aspirando a fumaça do cigarro e conduzindo-a para dentro da caixa. A taxa de fluxo de ar nesta segunda entrada podia ser alterada fornecendo mais ou menos mistura de fumo para a caixa. Definimos a taxa de fluxo de $1,5 \mathrm{~L} / \mathrm{min}$, o que produziu níveis de monóxido de carbono (CO) variando de 250 a 350 ppm (partes por milhão) (ToxiPro, biosystems, USA). A concentração de carboxihemoglobina em camundongos expostos ao fumo foi mantida a $10 \%( \pm 1,3)$. Os animais foram expostos a $12( \pm 1)$ cigarros comercialmente filtrados $(0,8 \mathrm{mg}$ de nicotina, $10 \mathrm{mg}$ de alcatrão e $10 \mathrm{mg}$ de $\mathrm{CO}$ por cigarro) com concentração total de partículas em suspensão (TPM) 354,8 \pm 50,3 $\mu \mathrm{g} / \mathrm{m} 3$ por dia $^{127}$. Os camundongos expostos à fumaça de cigarro foram mantidos na caixa com estes níveis de CO por um período de tempo de 30 min, duas vezes por dia, 5 dias por semana, durante 14 semanas (Figura 7). Os animais controles foram expostos ao ar filtrado. 


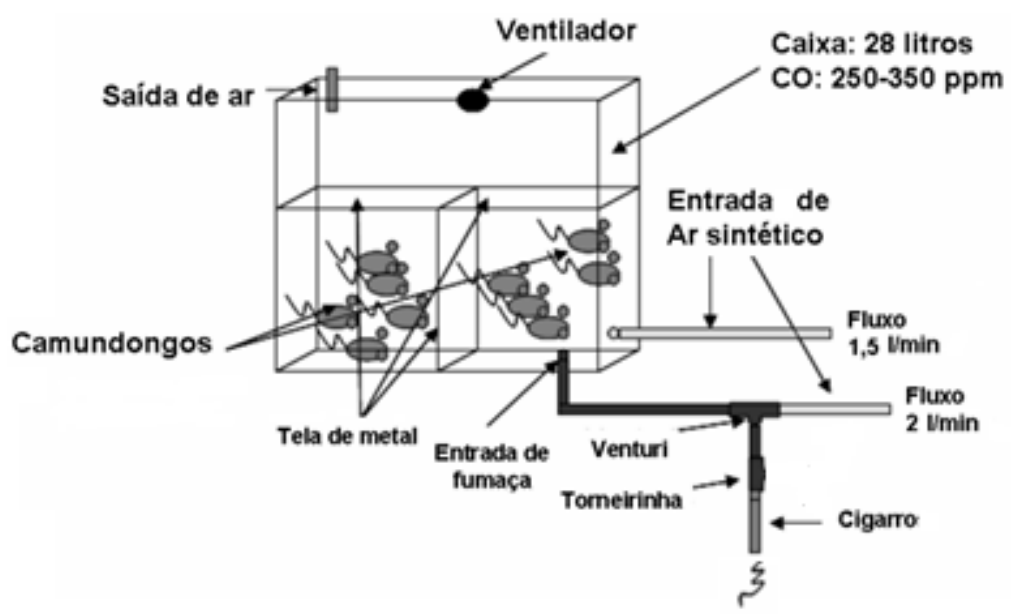

FONTE: Biselli PJC, $2011^{127}$ adaptado.

Figura 7 - Esquema ilustrativo da caixa de exposição à fumaça de cigarro

\subsection{Instilação de LPS}

Os animais foram anestesiados com ketamina (34 mg/kg) e xilazina (12 mg/kg) por via intramuscular, e posteriormente foram submetidos à uma pequena incisão na região do pescoço para a abertura do óstio anterior da traquéia, através da qual foram realizadas as instilações com as devidas soluções e doses mencionadas posteriormente. As instilações foram realizadas utilizando-se uma seringa de insulina ultrafina da marca BD (0,38X13mm; 27GX1/2”) e logo após a região foi suturada.

Os camundongos foram submetidos ao procedimento de recuperação póscirúrgica, no qual receberam tramadol $5 \mathrm{mg} / \mathrm{mL}$ por via intramuscular e permaneceram em ambiente aquecido $\left(30^{\circ} \mathrm{C}\right)$ até apresentarem movimentos ativos, e só então retornaram para sua caixa moradia.

\subsection{Avaliação da Mecânica do Sistema Respiratório}

Para avaliação da mecânica respiratória, os animais de cada grupo foram aneste- 
siados com thiopental $(70 \mathrm{mg} / \mathrm{kg})$, por via intra peritoneal (i.p) e traqueostomizados para instalação de um cateter intravascular 20G, sendo este fixado à traquéia por meio de fios de algodão e conectados a um respirador para pequenos animais (flexiVent, SCIREQ, Canadá).

Os animais foram ventilados com um volume corrente de $10 \mathrm{~mL} / \mathrm{kg}$ e frequência respiratória de 120 ciclos/min. Posteriormente foi induzida a paralisia muscular através da administração de brometo de pancurônio $(1 \mathrm{mg} / \mathrm{kg})$ i.p. O nível anestésico do animal foi verificado durante todo o procedimento.

Foi calculada a impedância do sistema respiratório (Zrs) dos animais de cada grupo, para tanto foi utilizado um sinal de perturbação em volume de 16 segundos. A ventilação mecânica foi interrompida somente para a aplicação das perturbações. Após a perturbação, os dados foram coletados.

Para análise das impedâncias obtidas, utilizaremos o modelo de fase constante, descrito por Hantos ${ }^{128}$.

$Z(f)=R_{a w}+i \cdot 2 \cdot \pi \cdot f \cdot I_{a w}+\frac{G-i \cdot H}{(2 \cdot \pi \cdot f)^{\alpha}}$

O Raw é a resistência de vias aéreas, Iaw é a inertância das vias aéreas, Gtis caracteriza a dissipação de energia nos tecidos pulmonares, Htis caracteriza a energia acumulada nos tecidos do pulmão, $i$ é a unidade imaginária, $f$ é a frequência e $\alpha=\frac{2}{\pi} \cdot$ arcotangente $\left(\frac{H}{G}\right)$

O parâmetro Raw (resistência de vias aéreas), nos permite a análise, isoladamente das vias aéreas, sem a interferência do tecido pulmonar. O parâmetro Gtis 
avalia a resistência tecidual, enquanto que o parâmetro Htis seria a elastância do tecido pulmonar.

\subsection{Coleta e Análise do LBA}

Para a coleta do LBA, os animais, ainda anestesiados, foram eutanasiados por meio de exsanguinação da aorta abdominal e em seguida os pulmões foram lavados com três instilações de $0,5 \mathrm{~mL}$ de solução salina estéril (NaCL 0,9\%) e o volume total recuperado, foi então centrifugado a $1000 \mathrm{rpm}$ (rotações por minuto), a $4^{\circ} \mathrm{C}$ durante 10 min, o sobrenadante foi armazenado a $-20^{\circ} \mathrm{C}$ e o botão celular ressuspenso em $0,2 \mathrm{~mL}$ de solução salina estéril para os grupos instilados salina e 1,5 mL para os grupos LPS, para contagem das células totais na câmara de Neubauer (Carl Roth, Karlsruhe, Germany). A contagem diferencial de 300 células foi feita em campos aleatoriamente selecionados. Alíquotas de $100 \mu \mathrm{l}$ da suspensão celular foram centrifugadas em lâminas de vidro usando uma citocentrífuga (Medion Diagnostics, Dündingen, Switzerland) durante 6 min em 450 rpm, e então coradas com Diff-Quick Romanowsky (DQS; Biochimical Sciences Inc., Swedesboro, NJ). As lâminas foram analisadas utilizando microscopia óptica na magnitude de 1000x e a obtenção do número absoluto de cada população celular no LBA foi estabelecida. Foram contadas 300 células inflamatórias por lâmina. Após a coleta do LBA a caixa torácica foi aberta para retirada dos pulmões e coração em monobloco.

\subsection{Remoção dos pulmões e análise histológica}

Os pulmões foram fixados em formaldeído (4\%) sob pressão constante de 
$20 \mathrm{cmH}_{2} \mathrm{O}$ durante $24 \mathrm{~h}$. Após a fixação foram feitos cortes transversais de $4 \mu \mathrm{m}$ destes pulmões para futuras análises histológicas.

\subsubsection{Avaliação morfométrica}

Para a análise morfométrica as lâminas foram coradas com hematoxilina e eosina (HE) e posteriormente fizemos a contagem do Lm no espaço subpleural (distal) (Figura 8) e no espaço peribronquial (proximal - ao redor das vias aéreas) (Figura 9) por microscopia óptica (Nikon Eclipse - E200, Japão). A análise quantitativa foi realizada através da técnica convencional de contagem de pontos ("point-couting") ${ }^{129}$. Em um aumento de 200x, utilizando-se uma ocular, contendo um sistema de referência de 100 pontos e 50 segmentos de reta dispostos em paralelo, acoplada ao microscópio de luz convencional (Figuras 8 e 9, respectivamente).

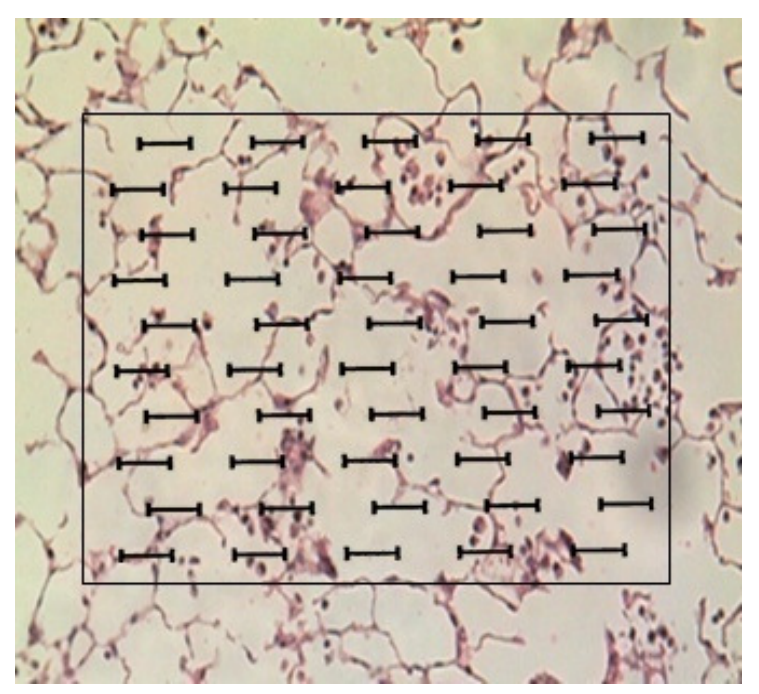

Figura 8 - Retículo com 100 pontos e 50 retas utilizado para quantificação dos parâmetros morfométricos distais (subpleural) no parênquima pulmonar. Aumento de 200x 


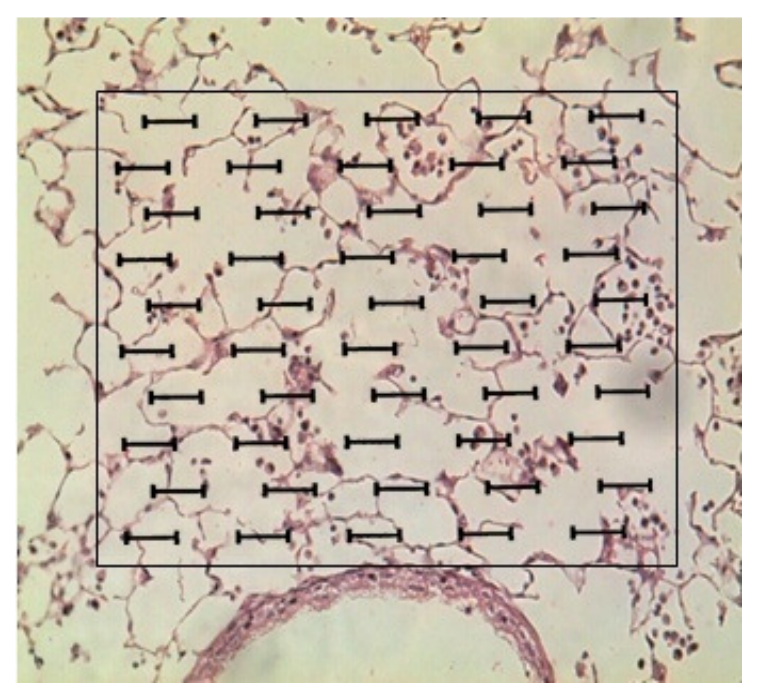

Figura 9 - Retículo com 100 pontos e 50 retas utilizado para quantificação dos parâmetros morfométricos proximais (peribronquial) no parênquima pulmonar. Aumento de 200x

O Lm é um índice do diâmetro médio dos espaços aéreos distais. Utilizando o retículo sobreposto ao parênquima pulmonar nas regiões mais periféricas do parênquima e ao redor das vias aéreas, foi contado o número de vezes que os interceptos cruzam as paredes dos alvéolos em um aumento de $200 \mathrm{x}^{130}$.

Foi feita uma média de vinte campos para cada lâmina e calculado o Lm através da seguinte equação:

$\mathrm{Lm}=2500 \mu \mathrm{m} /$ média do número de vezes que os interceptos cruzaram as paredes dos alvéolos.

O valor de $2500 \mu \mathrm{m}$ é obtido através da aferição do retículo utilizado, por meio de uma régua da fabricante Zeiss no aumento de 200x. A somatória de todos os segmentos do retículo resulta no valor $2500 \mu \mathrm{m}$.

\subsubsection{Espessura Epitelial}

A avaliação da espessura epitelial foi realizada por sistema de análise de imagens, utilizamos o programa Panoramic Viewer 1.5 (3DHISTECH, Budapeste, 
Hungria). Foram selecionadas 5 vias aéreas de cada animal em aumento de 400x. A espessura epitelial foi definida como a distância entre a membrana basal e a membrana da célula luminal, excluindo os cílios ${ }^{131}$, posteriormente foi medido o comprimento da membrana basal e então, a espessura epitelial foi expressa como uma relação entre a média da espessura epitelial e o comprimento da membrana basal (Figura 10).

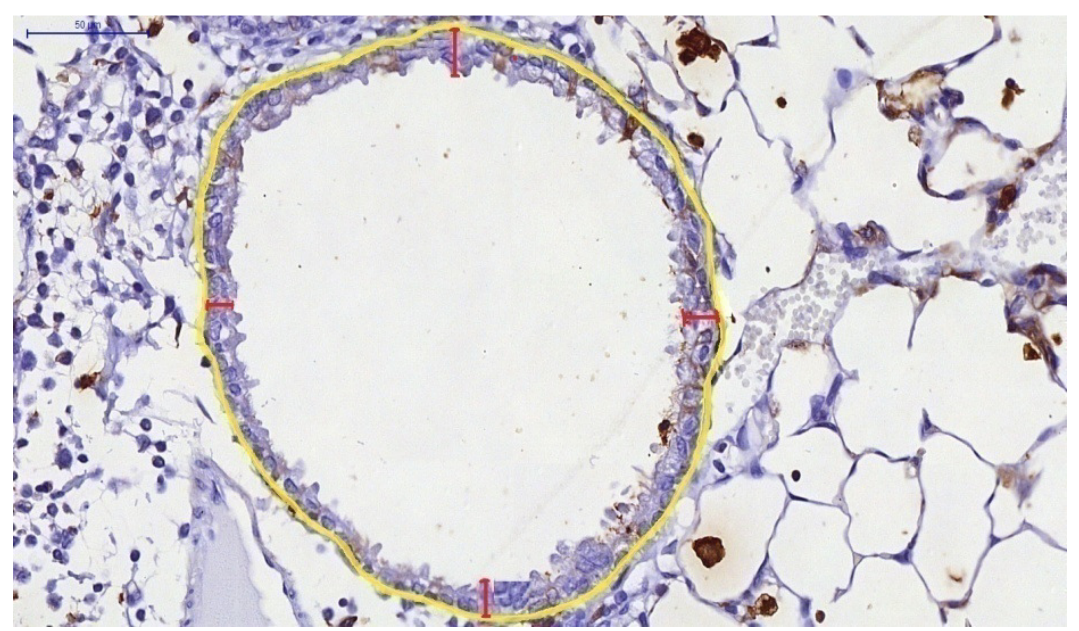

Figura 10 - Espessura epitelial. A espessura epitelial foi expressa como uma relação entre a média da espessura epitelial, representada pelo traço em vermelho e o comprimento da membrana basal, representado pelo traço em amarelo. Aumento de 400x

\subsection{Imuno-histoquímica}

Para realização das marcações específicas por imuno-histoquímica, as lâminas silanizadas foram desparafinizadas em xilol quente $\left(60-65^{\circ} \mathrm{C}\right)$ durante $30 \mathrm{~min}$ e reidratadas em concentrações decrescentes de etanol, água corrente e água destilada por 3 min cada. Os epítopos antigênicos foram recuperados por alta temperatura em solução de citrato $10 \mathrm{mM}(\mathrm{pH}=6.0)$ em panela de pressão. Posteriormente, para inativação de epítopos inespecíficos as lâminas foram bloqueadas com peroxidase endógena em temperatura ambiente. Em seguida, as lâminas foram incubadas durante toda a noite 
(overnight) a $4{ }^{\circ} \mathrm{C}$ com o anticorpo primário em câmara úmida. Após este período, os cortes foram lavados com tampão fosfato (PBS - pH=7,5) e incubados com anticorpo secundário e logo em seguida também foram incubados com complexo conjugado com peroxidase (Vector Laboratories - Sta. Cruz Biotechnology, CA, EUA). A incubação do anticorpo secundário e o complexo tiveram duração de 30 min a $37^{\circ} \mathrm{C}$, em câmara úmida (especificações na Tabela 1). Para alguns marcadores os cortes foram incubados com Histofine (Nichirei Biosciences inc., Tokyo, Japão) um polímero marcado e preparado com uma combinação de polímeros de aminoácidos com peroxidase e anticorpo secundário, durante 30 min a $37^{\circ} \mathrm{C}$, em câmara úmida (especificações na Tabela 1). Para a revelação foi utilizada solução de cromógeno (diaminobenzidina DAB) (Dako - Dako North America, Inc. CA, EUA) e hematoxilina de Harris (Merck, Darmstadt, Germany) para contracorar. As lâminas foram montadas com lamínulas e resina sintética.

Para cada marcador específico foi utilizado um determinado anticorpo com seu respectivo anticorpo secundário. Para controle negativo o anticorpo primário foi omitido do procedimento nas amostras de tecido ${ }^{126}$. Fizemos a padronização da diluição dos mesmos, iniciando os testes com as diluições sugeridas pelos fabricantes. As especificações utilizadas estão descritos na próxima tabela. 
Tabela 1 - Especificações das marcações específicas por imuno-histoquímica

\begin{tabular}{|c|c|c|c|c|}
\hline MARCADOR & $\begin{array}{l}\text { ANTICORPO } \\
\text { PRIMÁRIO }\end{array}$ & $\begin{array}{l}\text { ANTICORPO } \\
\text { SECUNDÁRIO }\end{array}$ & DILUIÇÃO & ESPECIFICAÇÃO \\
\hline MAC-2 & $\begin{array}{c}\text { Monoclonal } \\
\text { produzido em rato }\end{array}$ & Anti-rato (Vector) & 1:50000 & $\begin{array}{c}\text { clone M3/38, Cedarlane, } \\
\text { ON, Canadá }\end{array}$ \\
\hline $\begin{array}{c}\text { Elastase } \\
\text { Neutrofílica }\end{array}$ & $\begin{array}{l}\text { Policlonal } \\
\text { produzido em } \\
\text { coelho }\end{array}$ & $\begin{array}{l}\text { Anti-coelho } \\
\text { (Histofine) }\end{array}$ & $1: 2000$ & $\begin{array}{c}\text { ab21595, abcam, Biogen, } \\
\text { SP, Brasil }\end{array}$ \\
\hline $\mathrm{CD4}^{+}$ & $\begin{array}{c}\text { Monoclonal } \\
\text { produzido em rato }\end{array}$ & Anti-rato (Vector) & $1: 10$ & $\begin{array}{c}\text { sc } 13573, \text { Sta Cruz } \\
\text { Biotechnology, CA, USA }\end{array}$ \\
\hline $\mathrm{CD8}^{+}$ & $\begin{array}{l}\text { Policlonal } \\
\text { produzido em } \\
\text { coelho }\end{array}$ & $\begin{array}{l}\text { Anti-coelho } \\
\text { (Histofine) }\end{array}$ & $1: 100$ & $\begin{array}{l}\text { ab4055, abcam, Biogen, } \\
\text { SP, Brasil }\end{array}$ \\
\hline Foxp3 & $\begin{array}{l}\text { Policlonal } \\
\text { produzido em } \\
\text { coelho }\end{array}$ & $\begin{array}{l}\text { Anti-coelho } \\
\text { (Histofine) }\end{array}$ & $1: 500$ & $\begin{array}{c}\text { ab 54501, abcam, Biogen, } \\
\text { SP, Brasil }\end{array}$ \\
\hline Stat3 & $\begin{array}{l}\text { Policlonal } \\
\text { produzido em } \\
\text { coelho }\end{array}$ & $\begin{array}{l}\text { Anti-coelho } \\
\text { (Histofine) }\end{array}$ & $1: 1000$ & $\begin{array}{c}\text { sc } 482, \text { Sta Cruz } \\
\text { Biotechnology, CA, USA }\end{array}$ \\
\hline FosfoStat3 & $\begin{array}{c}\text { Policlonal } \\
\text { produzido em } \\
\text { cabra }\end{array}$ & Anti-cabra (Vector) & $1: 2000$ & $\begin{array}{c}\text { sc 7993, Sta Cruz } \\
\text { Biotechnology, CA, USA }\end{array}$ \\
\hline Stat5 & $\begin{array}{c}\text { Policlonal } \\
\text { produzido em } \\
\text { cabra }\end{array}$ & Anti-cabra (Vector) & $1: 2000$ & $\begin{array}{c}\text { Sc } 835 \mathrm{G}, \text { Sta Cruz } \\
\text { Biotechnology, CA, USA }\end{array}$ \\
\hline FosfoStat5 & $\begin{array}{c}\text { Policlonal } \\
\text { produzido em } \\
\text { cabra }\end{array}$ & Anti-cabra (Vector) & $1: 100$ & $\begin{array}{c}\text { sc } 11761, \text { Sta Cruz } \\
\text { Biotechnology, CA, USA }\end{array}$ \\
\hline
\end{tabular}

\subsubsection{Contagem de células positivas por área de parênquima}

As lâminas contendo os cortes dos pulmões com as marcações específicas realizadas pela imuno-histoquímica foram escaneadas por escaner de alta resolução (Pannoramic Scan, 3D Histech, Budapest, Hungary HUN). Foram analisados 15-20 campos do parênquima pulmonar por lâmina de cada animal. Os campos selecionados foram feitos com tamanhos iguais utilizando o software PannoramicViewer (aumento de 400x). Posteriormente, utilizando um software específico para análise de imagem (Image-Pro Plus version 4.5 for Windows, Media Cybernetics, MD, USA) foi aplicado um filtro pré-montado com base em um número representativo de fotos (Figura 11). Para cada imagem foram coletadas as áreas de marcação do parênquima pulmonar e 
contado o número de células positivas naquela área. A relação entre o número de células positivas por área de parênquima pulmonar foi determina e os resultados obtidos.

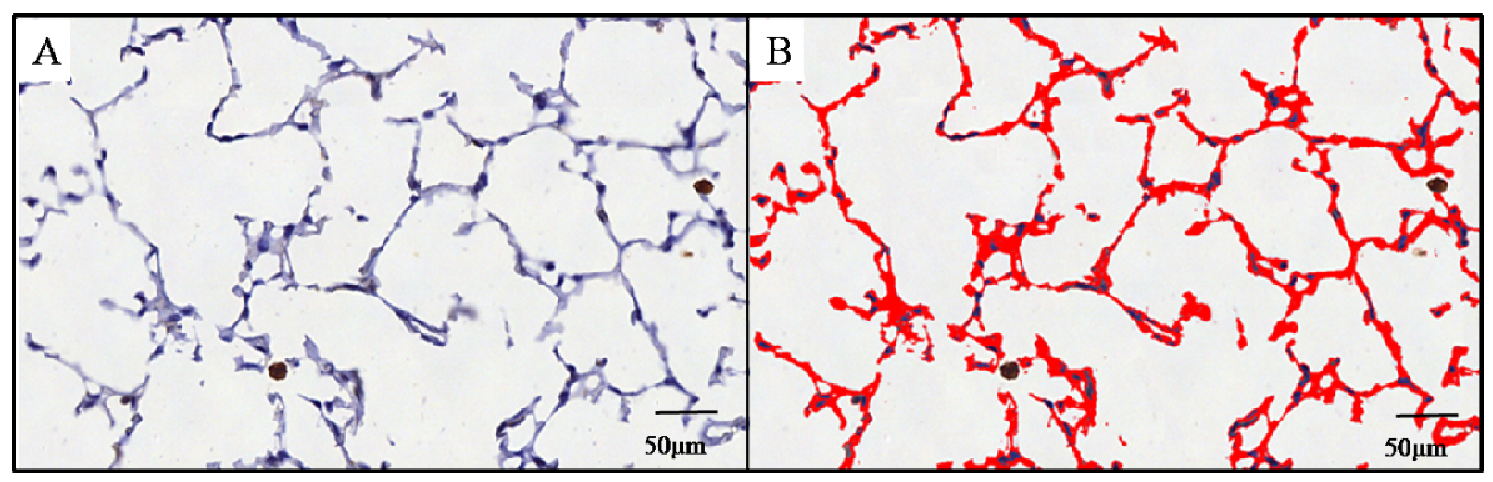

Figura 11 - Foto ilustrativa da contagem da área de parênquima pulmonar. (A) Lâmina original após escaneamento. (B) Lâmina após aplicação de filtro pré-montado para quantificação da área de parênquima pulmonar. Os resultados foram obtidos através da relação entre o número de células positivas por área de parênquima pulmonar. Aumento de 400x

\subsection{Dupla marcação por imuno-histoquímica}

A reação imuno-histoquímica de dupla marcação foi realizada para ilustrar as células positivas para Foxp3/IL-10. Essa reação baseou-se nos mesmos passos de uma reação imuno-histoquímica convencional, já descrita anteriormente. Inicialmente, fizemos a desparafinização, hidratação, recuperação antigênica, bloqueio e incubação overnight do anticorpo policlonal de coelho anti Foxp3 (1:300, Abcam, Cambridge, Reino Unido) e revelação com DAB. Após a revelação, numa segunda etapa os cortes foram lavados em água corrente, água destilada e PBS e posteriormente incubados com o anticorpo monoclonal de rato anti - IL-10 (1:100, Santa Cruz Biotechnology, CA, EUA) overnight a $4^{\circ} \mathrm{C}$. A etapa seguinte foi baseada em fosfatase alcalina, por $30 \mathrm{~min}$ a $37^{\circ} \mathrm{C}$. A reação de fosfatase alcalina foi então revelada com o cromógeno PermaRed/AP (Diagnostic BioSystems, Pleasanton, CA). Para contra-coloração, os cortes foram 
corados com hematoxilina de Harris (Merck, Darmstadt, Germany). As lâminas foram montadas com lamínulas e resina sintética.

O resultado final foi a marcação das células em castanho para Foxp3 e a IL-10 em vermelho ou ainda as células duplamente marcadas, demonstrando em tom alaranjado que as células Foxp3 estariam expressando IL-10.

As imagens foram tiradas com uma câmera digital AxioCam MRc5, usando o software Zen, ambos da marca Carl Zeiss (München-Hallbergmoos - Alemanha) em aumento de 400x e 1000x para cada imagem.

\subsection{Dosagem de Citocinas}

A análise das citocinas foi realizada pelo ensaio de imunoabsorção enzimática (ELISA - Enzyme Linked ImmunoSorbent Assay). Os pulmões foram homogeneizados em solução salina estéril (NaCL $0,9 \%$, volume $600 \mu \mathrm{l}$ ), e o sobrenadante estocado a -80 ${ }^{\circ} \mathrm{C}$. As especificações utilizadas estão descritos na tabela a seguir:

Tabela 2 - Especificações das dosagens de citocinas e quimiocinas

\begin{tabular}{cc}
\hline CITOCINAS E QUIMIOCINAS & ESPECIFICAÇÃO \\
\hline IL-17 & Kit ELISA - R\&D System (Minneapolis, MN) \\
IL-6 & Kit ELISA- BioLegend (San Diego, CA) \\
IL-10 & Kit ELISA- BioLegend (San Diego, CA) \\
IFN- $\gamma$ & Kit ELISA - R\&D System (Minneapolis, MN) \\
CXCL1 & Kit ELISA - R\&D System (Minneapolis, MN) \\
CXCL2 & Kit ELISA - R\&D System (Minneapolis, MN) \\
\hline
\end{tabular}

A análise foi realizada de acordo com as instruções do fabricante, de modo geral, 
para cada citocina utilizamos microplacas (Costar, Cambridge, MA, USA) sensibilizadas com anticorpos monoclonais específicos. Após lavagens e distribuição das amostras, foram adicionados anticorpos específicos para as diferentes citocinas conjugados à biotina. Para a revelação da ligação, solução reveladora contendo conjugado enzimático de estreptoavidina-peroxidase, substrato e cromógeno foi adicionada. A leitura da reação foi realizada a $450 \mathrm{~nm}$ em espectrofotômetro M2 (Spectramax L, Moleculas Devices). As concentrações das amostras foram calculadas a partir das curvas-padrão obtidas com as citocinas recombinantes. 


\section{ANÁLISE ESTATÍSTICA}

A análise estatística e os gráficos foram realizados utilizando o programa SigmaPlot (Systat Software, San Jose, CA, EUA; versão 11.0). Os dados paramétricos foram analisados utilizando teste de variância para um fator (One Way Analysis) seguido do pós teste de Holm - Sidak e para os dados não paramétricos utilizamos o teste de Kruskal - Wallis seguido do pós teste de Dunn's. Fizemos a transformação logarítmica dos dados para as análises de imuno-histoquímica e citocinas/quimiocinas. Os resultados foram apresentados com média \pm erro padrão (EP), sendo considerado o nível de significância de 5\% (p<0,05). 


\section{RESULTADOS}

\subsection{Avaliação da mecânica do sistema respiratório}

A análise da Gtis (Figura 12), revelou aumento no grupo FLPS quando comparado com o grupo controle CSAL. Em relação ao parâmetro Htis (Figura 13), houve aumento no grupo FLPS quando comparado ao grupo CSAL e FSAL. Já em relação a Raw (Figura 14), não foi observado diferença entre os grupos experimentais.

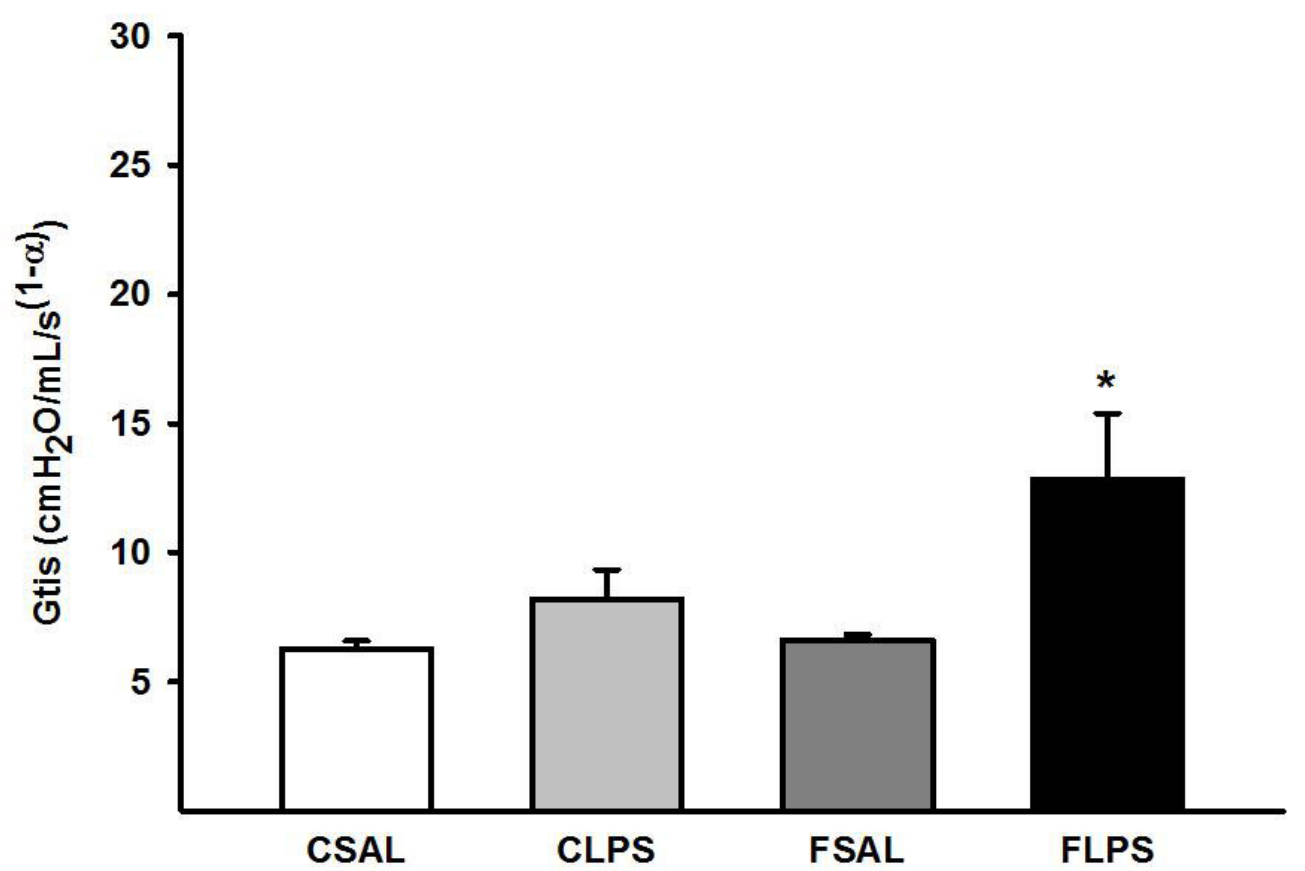

Figura 12 - Avaliação da mecânica do sistema respiratório, Gtis. * comparado com CSAL (p=0,006). CSAL $n=10$, CLPS n=6, FSAL n=9, FLPS n=7. Os valores são a média $\pm E P$ 


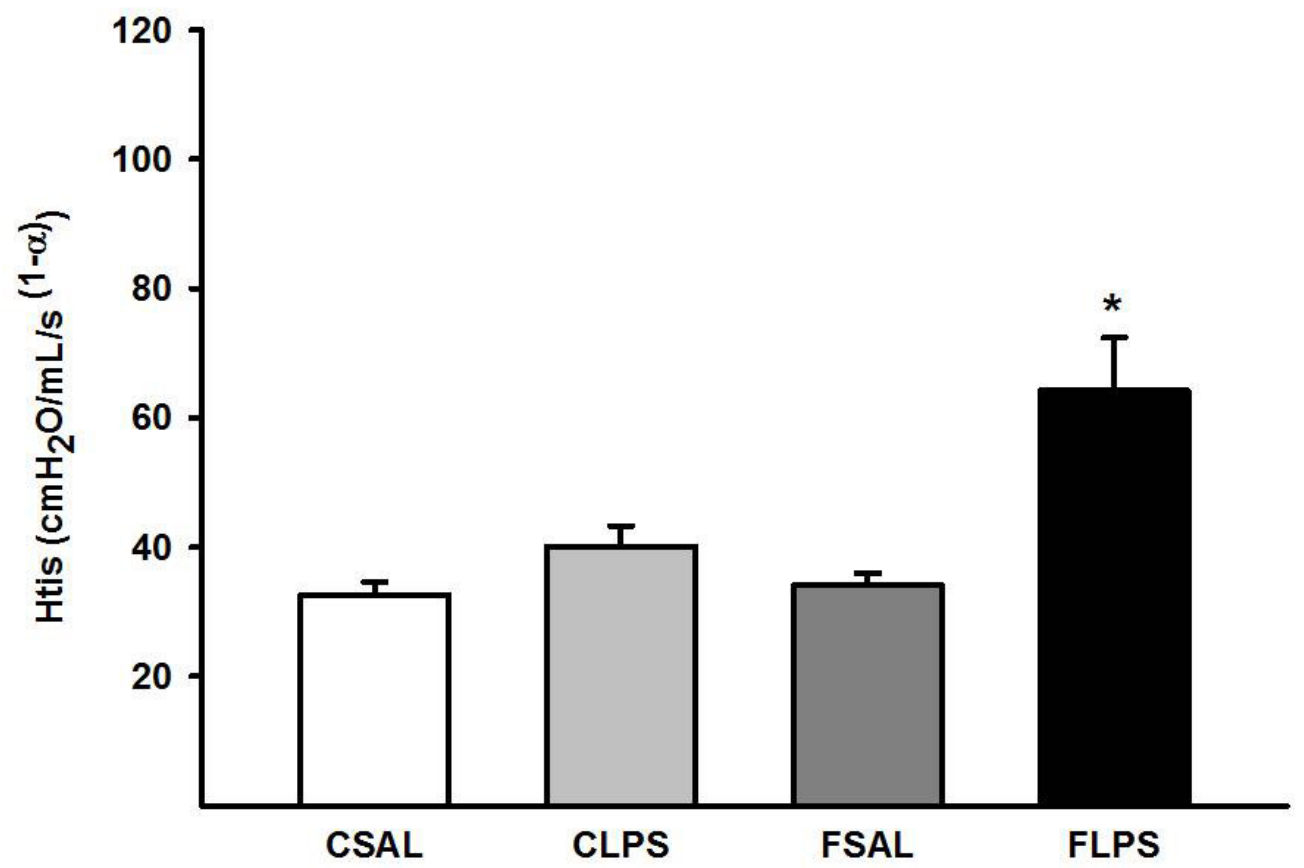

Figura 13 - Avaliação da mecânica do sistema respiratório, Htis. * comparado com CSAL e FSAL $(\mathrm{p}=0,002)$. CSAL $n=10$, CLPS $n=6, F S A L n=9$, FLPS $n=7$. Os valores são a média \pm EP

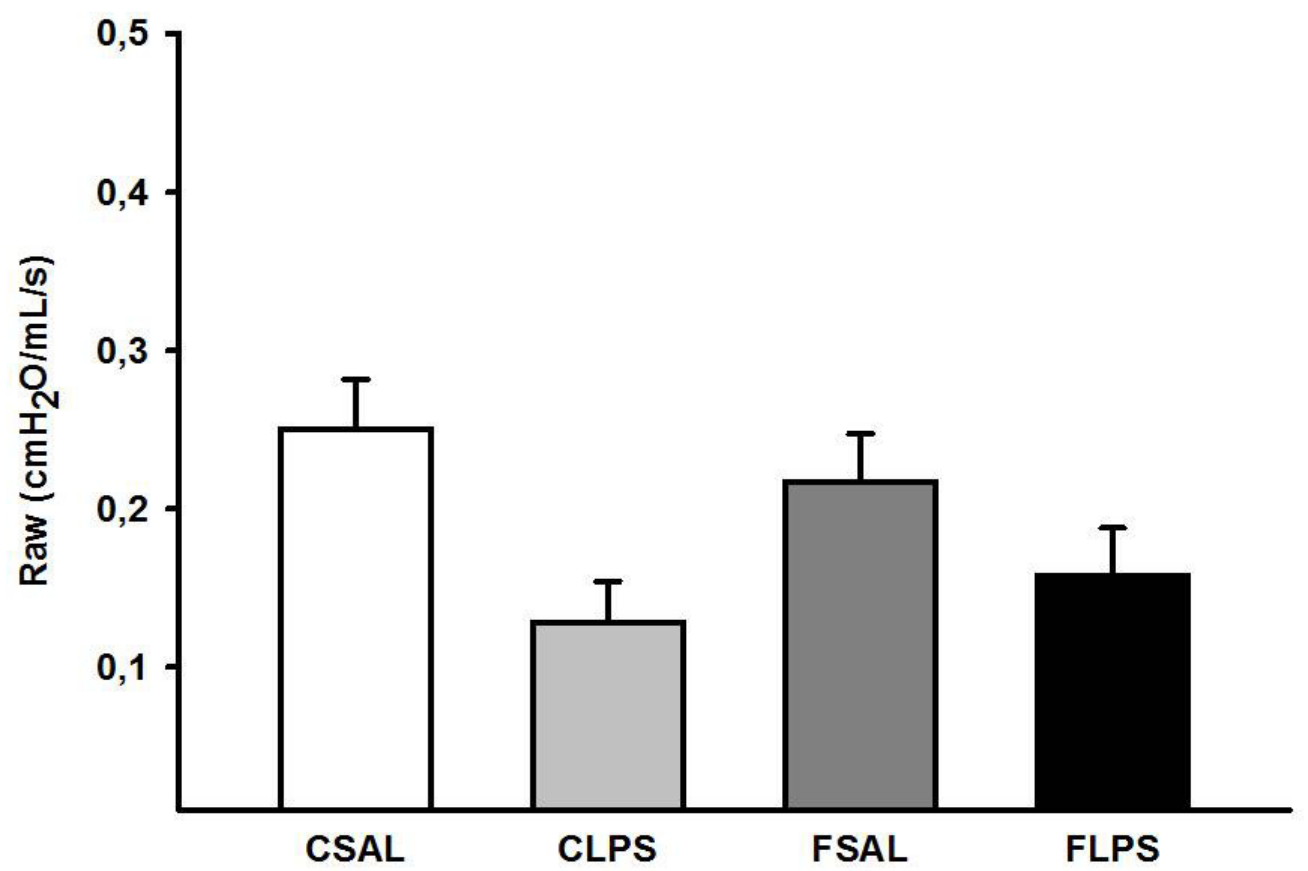

Figura 14 - Avaliação da mecânica do sistema respiratório, Raw. Não houve diferença entre os grupos experimentais. CSAL. CSAL n=10, CLPS n=6, FSAL n=9, FLPS n=7. Os valores são a média \pm EP 


\subsection{Análise do LBA}

Observamos aumento do número de células totais nos grupos CLPS e FLPS quando comparados aos grupos CSAL e FSAL (Figura 15).

A análise diferencial das células infamatórias demonstrou aumento de macrófagos nos grupos CLPS e FLPS quando comparados ao grupo CSAL (Figura 16) e aumento de neutrófilos e linfócitos nos grupos CLPS e FLPS quando comparados aos grupos CSAL e FSAL (Figuras 17 e 18, respectivamente).

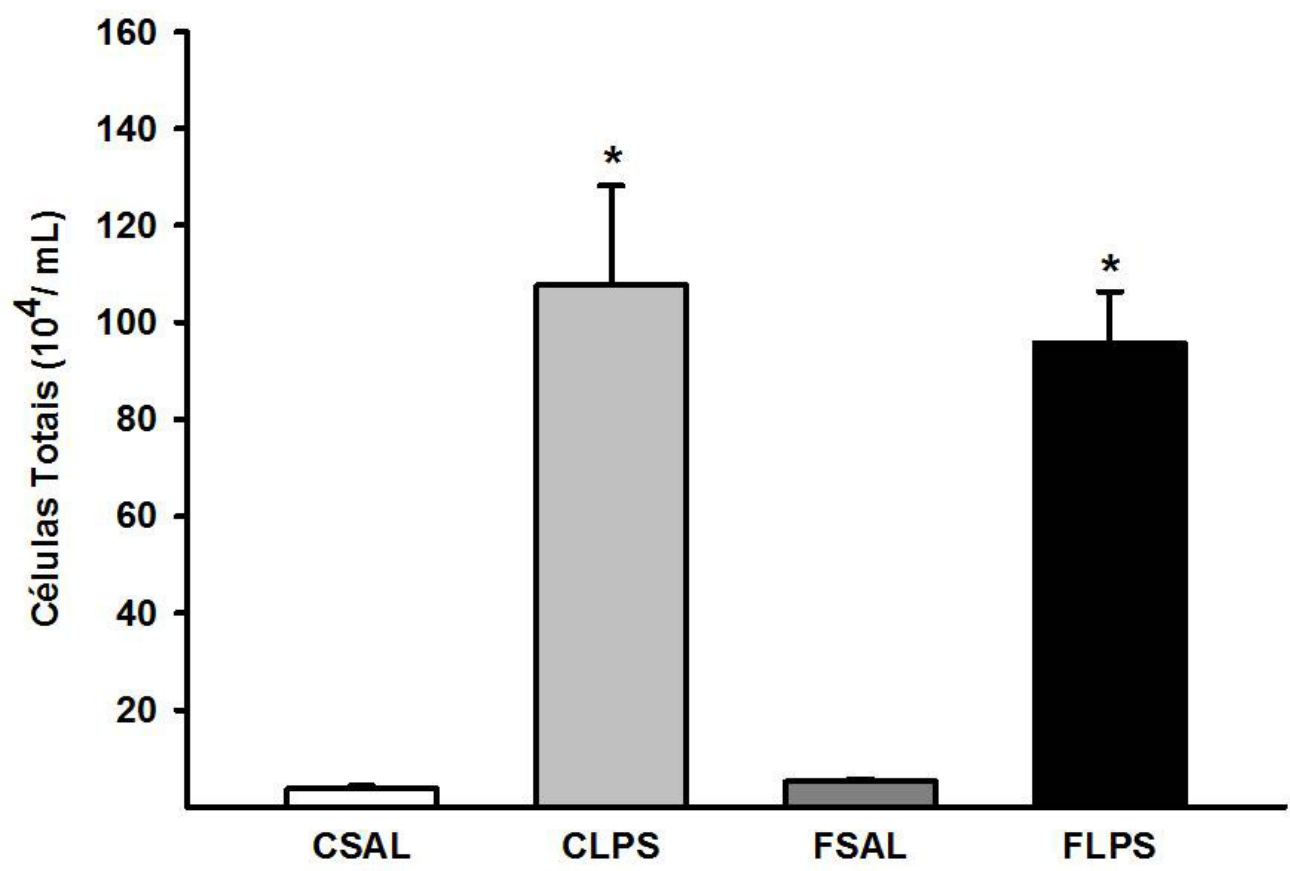

Figura 15 - Representação gráfica do número de células inflamatórias totais no LBA. Células totais. * comparado com CSAL e FSAL $(\mathrm{p}<0.001)$. CSAL $n=10$, CLPS $n=6$, FSAL $n=9$, FLPS $n=7$. Os valores são a média $\pm \mathrm{EP}$ 


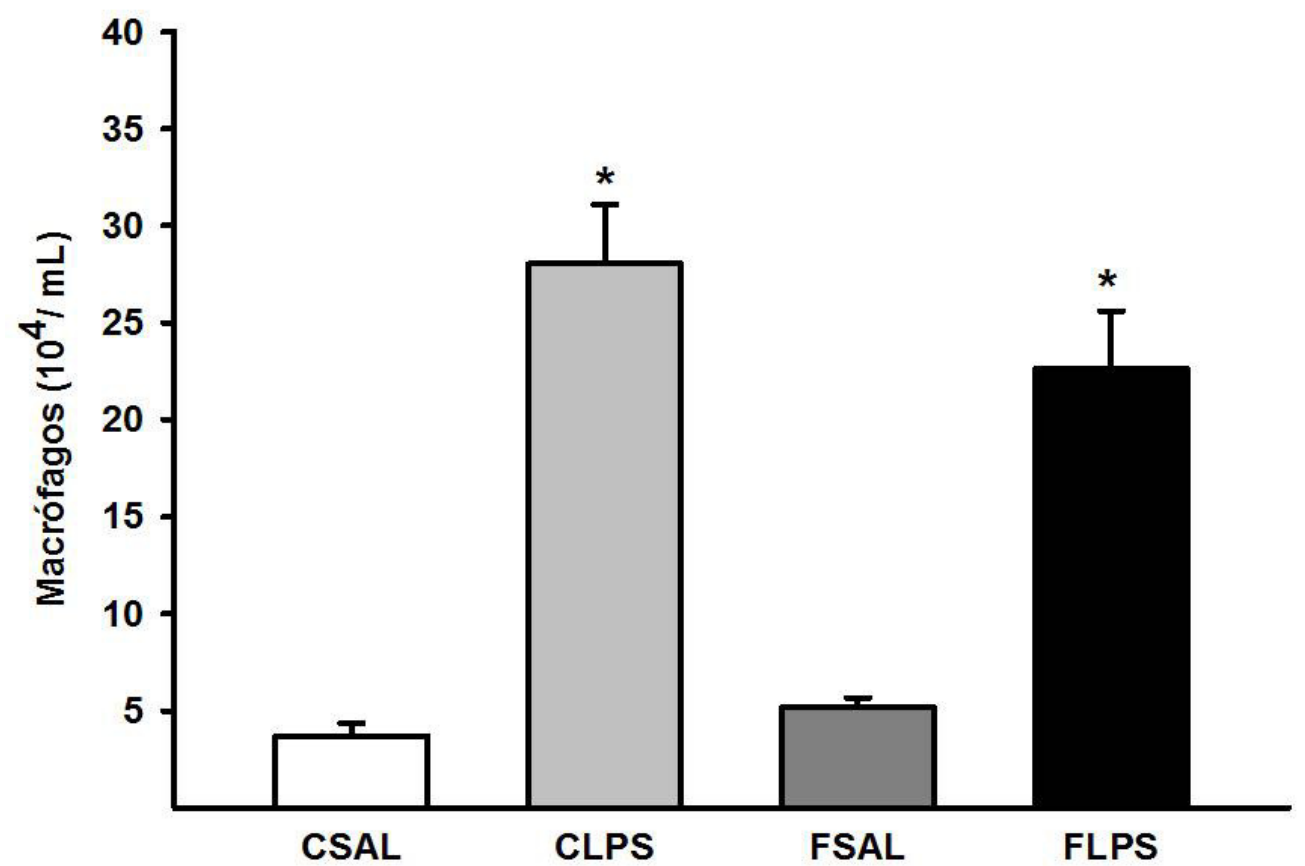

Figura 16 - Representação gráfica do número de macrófagos no LBA. * comparado com CSAL $(\mathrm{p}<0.001)$. CSAL $n=10$, CLPS $n=6, F S A L n=9$, FLPS $n=7$. Os valores são a média \pm EP

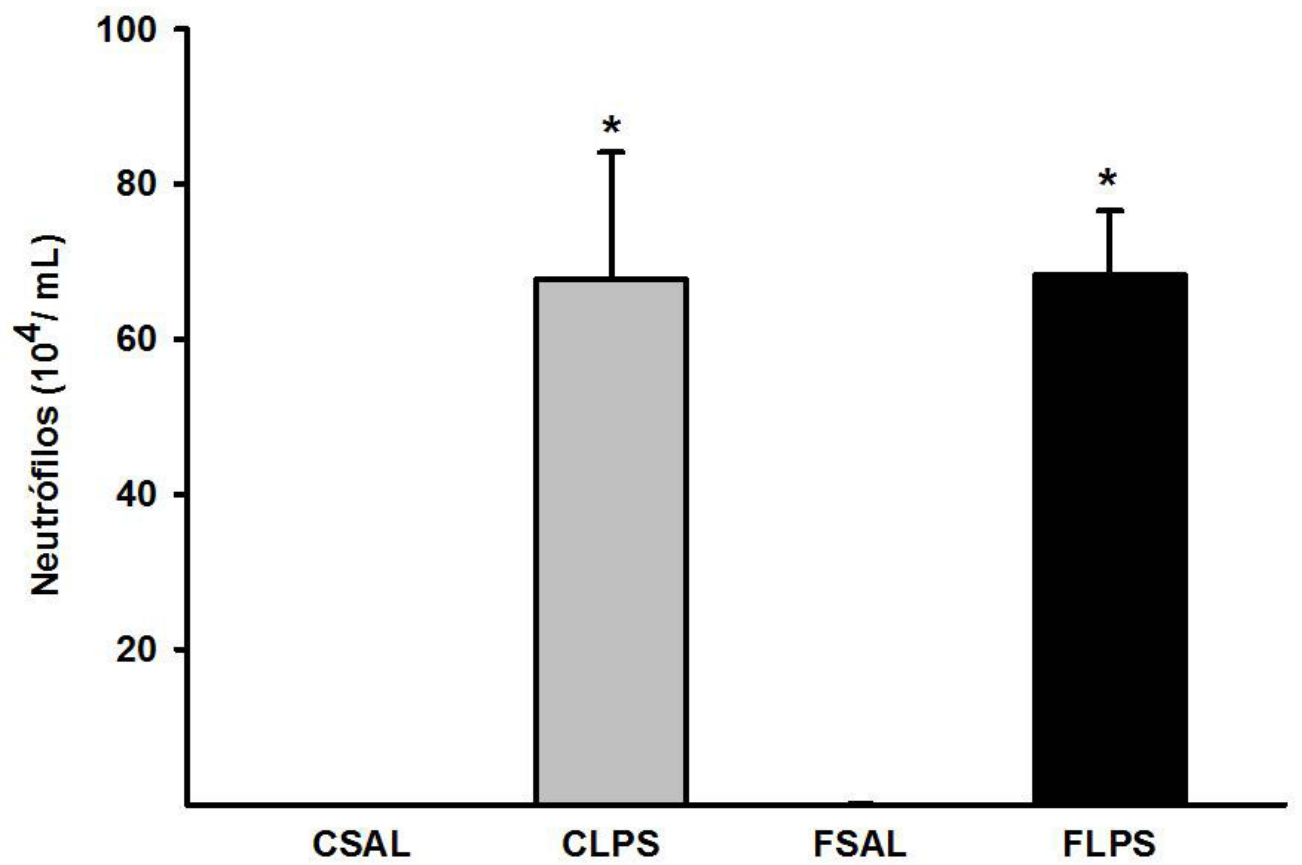

Figura 17 - Representação gráfica do número de neutrófilos no LBA. * comparado com CSAL e FSAL $(\mathrm{p}<0.001)$. CSAL n=10, CLPS n=6, FSAL n=9, FLPS n=7. Os valores são a média \pm EP 


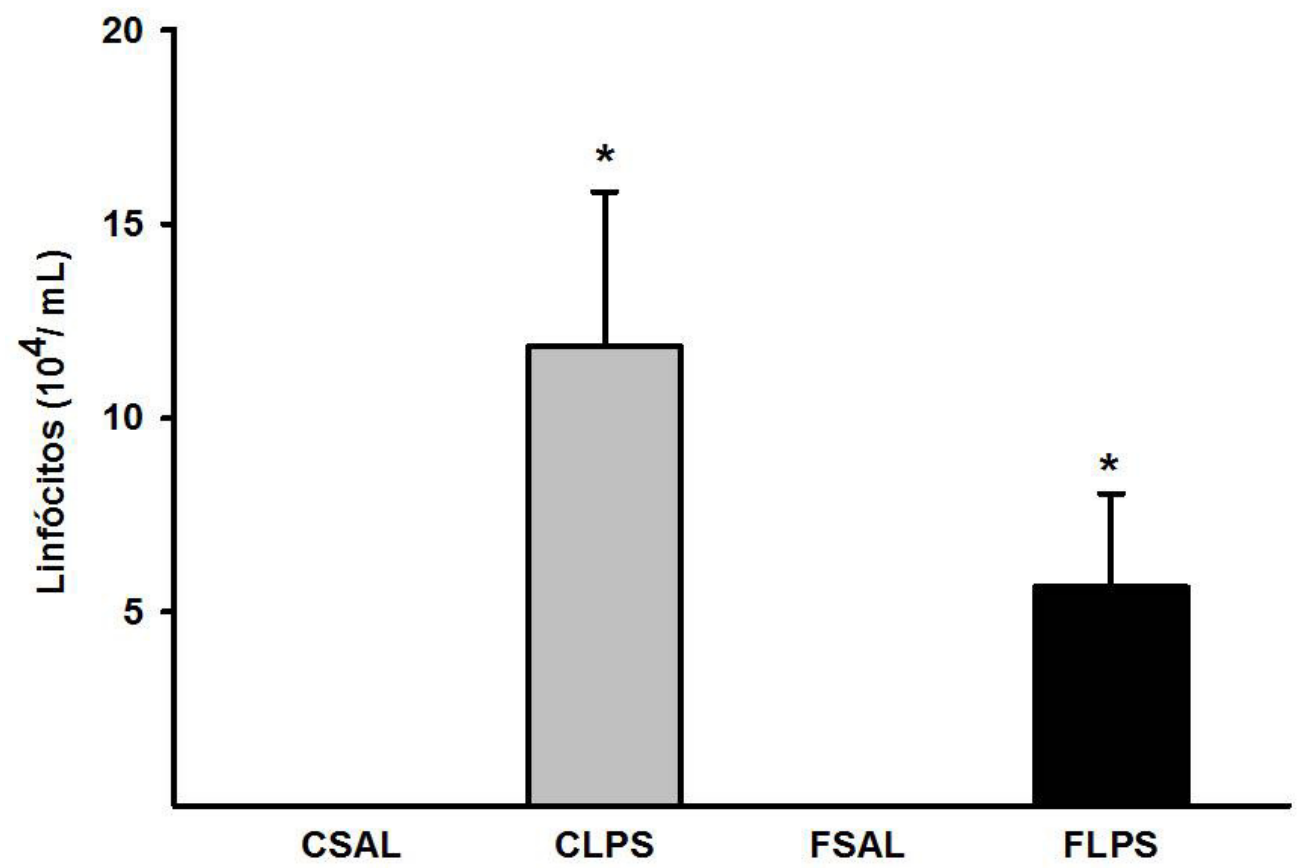

Figura 18 - Representação gráfica do número de linfócitos no LBA. * comparado com CSAL e FSAL $(\mathrm{p}<0.001)$. CSAL n=10, CLPS n=6, FSAL n=9, FLPS n=7. Os valores são a média \pm EP

\subsection{Avaliação morfométrica}

\subsection{1. $L m$}

A análise do parênquima pulmonar distal mostrou aumento do Lm nos grupos FSAL e FLPS quando comparado com os grupos CSAL e CLPS (Figura 19). Já os resultados da análise do parênquima pulmonar proximal mostrou aumento do Lm somente no grupo FLPS comparado com o grupo CSAL (Figura 19). Os cortes histológicos dos pulmões que caracterizam as mudanças morfológicas estão representados na figura $19 \mathrm{~A}-\mathrm{H}$. 


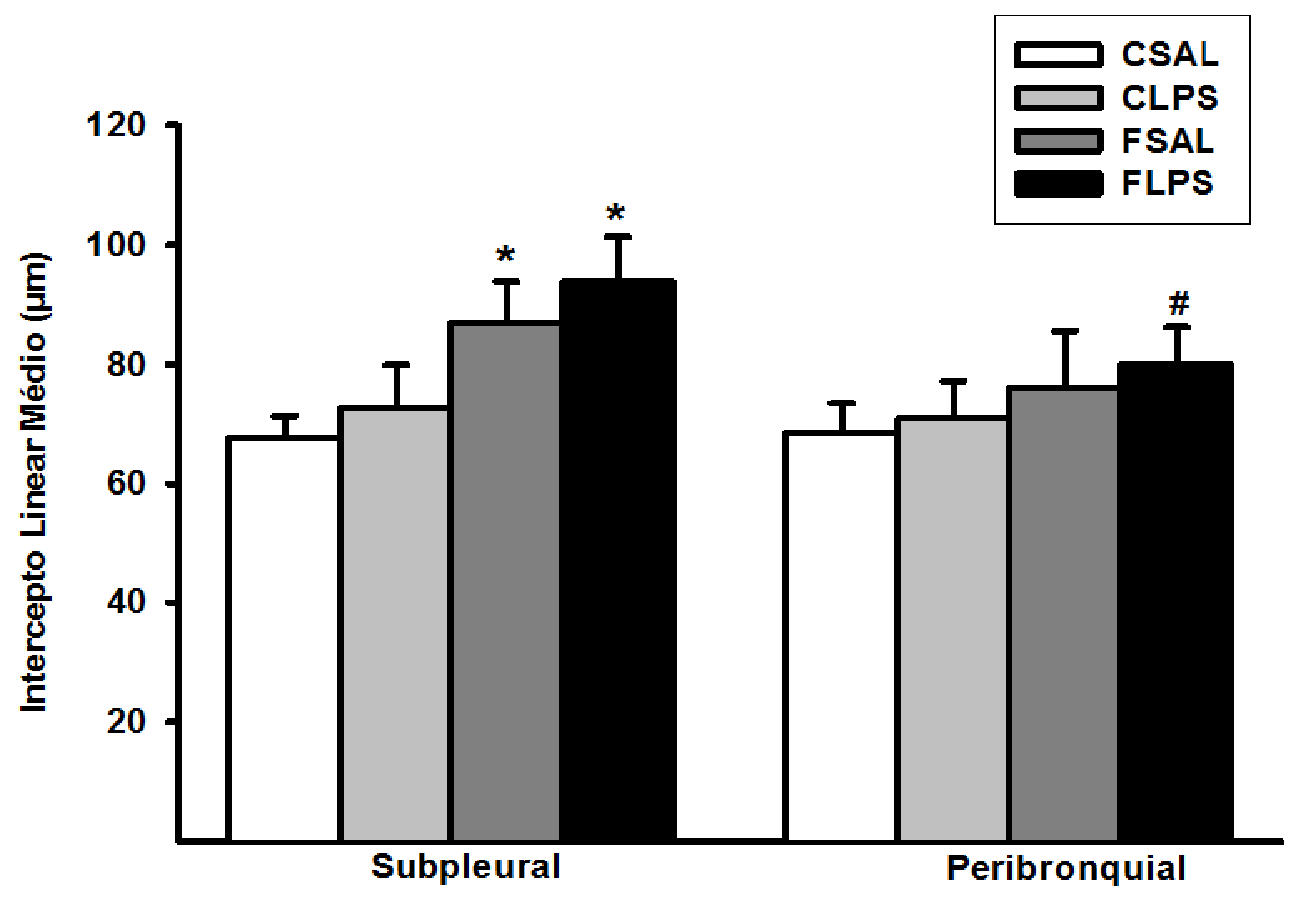

Espaço Aéreo

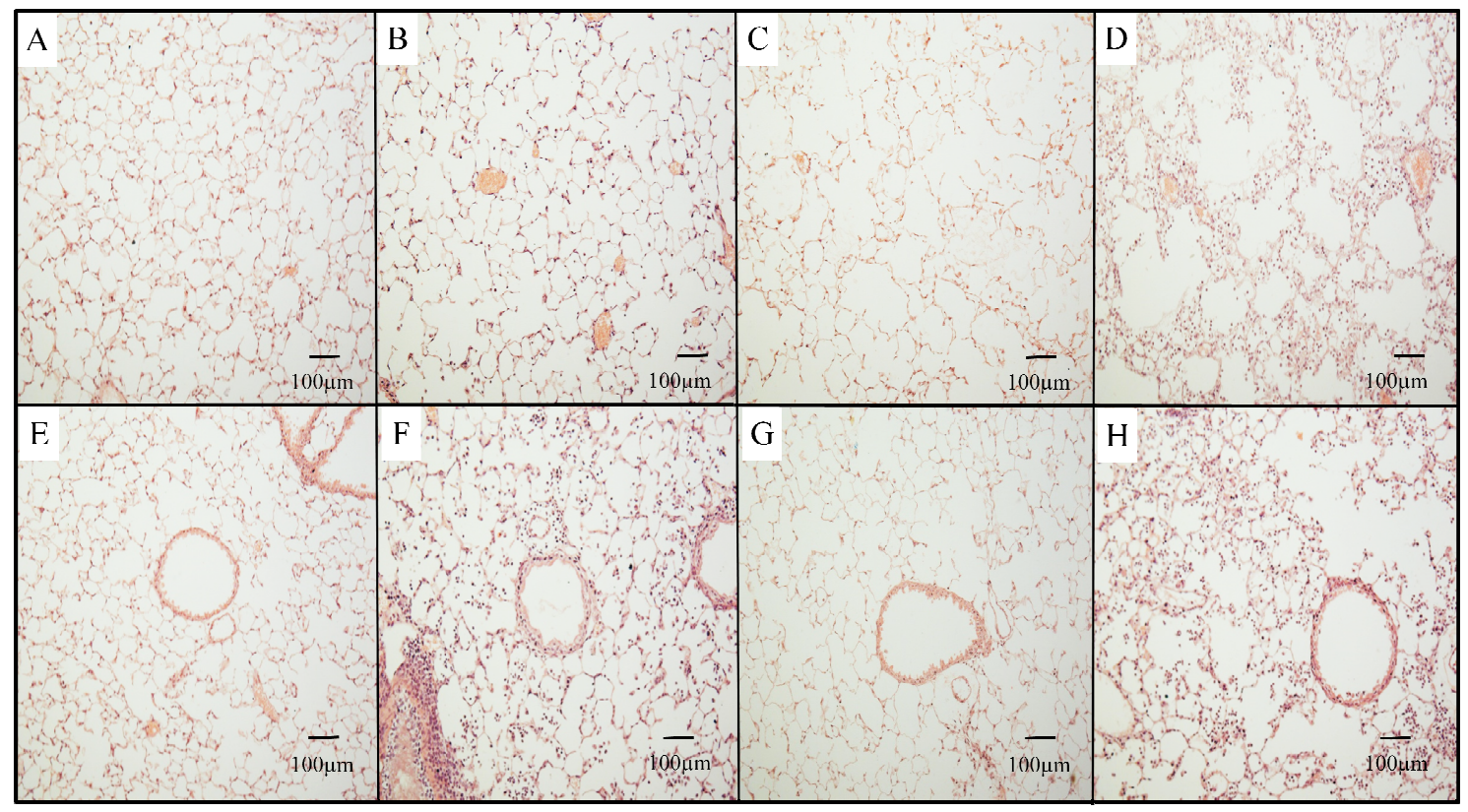

Figura 19 - Representação gráfica dos valores do Lm e fotomicrografias. Lm subpleural: * comparado com CSAL e CLPS ( $\mathrm{p}<0,001)$; Lm peribronquial: \# comparado com CSAL ( $\mathrm{p}=0,02)$. CSAL $\mathrm{n}=9$, CLPS $\mathrm{n}=9$, FSAL $\mathrm{n}=8$, FLPS $\mathrm{n}=5$. Os valores são a média \pm EP. (A-D) Fotomicrografias do parênquima pulmonar distal dos grupos (A) CSAL, (B) CLPS, (C) FSAL e (D) FLPS. (E-H) Fotomicrografias do parênquima pulmonar proximal dos grupos (E) CSAL, (F) CLPS, (G) FSAL e (H) FLPS. Aumento de 200x 


\subsubsection{Espessura Epitelial}

Observamos aumento na espessura epitelial apenas no grupo FLPS quando comparado ao grupo CSAL (Figura 20). Os cortes histológicos dos pulmões que caracterizam as mudanças na espessura epitelial estão representados na figura 20 A-D.
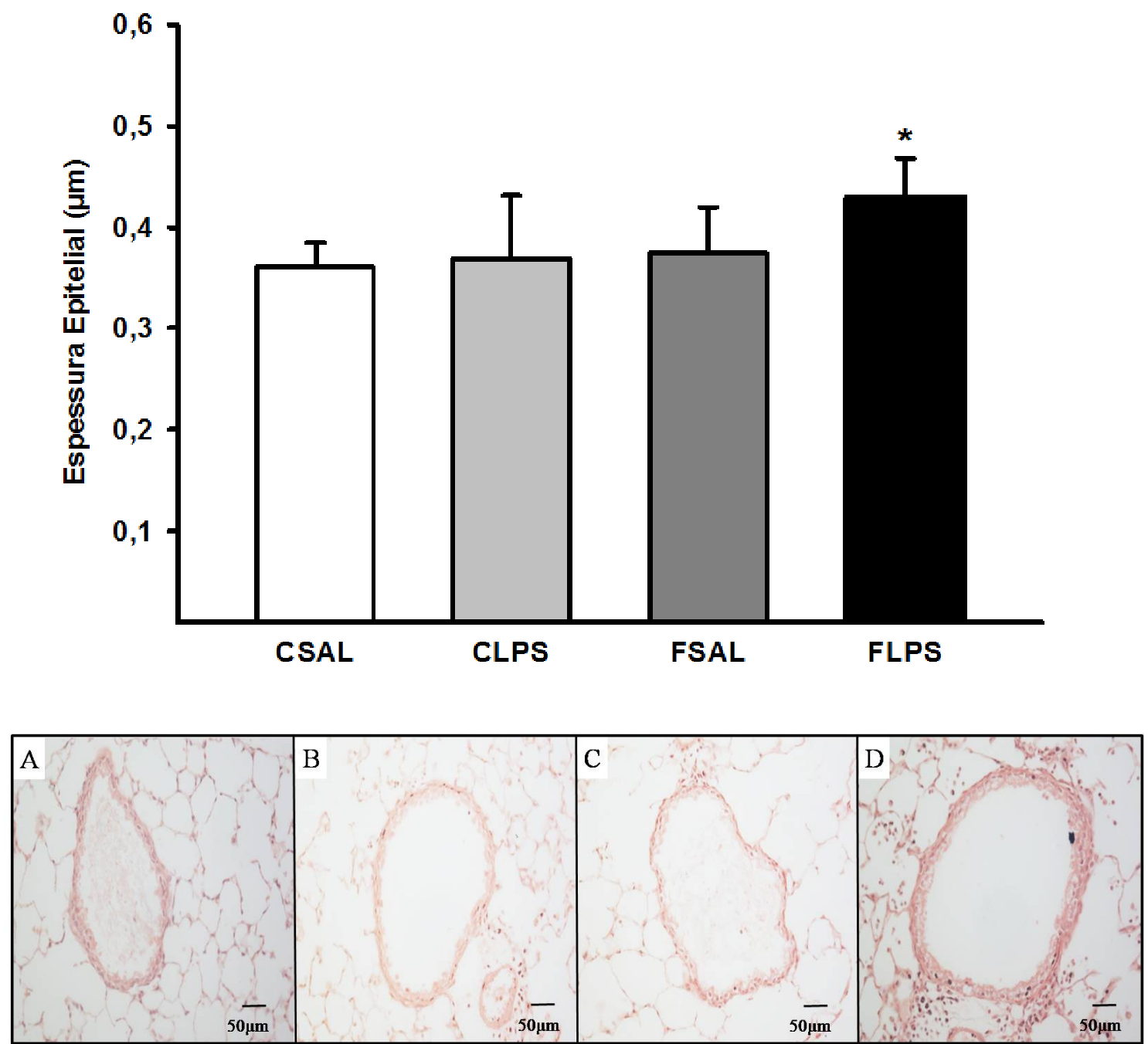

Figura 20 - Representação gráfica da espessura epitelial e fotomicrografias. * comparado com CSAL $(\mathrm{p}=0,02)$. CSAL $\mathrm{n}=9$, CLPS $\mathrm{n}=9$, FSAL $\mathrm{n}=8$, FLPS $\mathrm{n}=5$. Os valores são a média $\pm E P$. (A-D) Fotomicrografias das vias aéreas dos grupos (A) CSAL, (B) CLPS, (C) FSAL e (D) FLPS. Aumento de 400x 


\subsection{Imuno-histoquímica}

A contagem de células positivas no parênquima pulmonar demonstrou para a marcação de MAC-2 e neutrófilo aumento nos grupos CLPS, FSAL e FLPS quando comparados ao grupo CSAL. Também observamos aumento nos grupos CLPS e FLPS quando comparado ao grupo FSAL e ainda verificamos aumento no grupo FLPS quando comparado ao grupo CLPS (Figura 21 e 22 respectivamente). As fotomicrografias estão representadas na figura 21 e 22 A-D. 

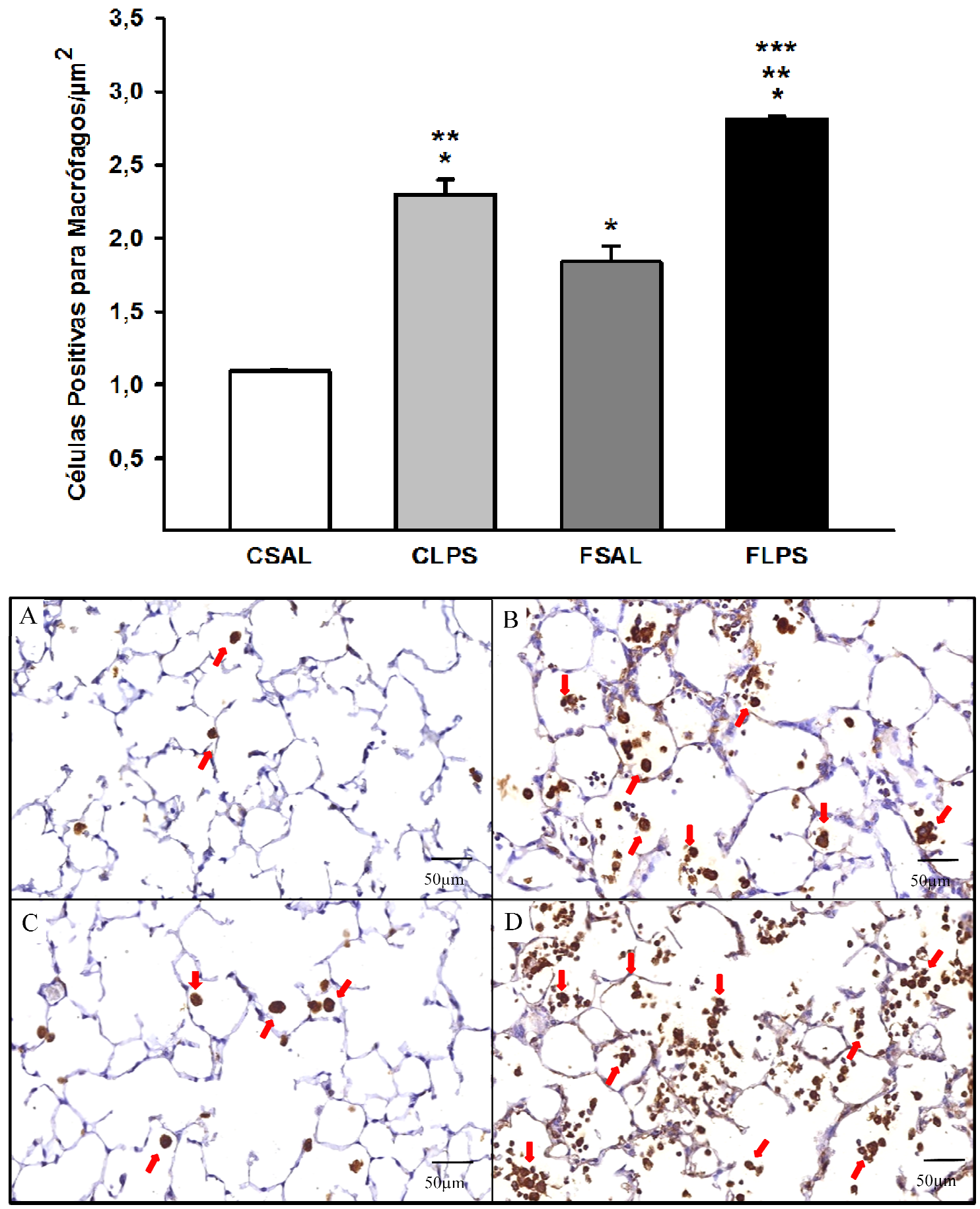

Figura 21 - Representação gráfica do número de células positivas para macrófagos e marcação específica por imuno-histoquímica. * comparado com CSAL $(\mathrm{p}<0,001)$, ** comparado com FSAL $(\mathrm{p}<0,001)$, *** comparado com CLPS ( $p<0,001)$; CSAL n=9, CLPS $n=9$, FSAL $n=8$, FLPS $n=5$. Os valores são a média \pm EP. (A-D) Fotomicrografias de células positivas para macrófagos no parênquima pulmonar dos grupos (A) CSAL, (B) CLPS, (C) FSAL e (D) FLPS. Aumento de 400x. As setas em vermelho sinalizam algumas células marcadas para macrófagos 

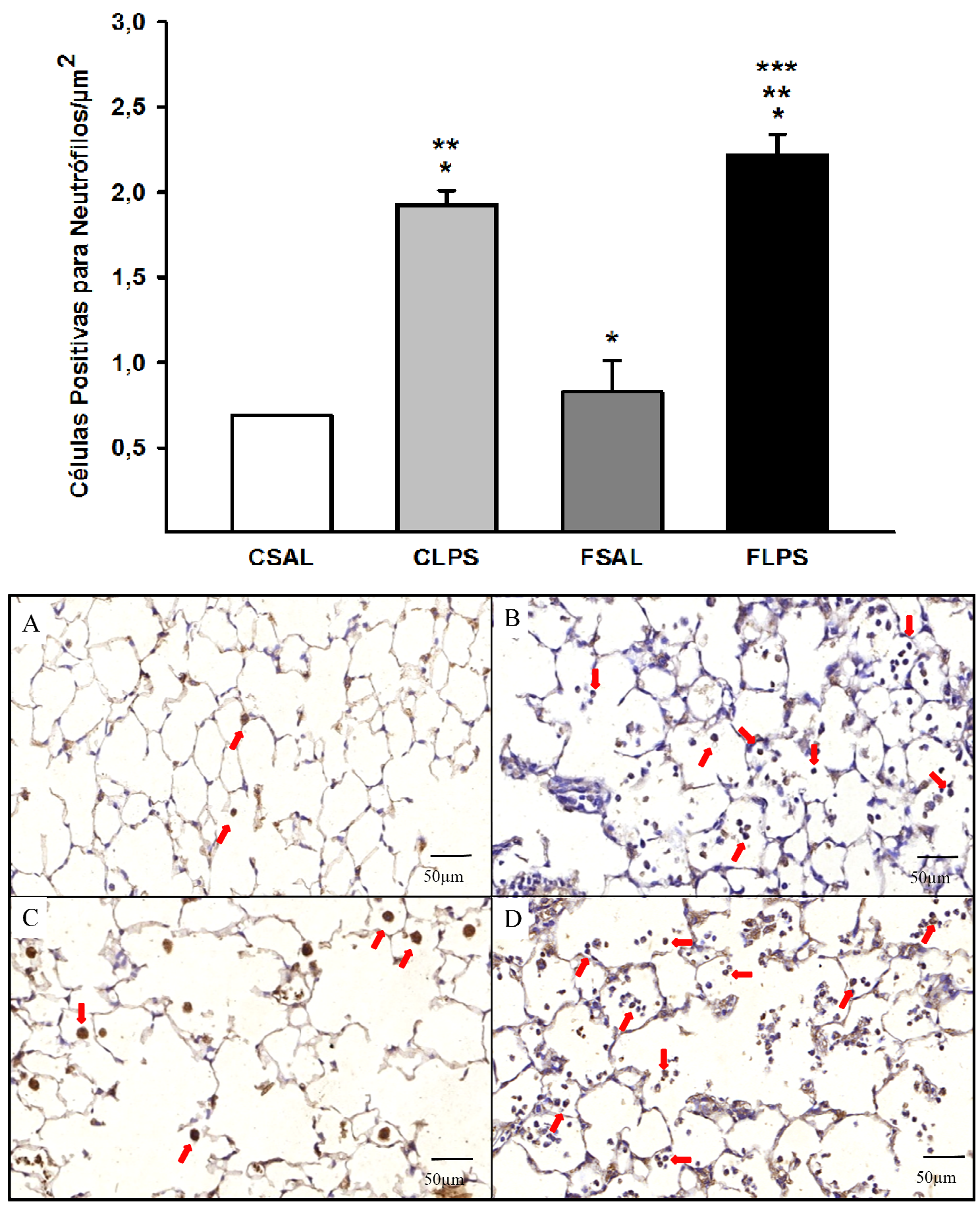

Figura 22 - Representação gráfica do número de células positivas para neutrófilos e marcação específica por imuno-histoquímica. * comparado com CSAL (p<0,001), ** comparado com FSAL ( $<<0,001)$, *** comparado com CLPS ( $\mathrm{p}<0,001$ ); CSAL n=9, CLPS $n=9$, FSAL n=8, FLPS $n=5$. Os valores são a média \pm EP. (A-D) Fotomicrografias de células positivas para neutrófilos no parênquima pulmonar dos grupos (A) CSAL, (B) CLPS, (C) FSAL e (D) FLPS. Aumento de 400x. As setas em vermelho sinalizam algumas células marcadas para neutrófilos 
Para marcação de $\mathrm{CD}^{+}$, observamos aumento nos grupos CLPS, FSAL e FLPS quando comparado ao grupo CSAL e verificamos aumento no grupo FLPS quando comparado aos grupos CLPS e FSAL (Figura 23). Na figura 23 A-D estão representadas as fotomicrografias das marcações específicas no parênquima pulmonar para $\mathrm{CD} 4^{+}$. 

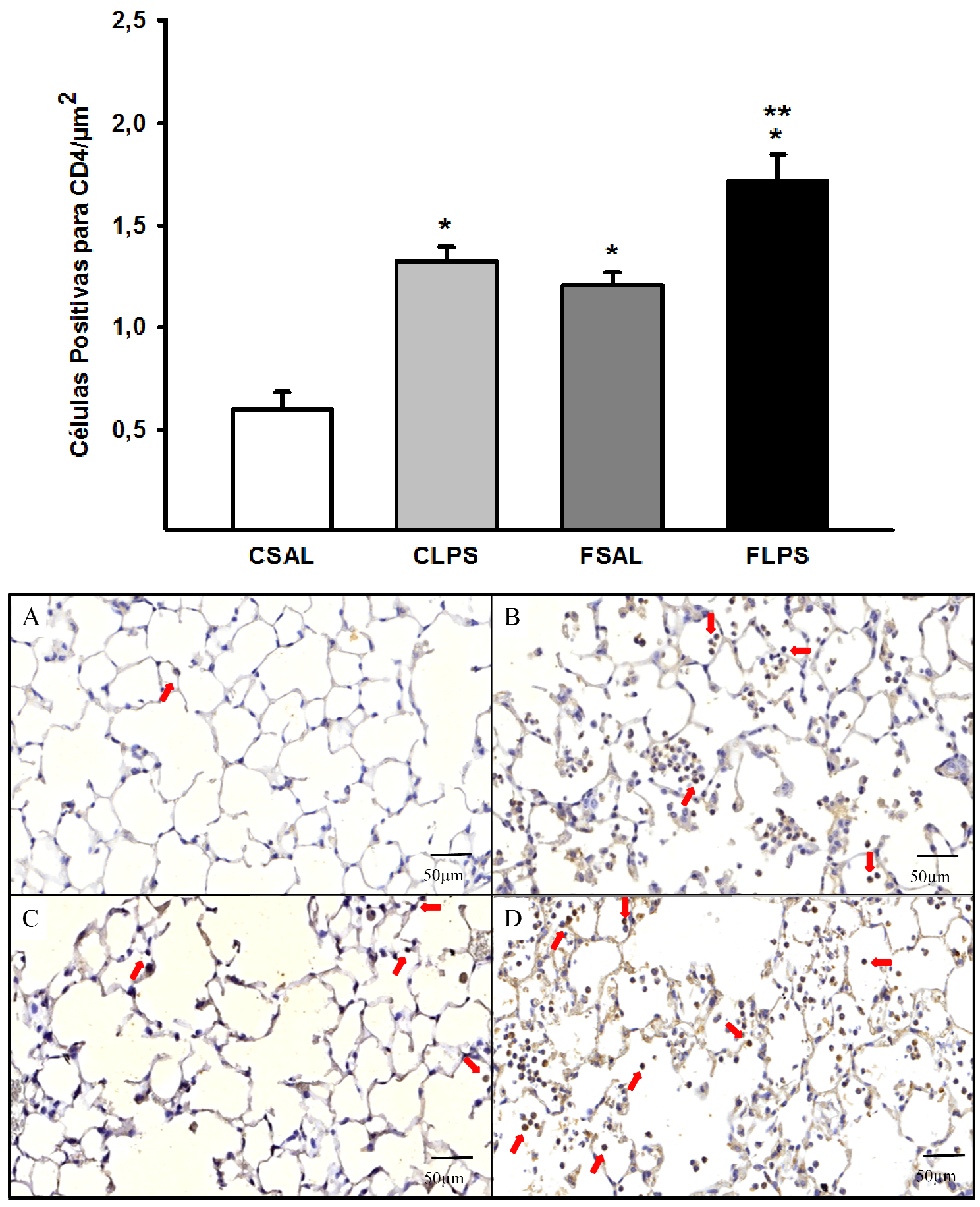

Figura 23 - Representação gráfica do número de células positivas para CD4 e marcação específica por imuno-histoquímica. * comparado com CSAL ( $<<0,001)$, ** comparado com CLPS e FSAL $(\mathrm{p}<0,001)$; CSAL n=9, CLPS n=9, FSAL n=8, FLPS n=5. Os valores são a média \pm EP. (A-D) Fotomicrografias de células positivas para $\mathrm{CD}^{+}$no parênquima pulmonar dos grupos (A) CSAL, (B) CLPS, (C) FSAL e (D) FLPS. Aumento de 400x. As setas em vermelho sinalizam algumas células marcadas para CD4 ${ }^{+}$ 
Em relação a contagem de células positivas para CD8, foi observado aumento nos grupos CLPS, FSAL e FLPS quando comparados ao grupo CSAL (Figura 24). As fotomicrografias estão representadas na figura 24 A-D.
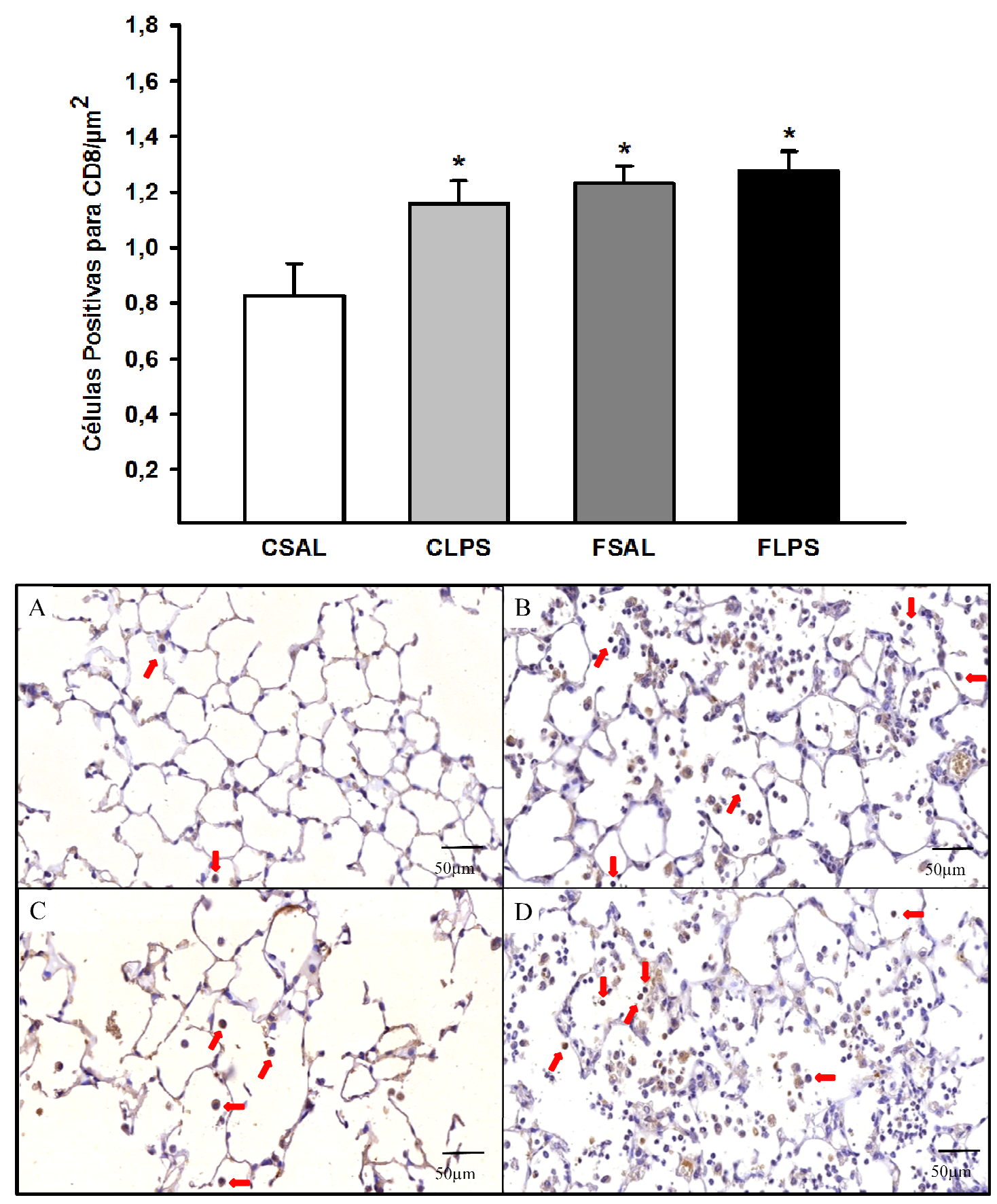

Figura 24 - Representação gráfica do número de células positivas para CD8 e marcação específica por imuno-histoquímica. * comparado com CSAL ( $p=0,006$ ); CSAL $n=9$, CLPS $n=9$, FSAL $n=8$, FLPS $n=5$. Os valores são a média \pm EP. (A-D) Fotomicrografias de células positivas para $\mathrm{CD} 8^{+}$no parênquima pulmonar dos grupos (A) CSAL, (B) CLPS, (C) FSAL e (D) FLPS. Aumento de 400x. As setas em vermelho sinalizam algumas células marcadas para $\mathrm{CD} 8^{+}$ 
A marcação de células positivas para Foxp3, demonstrou aumento nos grupos CLPS e FLPS quando comparados ao grupo CSAL (Figura 25). Na figura 25 A-D estão as fotomicrografias das células positivas para Foxp3.
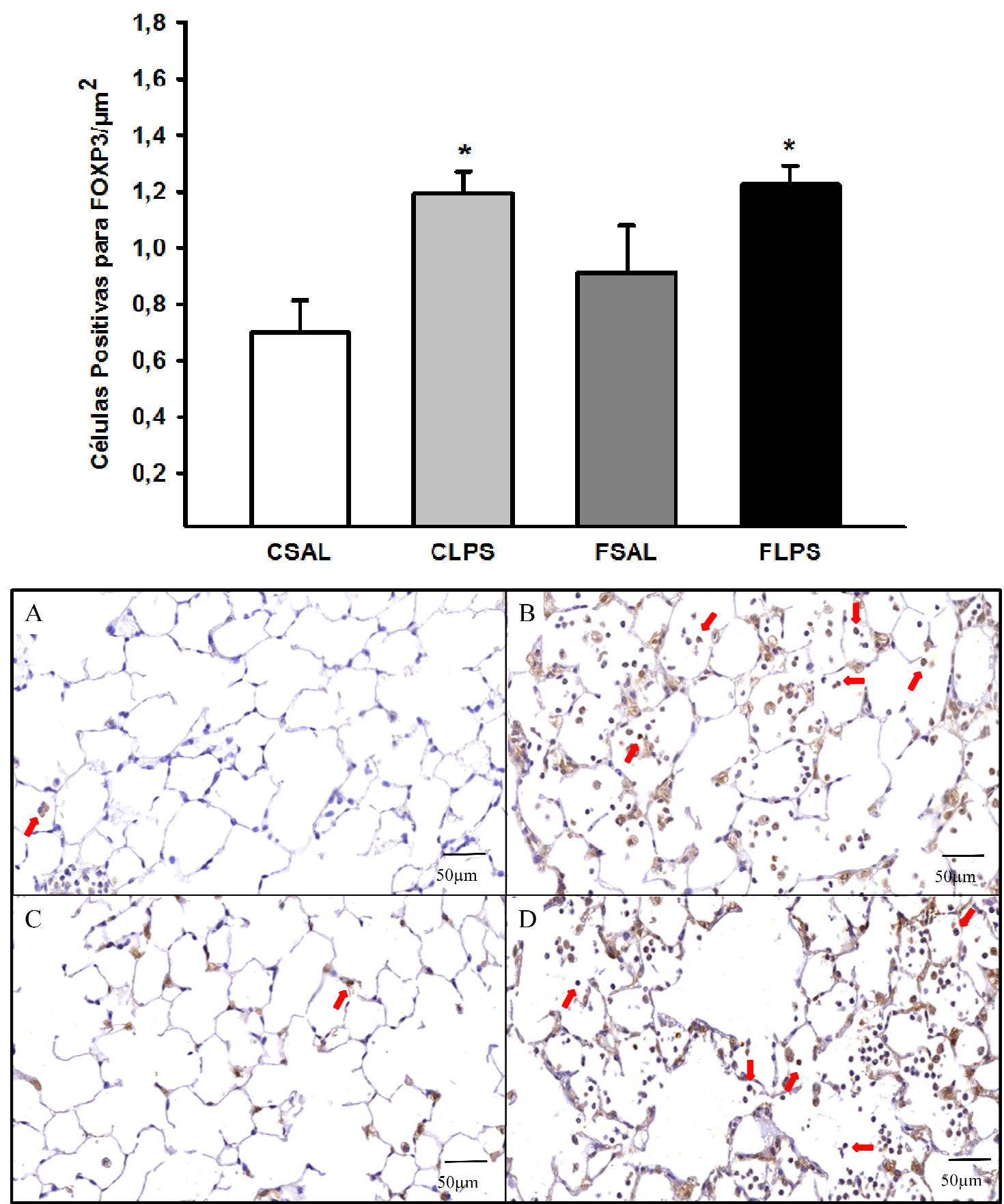

Figura 25 - Representação gráfica do número de células positivas para Foxp3 e marcação específica por imuno-histoquímica. * comparado com CSAL ( $\mathrm{p}=0,008$ ); CSAL $\mathrm{n}=9$, CLPS $\mathrm{n}=9$, FSAL $\mathrm{n}=8$, FLPS $\mathrm{n}=5$. Os valores são a média \pm EP. (A-D) Fotomicrografias de células positivas para Foxp3 no parênquima pulmonar dos grupos (A) CSAL, (B) CLPS, (C) FSAL e (D) FLPS. Aumento de 400x. As setas em vermelho sinalizam algumas células marcadas para Foxp3 
Nos resultados referentes a quantificação de Stat3 observamos aumento nos grupos CLPS, FSAL e FLPS quando comparados ao grupo CSAL. Também observamos aumento nos grupos CLPS e FLPS quando comparado ao grupo FSAL e ainda verificamos a intensificação no grupo FLPS quando comparado ao grupo CLPS (Figura 26). As fotomicrografias estão representadas na figura 26 A-D. 

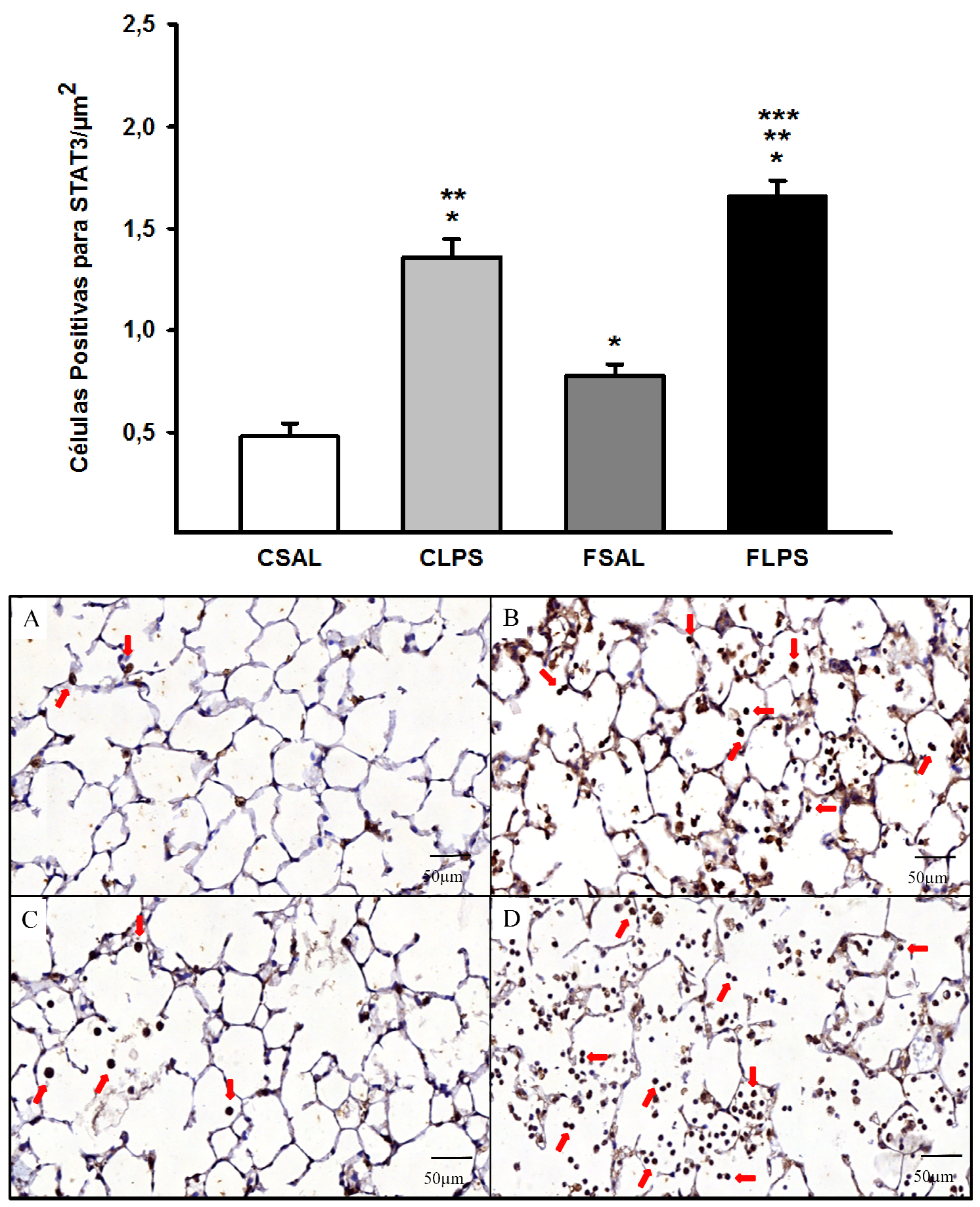

Figura 26 - Representação gráfica do número de células positivas para Stat3 e marcação específica por imuno-histoquímica. * comparado com CSAL $(\mathrm{p}<0,001)$, ** comparado com FSAL $(\mathrm{p}<0,001)$, *** comparado com CLPS ( $\mathrm{p}<0,001$ ); CSAL $\mathrm{n}=7$, CLPS $\mathrm{n}=9$, FSAL $\mathrm{n}=6$, FLPS $\mathrm{n}=5$. Os valores são a média \pm EP. (A-D) Fotomicrografias de células positivas para Stat3 no parênquima pulmonar dos grupos (A) CSAL, (B) CLPS, (C) FSAL e (D) FLPS. Aumento de 400x. As setas em vermelho sinalizam algumas células marcadas para Stat3 
Para marcação de FosfoStat3 foi demonstrado aumento nos animais desafiados com LPS (CLPS e FLPS) quando comparado com o grupo CSAL (Figura 27). Na figura 27 A-D estão representadas as fotomicrografias.
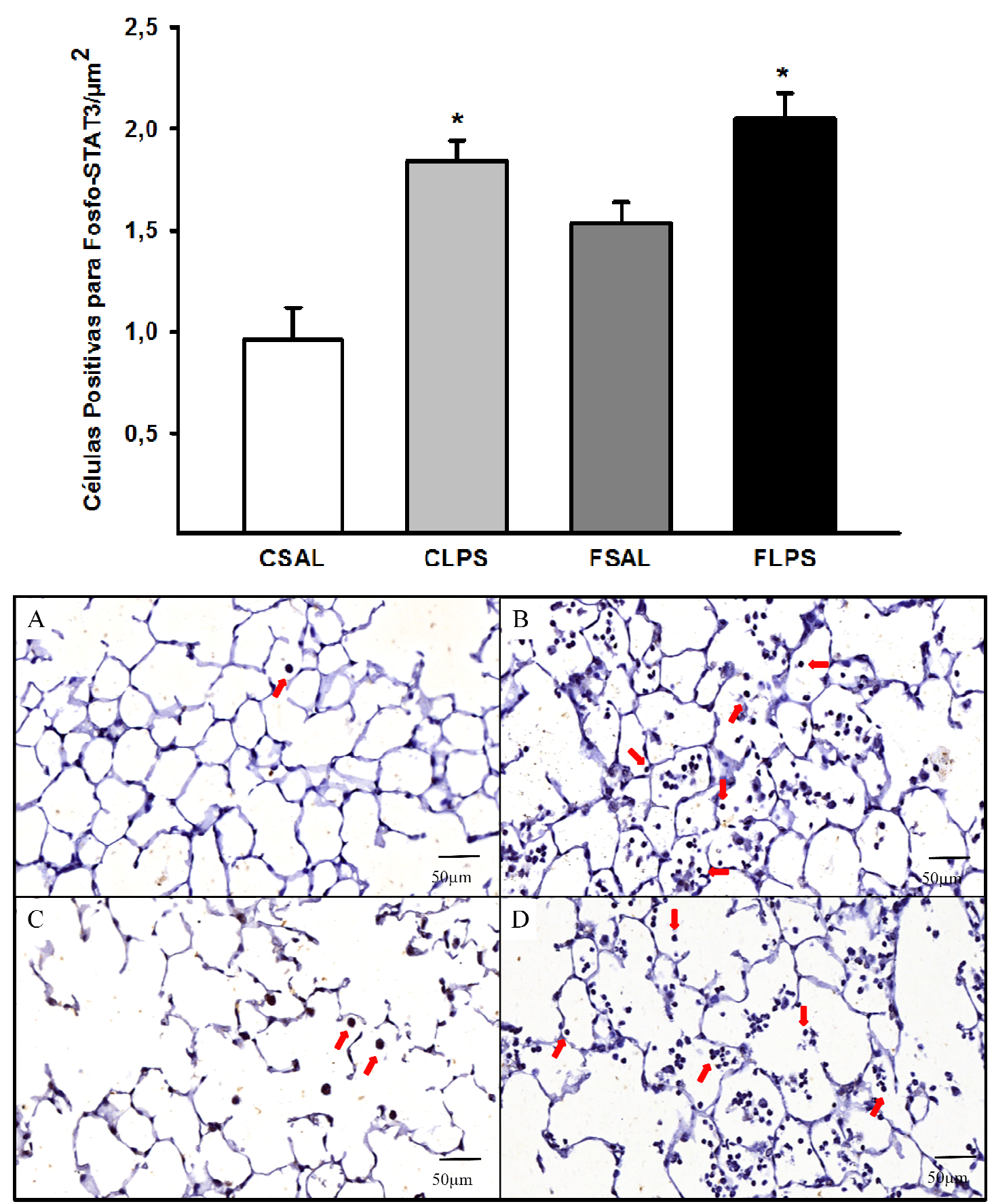

Figura 27 - Representação gráfica do número de células positivas para FosfoStat3 e marcação específica por imuno-histoquímica. * comparado com CSAL ( $\mathrm{p}<0,001$ ), CSAL $\mathrm{n}=8$, CLPS $\mathrm{n}=8$, FSAL $\mathrm{n}=8$, FLPS $\mathrm{n}=4$. Os valores são a média \pm EP. (A-D) Fotomicrografias de células positivas para FosfoStat3 no parênquima pulmonar dos grupos (A) CSAL, (B) CLPS, (C) FSAL e (D) FLPS. Aumento de 400x. As setas em vermelho sinalizam algumas células marcadas para FosfoStat3 
Os resultados referentes a quantificação de Stat5, observamos aumento no grupo CLPS quando comparado aos grupos CSAL e FSAL (Figura 28). As fotomicrografias estão representadas na figura 28 A-D.
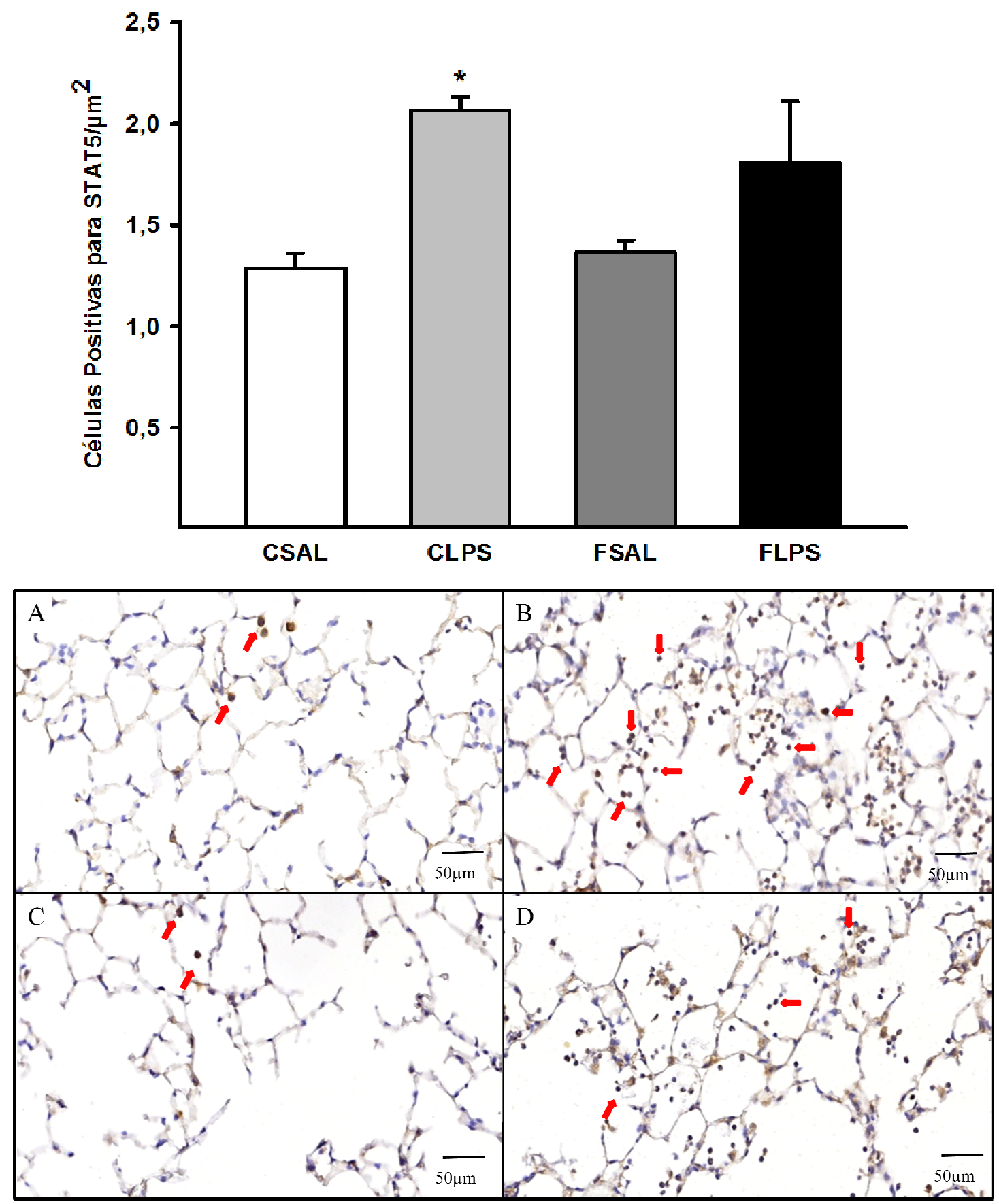

Figura 28 - Representação gráfica do número de células positivas para Stat5 e marcação específica por imuno-histoquímica. * comparado com CSAL e FSAL ( $p<0,001$ ), CSAL n=9, CLPS $n=9$, FSAL $n=8$, FLPS $n=5$. Os valores são a média \pm EP. (A-D) Fotomicrografias de células positivas para Stat5 no parênquima pulmonar dos grupos (A) CSAL, (B) CLPS, (C) FSAL e (D) FLPS. Aumento de 400x. As setas em vermelho sinalizam algumas células marcadas para Stat5 
Para marcação de FosfoStat5 foi demonstrado aumento nos animais desafiados com LPS (CLPS e FLPS) quando comparado com aos grupos CSAL e FSAL. Também observamos um aumento ainda maior no grupo FLPS quando comparado ao grupo CLPS (Figura 29). Na figura 29 A-D estão representadas as fotomicrografias. 

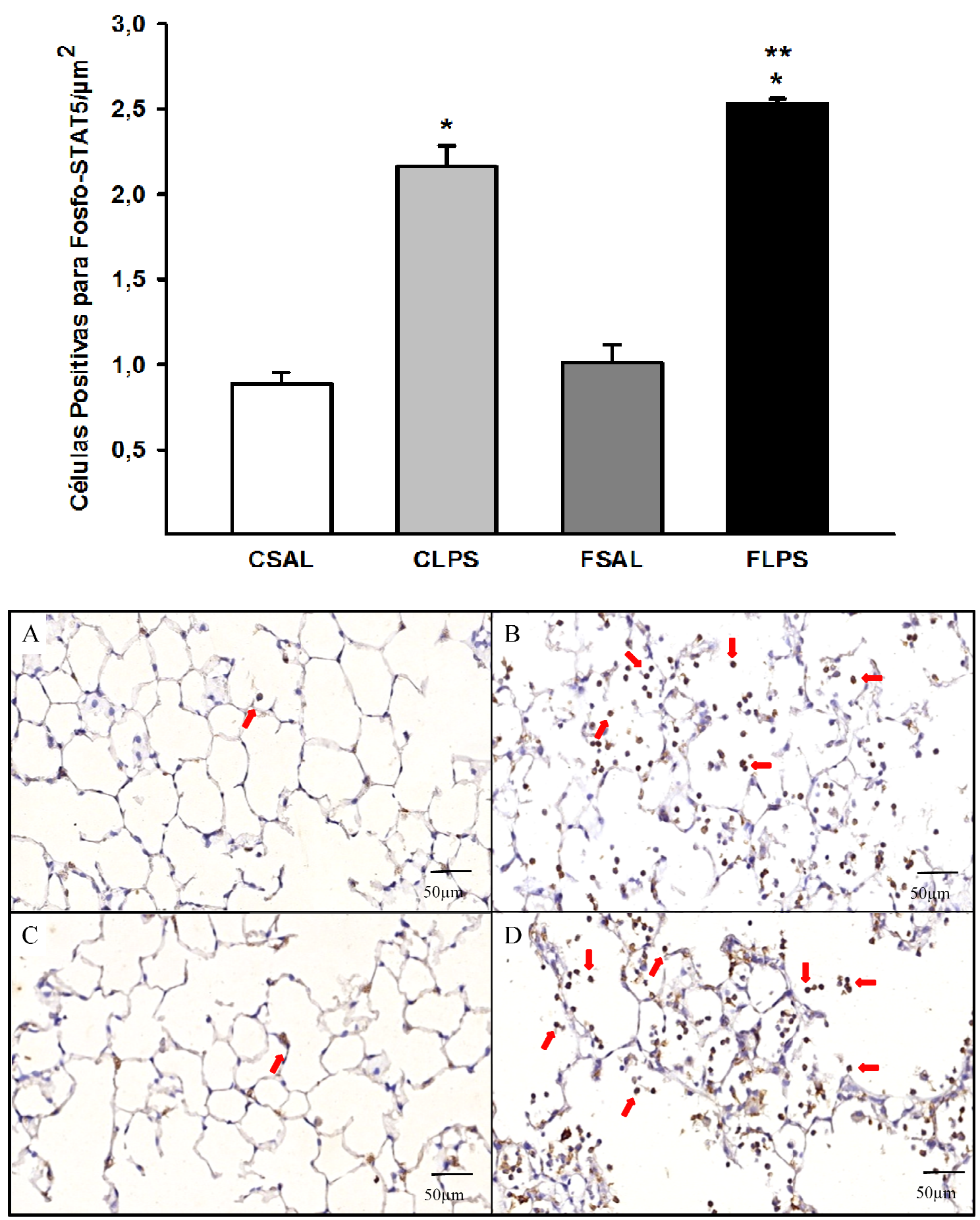

Figura 29 - Representação gráfica do número de células positivas para FosfoStat5 e marcação específica por imuno-histoquímica. * comparado com CSAL e FSAL $(\mathrm{p}<0,001)$, ** comparado com CLPS $(\mathrm{p}<0,001)$. CSAL $n=9$, CLPS $n=9$, FSAL $n=8$, FLPS $n=5$. Os valores são a média \pm EP. (A-D) Fotomicrografias de células positivas para FosfoStat5 no parênquima pulmonar dos grupos (A) CSAL, (B) CLPS, (C) FSAL e (D) FLPS. Aumento de 400x. As setas em vermelho sinalizam algumas células marcadas para FosfoStat5 


\subsection{Análise das citocinas}

A análise das citocinas no homogenato pulmonar para IL-6 e IL-17 revelou aumento nos grupos CLPS e FLPS quando comparado ao grupo CSAL (Figura 30 e 31, respectivamente). Para a IL-10 verificamos aumento somente no grupo CLPS comparado com os grupos CSAL e FSAL (Figura 32). Em relação a quantificação de IFN- $\gamma$ não observamos diferenças nos grupos experimentais (Figura 33). A quimiocina CXCL1 aumentou nos grupos CLPS, FSAL e FLPS, quando comparado ao grupo CSAL, também observamos aumento nos grupos CLPS e FLPS quando comparado ao grupo FSAL (Figura 34). Para CXCL2 observamos aumento nos grupos CLPS e FLPS quando comparado aos grupos CSAL e FSAL, e também verificamos um aumento ainda maior no grupo FLPS quando comparado ao grupo CLPS (Figura 35).

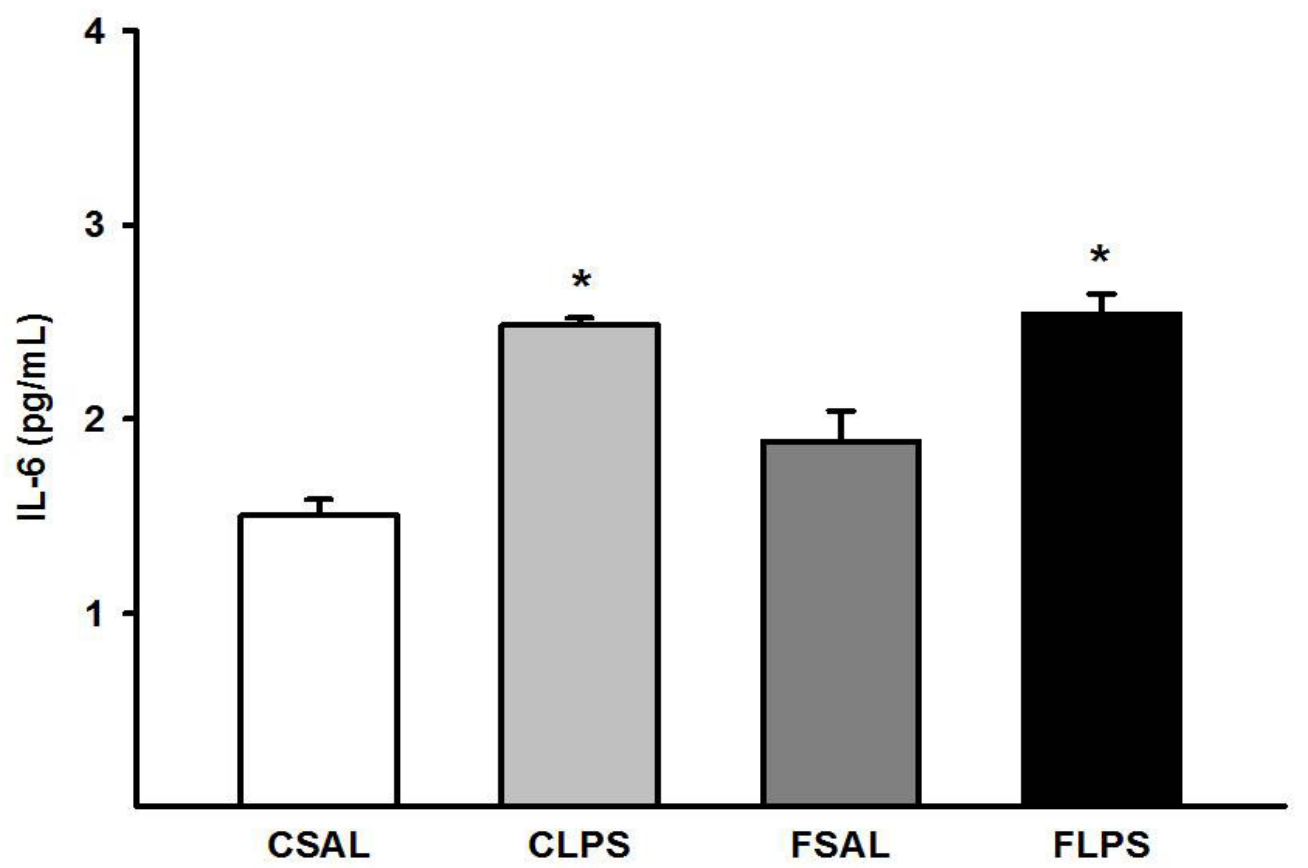

Figura 30 - Quantificação da IL-6 no homogenato pulmonar. * comparado com CSAL (p<0,001). CSAL $\mathrm{n}=10$, CLPS $\mathrm{n}=6$, FSAL $\mathrm{n}=8$, FLPS $\mathrm{n}=7$. Os valores são a média $\pm \mathrm{EP}$ 


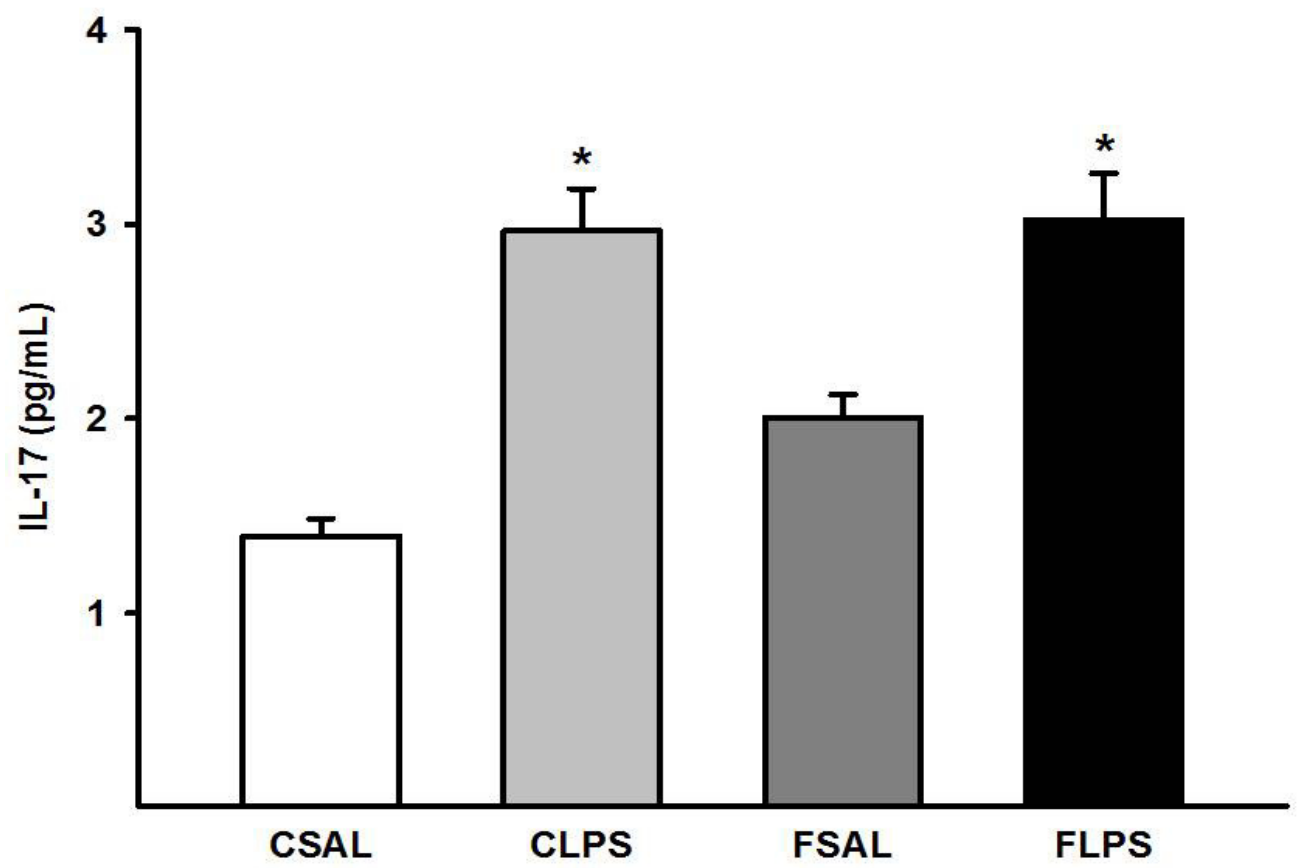

Figura 31 - Quantificação da IL-17 no homogenato pulmonar. * comparado com CSAL (p<0,001). CSAL n=10, CLPS n=6, FSAL n=8, FLPS n=7. Os valores são a média $\pm E P$

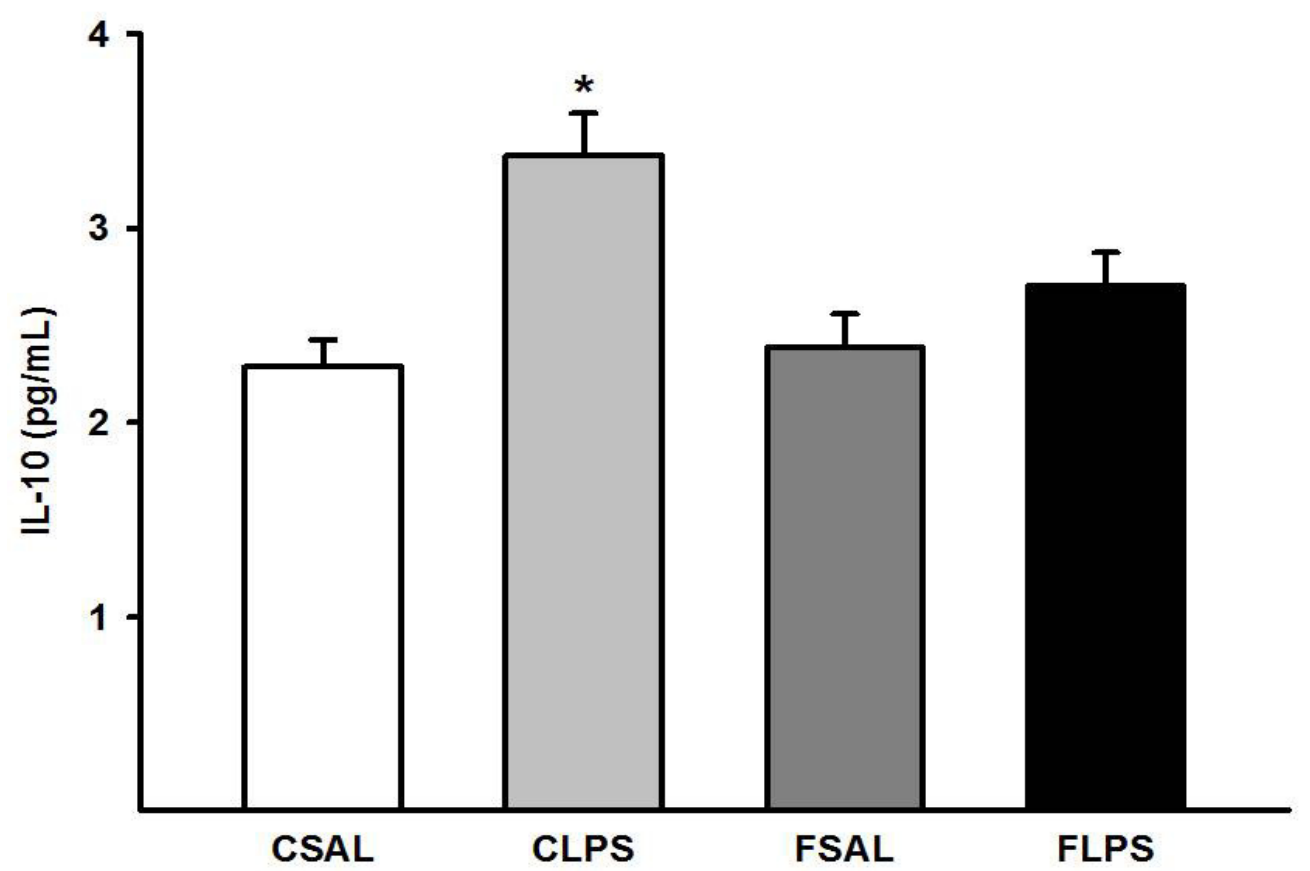

Figura 32 - Quantificação da IL-10 no homogenato pulmonar. * comparado com CSAL e FSAL $(\mathrm{p}<0,001)$. CSAL $n=10$, CLPS $n=6$, FSAL n=8, FLPS $n=7$. Os valores são a média \pm EP 


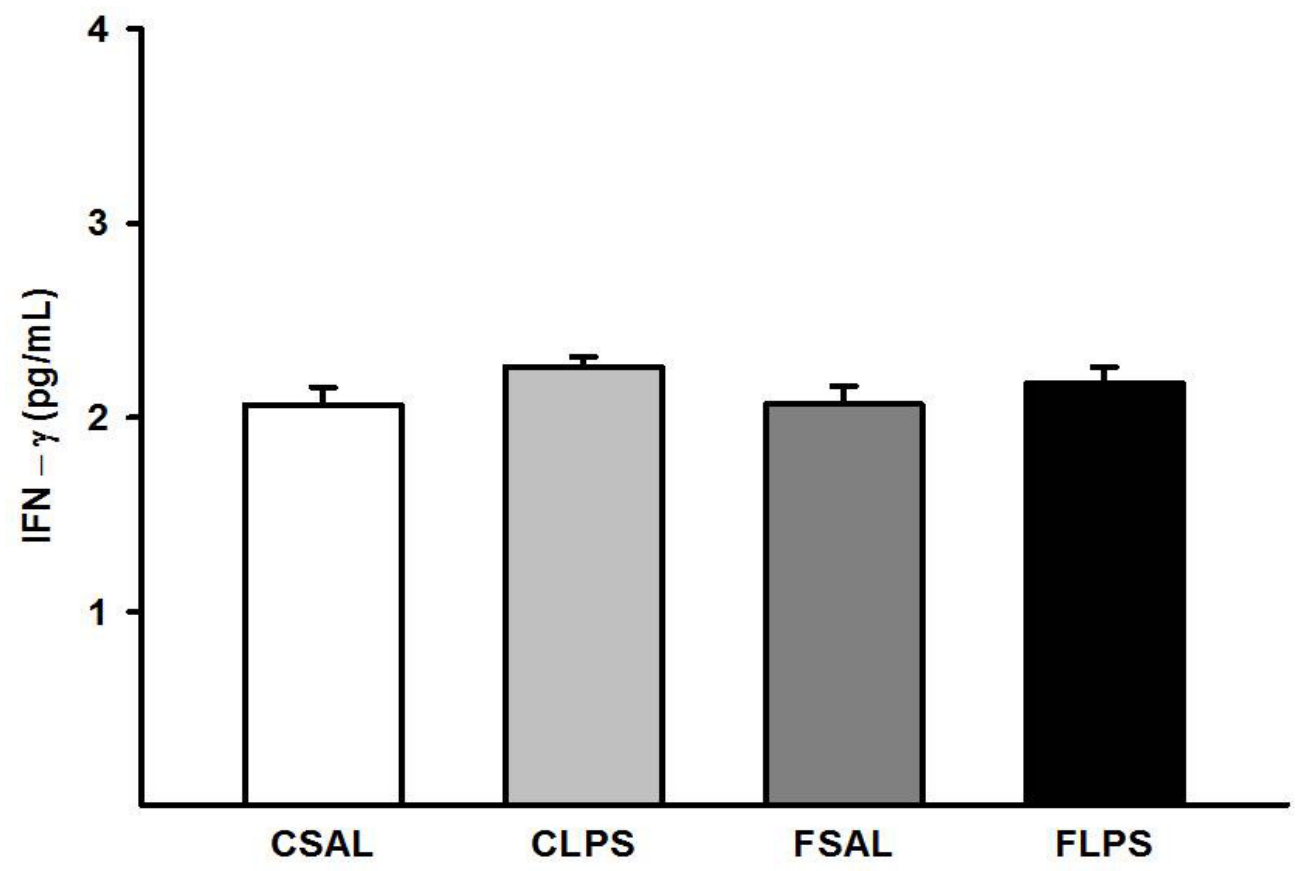

Figura 33 - Quantificação de IFN- $\gamma$ no homogenato pulmonar. Não houve diferença entre os grupos experimentais. CSAL $n=10$, CLPS $n=6$, FSAL n=8, FLPS $n=7$. Os valores são a média \pm EP.

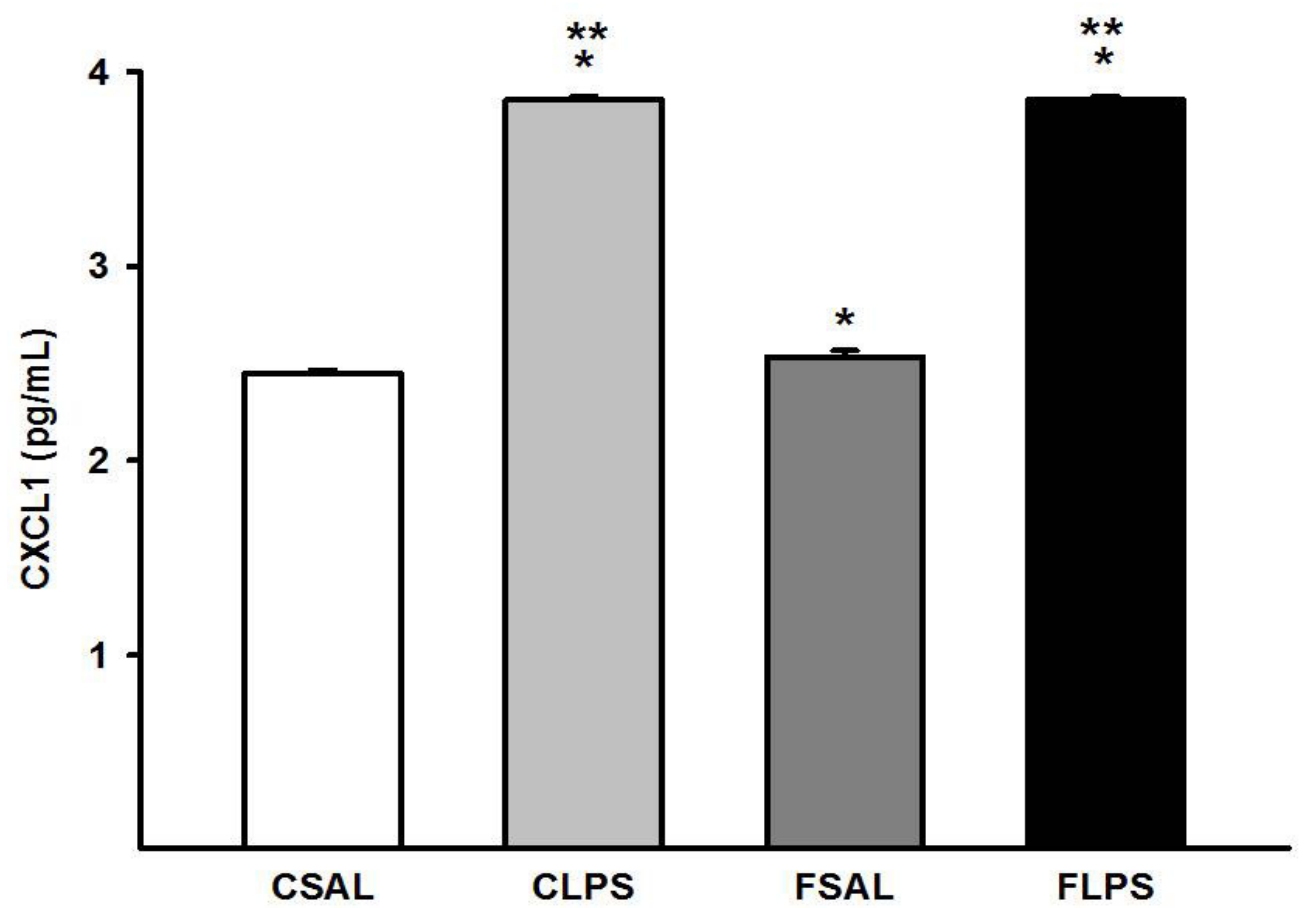

Figura 34 - Quantificação da CXCL1 no homogenato pulmonar. * comparado com CSAL (p<0,001), ** comparado com FSAL. CSAL n=10, CLPS n=6, FSAL n=8, FLPS n=7. Os valores são a média \pm EP. 


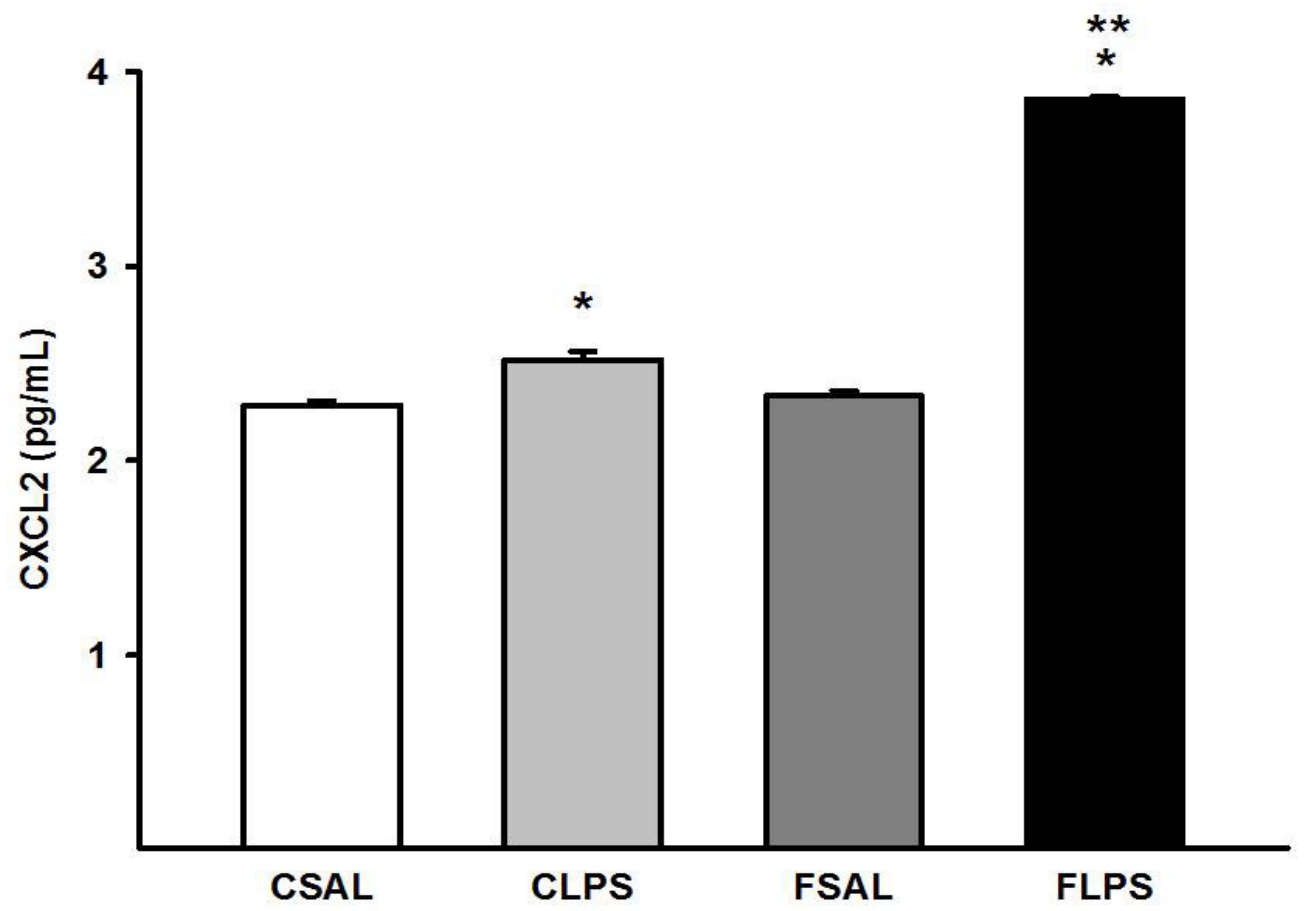

Figura 35 - Quantificação da CXCL2 no homogenato pulmonar. * comparado com CSAL e FSAL $(\mathrm{p}<0,001)$, ** comparado com CLPS. CSAL $\mathrm{n}=10$, CLPS $\mathrm{n}=6$, FSAL $\mathrm{n}=8$, FLPS $\mathrm{n}=7$. Os valores são a média $\pm \mathrm{EP}$

\subsection{Dupla marcação}

A reação imuno-histoquímica de dupla marcação ilustrando as células positivas para Foxp3/IL-10 estão ilustradas abaixo. O resultado ilustra que a marcação em vermelho são as células positivas para IL-10, a marcação em castanho são as células positivas para Foxp3 e ainda as células duplamente marcadas (Foxp3/IL-10) são demonstradas em tom alaranjado (Figura 36). 


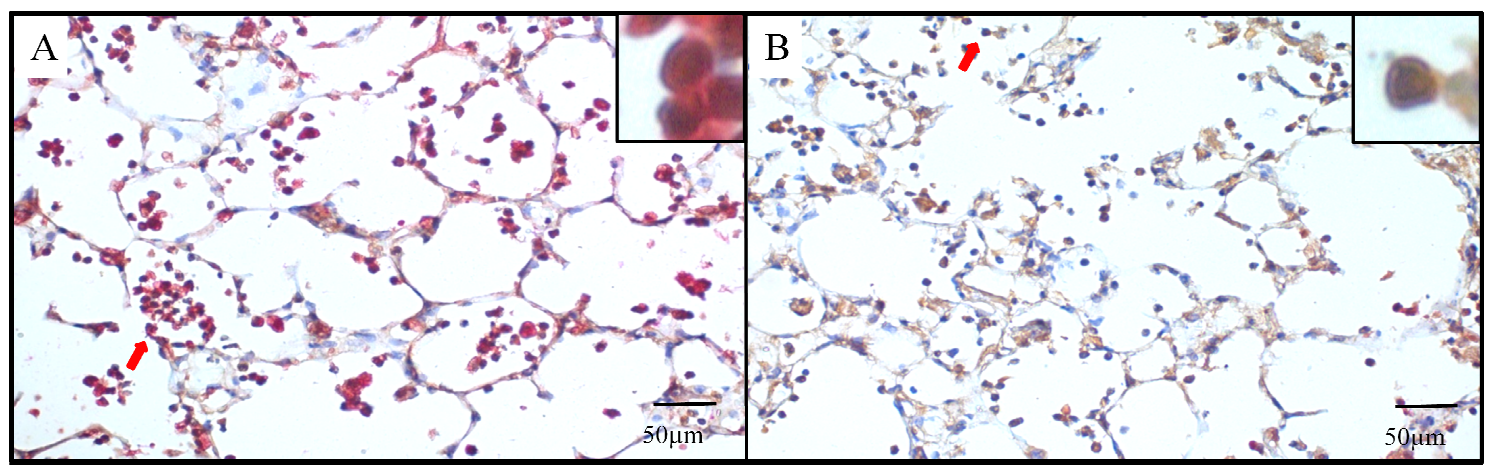

Figura 36 - Dupla marcação para Foxp3/IL-10. (A) Grupo CLPS e (B) Grupo FLPS. Aumento de 400x e $1000 \mathrm{x}$

\subsection{Resumo dos Resultados}

A figura 37 ilustra de maneira geral os resultados encontrados neste estudo.

\begin{tabular}{|c|c|c|c|c|c|}
\hline \multirow{2}{*}{ Análises } & \multirow{2}{*}{ Especificações } & \multicolumn{4}{|c|}{ GRUPOS EXPERIMENTAIS } \\
\hline & & CSAL & CLPS & FSAL & FLPS \\
\hline \multirow[t]{3}{*}{ Mecânica do Sistema Respiratório } & Gtis & - & - & - & $\boldsymbol{1}$ \\
\hline & Htis & - & - & - & - \\
\hline & Raw & - & - & - & - \\
\hline \multirow[t]{3}{*}{ Morfometria } & Lm - Subpleural & - & - & $\boldsymbol{\top}$ & $\boldsymbol{\top}$ \\
\hline & Lm - Peribronquial & - & - & - & $\uparrow$ \\
\hline & Espessura Epitelial & - & - & - & $\boldsymbol{1}$ \\
\hline \multirow[t]{4}{*}{ Perfil Inflamatório - LBA } & Células Totais & - & $\boldsymbol{\top}$ & - & $\boldsymbol{\top}$ \\
\hline & Macrófagos & - & $\mathbf{1}$ & - & - \\
\hline & Neutrófilos & - & - & - & - \\
\hline & Linfócitos & - & 个 & - & $\boldsymbol{1}$ \\
\hline \multirow[t]{9}{*}{ Imuno - histoquímica } & Macrófagos & - & $\uparrow \uparrow$ & $\boldsymbol{1}$ & 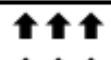 \\
\hline & Neutrófilos & - & $\uparrow \uparrow$ & 个 & $\uparrow \uparrow \uparrow$ \\
\hline & CD4+ & - & - & $\boldsymbol{1}$ & $\uparrow$ \\
\hline & CD8+ & - & $\boldsymbol{\top}$ & $\boldsymbol{\top}$ & $\uparrow$ \\
\hline & Foxp3 & - & $\boldsymbol{1}$ & - & - \\
\hline & Stat3 & - & $\uparrow \uparrow$ & $\boldsymbol{\uparrow}$ & 1 1 เ \\
\hline & FosfoStat3 & - & $\boldsymbol{1}$ & - & $\uparrow$ \\
\hline & Stat5 & - & $\boldsymbol{1}$ & - & - \\
\hline & FosfoStat5 & - & $\mathbf{1}$ & - & 1 1 \\
\hline \multirow[t]{6}{*}{ Citocinas e Quimiocinas } & IL-17 & - & $\boldsymbol{\top}$ & - & 个 \\
\hline & $\mathrm{IL}-6$ & - & -1 & - & - \\
\hline & IL-10 & - & $\boldsymbol{1}$ & - & - \\
\hline & IFN-Y & - & - & - & - \\
\hline & CXCL-1 & - & 11 & - & 1 เ \\
\hline & CXCL-2 & - & - & - & 1 1 \\
\hline
\end{tabular}

Figura 37 - Figura ilustrativa com o resumo dos resultados 


\section{DISCUSSÃO}

A exposição à fumaça de cigarro associada ao desafio com LPS induziu o aumento do processo inflamatório mediado pela imunidade inata e adaptativa semelhante ao observado em pacientes com exacerbação da $\operatorname{DPOC}^{114,132,133}$. Além disso, acarretou o aumento da espessura do epitélio respiratório e alargamento alveolar distribuído de forma difusa em espaços aéreos peribrônquicos e subpleurais, refletindo uma alteração importante da histoarquitetura do parênquima pulmonar.

Caracterização do modelo experimental de exposição à fumaça de cigarro e instilação de LPS: alterações da histoarquitetura e função Pulmonar

Existem três principais abordagens experimentais que mimetizam os aspectos fisiopatológicos da DPOC, são elas: a inalação de gases nocivos, como por exemplo a exposição à fumaça de cigarro, instilação traqueal ou intranasal de proteases e modificação genética ${ }^{134}$.

A lesão pulmonar promovida pela instilação de proteases (elastase) é maior do que a lesão causada pela exposição à fumaça de cigarro ${ }^{135}$, porém o uso das proteases não reproduz os mecanismos fisiopatológicos da exposição à fumaça do cigarro, que é o principal fator de risco da DPOC em humanos ${ }^{136}$, o que justifica o uso deste tipo de exposição no nosso modelo experimental.

Os nossos resultados mostraram que os animais que foram expostos à fumaça de cigarro tiveram um aumento do Lm, caracterizando a presença do enfisema pulmonar. Além disso, a associação da fumaça de cigarro e o desafio com o LPS promoveu alterações morfológicas tanto nos espaços aéreos subpleurais quanto nos espaços aéreos 
peribrônquicos e aumento da espessura epitelial. Nossos achados corroboram com estudos prévios em modelos experimentais, os quais demonstraram que a exposição à fumaça de cigarro e a associação com a instilação de LPS induziu aumento dos espaços aéreos $^{137}$, que são características observadas em pacientes com a $\mathrm{DPOC}^{49}$.

Com relação aos parâmetros funcionais, observamos aumento de Gtis e Htis no grupo FLPS, possivelmente devido ao intenso infiltrado inflamatório observado no parênquima pulmonar. De acordo com Vernooy et al. (2002) ${ }^{124}$ camundongos instilados com repetidas doses de LPS apresentam alterações nas vias aéreas e alvéolos, como metaplasia de células mucosas, espessamento da parede das vias aéreas, e alargamento alveolar irreversível acompanhado de uma resposta inflamatória crônica. Essas características podem acarretar alterações nos parâmetros funcionais da mecânica do sistema respiratório.

Embora tenhamos encontrado alterações estruturais no parênquima pulmonar dos animais que foram expostos à fumaça de cigarro as alterações funcionais somente foram encontradas nos animais expostos à fumaça de cigarro e desafiados com LPS, provavelmente devido ao intenso processo inflamatório no parênquima pulmonar resultante da associação dos dois fatores. Estudos prévios relatam que para caracterizar a presença do enfisema pulmonar a avaliação do Lm é mais sensível que as alterações funcionais devido às dificuldades técnicas encontradas para avaliação da mecânica respiratória em roedores ${ }^{138}$.

O papel da imunidade inata no modelo experimental de exposição à fumaça de cigarro e instilação de LPS 
A exposição à fumaça de cigarro induz a inflamação pulmonar através da liberação de mediadores inflamatórios que recrutam e ativam diversas células inflamatórias como macrófagos, neutrófilos e células $\mathrm{T}^{139}$.

A análise do LBA, a qual inclui tanto vias aéreas quanto parênquima pulmonar, revelou aumento de células totais, macrófagos, neutrófilos e linfócitos nos animais desafiados com LPS.

Entretanto as análises dos diferentes tipos celulares no parênquima pulmonar demonstrou aumento do processo inflamatório, caracterizado pelo aumento principalmente de macrófagos e neutrófilos nos animais expostos à fumaça de cigarro e desafiados com LPS e houve uma exacerbação desta resposta com a associação destes dois fatores.

Uma vez que as análises do LBA contemplam as regiões das vias aéreas e parênquima e neste modelo experimental a associação da exposição à fumaça de cigarro e instilação de LPS acarretou intensificação desta resposta somente pelas análises no parênquima, acreditamos que neste modelo, o principal sinal inflamatório não está em vias aéreas e sim no parênquima mais distal.

Hardaker et al. (2010) ${ }^{104}$ demonstraram em ratos expostos à fumaça de cigarro associado ao LPS, aumento do infiltrado de células inflamatórias no LBA e intenso infiltrado de neutrófilos no parênquima pulmonar. Nie et al. (2012) ${ }^{137}$ também demonstraram em ratos aumento de macrófagos em animais expostos à fumaça de cigarro e instilados com LPS.

Os macrófagos alveolares também são responsáveis pelo recrutamento de outros tipos de células para o local da inflamação, liberando quimiocinas ${ }^{140}$, como por exemplo, CXCL1 (quimiocina homóloga para IL-8) e CXCL2 ${ }^{61}$, as quais são 
quimiotáticas para neutrófilos ${ }^{62}$. O aumento da liberação de IL-8 têm sido associados à piora da obstrução em fumantes ${ }^{141-143}$.

Nossos resultados mostraram aumento na expressão das quimiocinas CXCL1 e CXCL2 no homogenato pulmonar. Enquanto a expressão de CXCL1 foi aumentada nos animais CLPS, FSAL e FLPS, os níveis de CXCL2 foram aumentados apenas nos grupos LPS, e a associação da exposição á fumaça de cigarro e o LPS exacerbou esta resposta. Dados semelhantes ao nosso foram encontrados por van der Strate et al. $(2005)^{144}$ que também encontraram aumento de CXCL1/KC no homogenato pulmonar de camundongos após 4 meses de exposição á fumaça de cigarro. Singanayagam et al. $(2015)^{145}$ desenvolveram um modelo de exacerbação da DPOC, no qual os autores utilizaram camundongos que foram previamente instilados por via intranasal com múltiplas doses de elastase (1.2 U) e LPS (70 U) e foram infectados com rinovírus serotipo 1B, durante 4 semanas consecutivas e os seus resultados mostraram aumento da quimiocina CXCL2/MIP-2 nos animais controle rinovírus serotipo $1 \mathrm{~B}$ e nos animais tratados com elastase e rinovírus serotipo $1 \mathrm{~B}^{145}$. Nossos resultados sugerem que o aumento da quimiocina CXCL1 e CXCL2 possivelmente é um dos fatores que justificam o aumento de neutrófilos no nosso modelo experimental.

Os neutrófilos são células importantes para combater as infecções por bactérias, estas células rapidamente migram para o local da inflamação ${ }^{146}$, no qual exercem função fagocitária $^{147}$. Encontramos no LBA aumento de neutrófilos nos animais desafiados com LPS, também observamos aumento de neutrófilos no parênquima pulmonar dos animais que foram expostos à fumaça de cigarro e/ou instilados com LPS (CLPS, FSAL e FLPS) e além disso tivemos uma intensificação desta resposta nos animais do grupo FLPS. 
Vários estudos têm demonstrado aumento de neutrófilos em animais expostos à fumaça de cigarro ${ }^{139,148}$ e em animais que receberam instilação de LPS $^{104,148}$. Durante o aumento da fagocitose exercida pelo neutrófilos na tentativa de controlar o processo inflamatório, ocorre a liberação de substâncias tóxicas aos microorganismos mas que também promovem lesão dos tecidos, como metabólitos do oxigênio, proteases, fosfolipases e óxido nítrico ${ }^{149}$.

No pulmão, estas células são responsáveis pela liberação de mediadores que causam danos tanto para as vias aéreas quanto para o parênquima pulmonar. Além disso, os neutrófilos promovem o recrutamento de células $\mathrm{T}$ e macrófagos, através da liberação de mediadores, que levam a consequente progressão do enfisema ${ }^{150}$.

Ambas as associações de estímulos, em nosso estudo, intensificaram o aumento da densidade de neutrófilos, o que reforça a importância da resposta imune inata neste modelo experimental e corrobora com estudo prévio que demonstrou o papel fundamental da resposta imune inata no processo inflamatório induzido pela exposição à fumaça de cigarro e infecções virais ${ }^{151}$.

O papel da imunidade adaptativa no modelo experimental de exposição à fumaça de cigarro e instilação de LPS

Com o avanço do processo inflamatório, as células T são recrutadas para o local da lesão e são responsáveis por promover lesão tecidual, ou por atividade citotóxica ou através da secreção de mediadores pró-inflamatórios que recrutam e ativam outros tipos de células do sistema imune ${ }^{152}$.

As células T exercem importante papel na fisiopatologia da DPOC, o aumento da migração destas células para os pulmões em fumantes com DPOC, está relacionada à 
ativação da imunidade adaptativa, caracterizada pelo aumento de células $\mathrm{T} \mathrm{CD}^{+} \mathrm{e}$ $\mathrm{CD}^{+}$nas paredes dos alvéolos e nas pequenas vias aéreas ${ }^{153}$.

Em nosso estudo, os animais que foram expostos à fumaça de cigarro e/ou LPS (FSAL, CLPS e FLPS) apresentaram aumento de células $\mathrm{T} \mathrm{CD}^{+}$e $\mathrm{CD}^{+}$no parênquima pulmonar. Além disso, a associação da fumaça de cigarro com o LPS promoveu um aumento ainda maior das células $\mathrm{T} \mathrm{CD}^{+}$, corroborando com achados descritos em pacientes com DPOC, os quais demonstraram aumento no número de células $\mathrm{T} \mathrm{CD}^{+}{\text {e } \mathrm{CD} 8^{+} \text {nas vias aéreas e parênquima pulmonar }}^{78,153}$.

A ativação das células $\mathrm{T} \mathrm{CD}^{+}$desempenham um papel importante na patogênese da DPOC, pois podem contribuir para a progressão da doença por meio da produção de IFN- $\gamma$, favorecendo a resposta Th1 em resposta às infecções ${ }^{154}$. Embora tenhamos detectado o aumento de células $\mathrm{T} \mathrm{CD}^{+}$, não observamos o aumento da expressão de IFN- $\gamma$.

Em relação as células $\mathrm{T} \mathrm{CD}^{+}$, a ativação destas células desempenha um papel importante na resposta imune adaptativa na DPOC, uma vez que estas células se diferenciam em subtipos específicos envolvidos em diferentes tipos de respostas imunológicas ${ }^{155,156}$.

Resposta Th17/Treg

A diferenciação das células $\mathrm{T} \mathrm{CD}^{+}$requer a participação tanto de interleucinas específicas quanto de proteínas intracelulares, as Stats.

Entre as diferentes Stats descritas na literatura, priorizamos as que estão envolvidas na diferenciação para as resposta Th17 e Treg, as Stat3 e 5, respectivamente, bem como suas formas fosforiladas. 
Os nossos resultados mostraram que o desafio com LPS promoveu aumento das células positivas para FosfoStat $3^{+}$. Já, o desafio com LPS e a exposição à fumaça de cigarro induziram o aumento na densidade das células positivas para $\mathrm{Stat}^{+}$e a associação da fumaça de cigarro e o LPS exacerbou esse aumento, corroborando com o aumento dos níveis de IL-17 no pulmão.

Di Stefano et al. (2009) ${ }^{83}$ mostraram aumento nos níveis de IL-17A e IL-22 em biópsias de mucosa brônquica de pacientes com DPOC estável. Além disso, Zhang et al. (2013) ${ }^{157}$ observaram aumento nos níveis de expressão de células CD $4^{+} \mathrm{IL} 7^{+}$na parede alveolar de pacientes com DPOC e este resultado foi positivamente correlacionado com a obstrução das vias aéreas.

Além disso, observamos aumento dos níveis de IL-6 em ambos os grupos desafiados com LPS, que pode estar associado com o aumento da expressão de IL-17, uma vez que a IL-6 é reconhecida por sua potencial capacidade de desviar a diferenciação de células T CD4 para células Th17 em infecções crônicas ${ }^{51}$.

Também observamos aumento na densidade de células positivas no grupo CLPS para Stat5+. Além disso, observamos aumento de FosfoStat5+ nos grupos LPS e os valores foram ainda mais altos para as células FosfoStat5+ no grupo exposto á fumaça de cigarro e desafiado com LPS, corroborando com o aumento da densidade das células Treg.

No entanto, o aumento das células Treg nem sempre reflete um aumento na liberação de IL-10 ${ }^{158}$. Não detectamos aumento nos níveis de IL-10 no grupo FLPS, apesar do grupo CLPS ter apresentado aumento da expressão dessa citocina.

Couper et al. (2008) ${ }^{159}$ descreveram que a IL-10 pode ser produzida por várias células mielóides e linfóides e que, durante uma infecção, mais de uma população de células pode produzir IL-10. No entanto, o aumento de macrófagos e neutrófilos no 
grupo FLPS que também foram reconhecidos por liberar essa IL anti-inflamatória, não parece ter interferido na expressão de IL-10.

Na maioria das infecções, a IL-10 é um regulador essencial para controlar a resposta inflamatória, mais do que qualquer outra citocina ${ }^{159}$. A IL-10 produzida pelas células Treg está intimamente relacionada à manutenção do equilíbrio imunopatológico nas infecções virais ${ }^{160-163}$. No entanto, a inibição da sinalização da IL-10 pode exacerbar uma resposta pró-inflamatória e danificar o tecido pulmonar ${ }^{164}$. Takanashi et al. (1999) ${ }^{165}$ demonstraram níveis diminuídos de IL-10 no escarro tanto em fumantes sem obstrução quanto em fumantes com DPOC.

Jin et al. (2014) $)^{166}$ observaram que embora as células Treg sejam suprarreguladas durante as exacerbações agudas, sua capacidade de geração e diferenciação não é suficiente, sugerindo que ambas as reações pró-inflamatórias e antiinflamatórias são aumentadas, com predominância de reações pró-inflamatórias durante exacerbações agudas em pacientes com DPOC.

Os achados descritos acima corroboram com os dados do presente estudo, onde demonstramos em um modelo experimental de exacerbação da DPOC alteração da histoarquitetura pulmonar associada a um intenso processo inflamatório, no qual, apesar de termos um desvio de resposta Th17, com aumento nos níveis da IL-17 e aumento da densidade de células Treg, não temos o aumento da IL-10, que desempenha um papel fundamental no controle da exacerbação da DPOC. 


\section{CONCLUSÃO}

Desta forma, observamos que neste modelo experimental de exposição à fumaça de cigarro e instilação de LPS tivemos um desvio de resposta para diferenciação de células Th17 e Treg. A análise das interleucinas revelaram aumento da expressão de IL6 e IL-17 sem alteração na expressão de IL-10. Tais resultados, reforçam a importância da resposta Th17 na exacerbação da DPOC induzida pelo LPS e sugere que a falha na liberação de IL-10 pode exercer um papel fundamental na exacerbação do processo inflamatório. 


\section{REFERÊNCIA BIBLIOGRÁFICAS}

1. GOLD. Global Strategy for the Diagnosis, Management and Prevention of Chronic Obstructive Pulmonary Disease [cited 201815 jun].

2. Celli BR. Predictors of mortality in COPD. Respiratory medicine. 2010;104(6):773-9.

3. Barnes PJ. Chronic obstructive pulmonary disease. The New England journal of medicine. 2000;343(4):269-80.

4. Snider GL. Chronic obstructive pulmonary disease: a definition and implications of structural determinants of airflow obstruction for epidemiology. The American review of respiratory disease. 1989;140(3 Pt 2):S3-8.

5. Rabe KF, Hurd S, Anzueto A, Barnes PJ, Buist SA, Calverley P, et al. Global strategy for the diagnosis, management, and prevention of chronic obstructive pulmonary disease: GOLD executive summary. American journal of respiratory and critical care medicine. 2007;176(6):532-55.

6. Zhang X, Shan P, Jiang G, Cohn L, Lee PJ. Toll-like receptor 4 deficiency causes pulmonary emphysema. The Journal of clinical investigation. 2006;116(11):3050-9.

7. Global Alliance Against Chronic Respiratory Disease (GARD), Global surveillance. Prevention and control of chronic respiratory diseases: a comprehensive $\begin{array}{llllll}\text { approach } & \text { [cited } 2017 & 24 & \text { Out] } & \text { Available from: }\end{array}$ http://www.who.int/gard/publications/GARD\%20Book\%202007.pdf.

8. Lopez AD, Murray CC. The global burden of disease, 1990-2020. Nature medicine. 1998;4(11):1241-3.

9. Decramer M, Janssens W, Miravitlles M. Chronic obstructive pulmonary disease. Lancet. 2012;379(9823):1341-51.

10. Rabahi MF. Epidemiologia da DPOC: Enfrentando Desafios. Pulmão RJ. 2013;22(2):4-8.

11. II Consenso Brasileiro sobre Doença Pulmonar Obstrutiva Crônica - DPOC "Caracterização da Doença Pulmonar Obstrutiva Crônica (DPOC) - Definição, Epidemiologia, Diagnóstico e Estadiamento". 2004;30:1-5.

12. SUS DdId. Bronquite crônica causa 40 mil mortes a cada ano, revela dados do DATASUS [cited 201605 set 2016]. Available from: http://datasus.saude.gov.br/nucleos-regionais/alagoas/noticias-alagoas/565-bronquitecronica-causa-40-mil-mortes-a-cada-ano-revela-dados-do-datasus.

13. Menezes AM, Jardim JR, Perez-Padilla R, Camelier A, Rosa F, Nascimento O, et al. Prevalence of chronic obstructive pulmonary disease and associated factors: the PLATINO Study in Sao Paulo, Brazil. Cadernos de saude publica. 2005;21(5):1565-73.

14. Chaly PE. Tobacco control in India. Indian journal of dental research : official publication of Indian Society for Dental Research. 2007;18(1):2-5.

15. Leung CM, Leung AK, Hon KL, Kong AY. Fighting tobacco smoking--a difficult but not impossible battle. International journal of environmental research and public health. 2009;6(1):69-83.

16. Kornmann O, Beeh KM, Beier J, Geis UP, Ksoll M, Buhl R, et al. Newly diagnosed chronic obstructive pulmonary disease. Clinical features and distribution of the novel stages of the Global Initiative for Obstructive Lung Disease. Respiration; international review of thoracic diseases. 2003;70(1):67-75. 
17. Bruce N, Perez-Padilla R, Albalak R. Indoor air pollution in developing countries: a major environmental and public health challenge. Bulletin of the World Health Organization. 2000;78(9):1078-92.

18. Rivera RM, Cosio MG, Ghezzo H, Salazar M, Perez-Padilla R. Comparison of lung morphology in COPD secondary to cigarette and biomass smoke. The international journal of tuberculosis and lung disease : the official journal of the International Union against Tuberculosis and Lung Disease. 2008;12(8):972-7.

19. Demedts IK, Demoor T, Bracke KR, Joos GF, Brusselle GG. Role of apoptosis in the pathogenesis of COPD and pulmonary emphysema. Respiratory research. 2006;7:53.

20. American Thoracic S, European Respiratory S. American Thoracic Society/European Respiratory Society statement: standards for the diagnosis and management of individuals with alpha-1 antitrypsin deficiency. American journal of respiratory and critical care medicine. 2003;168(7):818-900.

21. Camelier AA, Winter DH, Jardim JR, Barboza CE, Cukier A, Miravitlles M. [Alpha-1 antitrypsin deficiency: diagnosis and treatment]. Jornal brasileiro de pneumologia : publicacao oficial da Sociedade Brasileira de Pneumologia e Tisilogia. 2008;34(7):514-27.

22. Suki B, Lutchen KR, Ingenito EP. On the progressive nature of emphysema: roles of proteases, inflammation, and mechanical forces. American journal of respiratory and critical care medicine. 2003;168(5):516-21.

23. Barnes PJ. Mediators of chronic obstructive pulmonary disease. Pharmacological reviews. 2004;56(4):515-48.

24. Ogushi F, Fells GA, Hubbard RC, Straus SD, Crystal RG. Z-type alpha 1antitrypsin is less competent than M1-type alpha 1-antitrypsin as an inhibitor of neutrophil elastase. The Journal of clinical investigation. 1987;80(5):1366-74.

25. Antunes MA, Rocco PR. Elastase-induced pulmonary emphysema: insights from experimental models. Anais da Academia Brasileira de Ciencias. 2011;83(4):1385-96.

26. Cavalcante AG, de Bruin PF. The role of oxidative stress in COPD: current concepts and perspectives. Jornal brasileiro de pneumologia : publicacao oficial da Sociedade Brasileira de Pneumologia e Tisilogia. 2009;35(12):1227-37.

27. Campos JC, Gomes KM, Ferreira JC. Impact of exercise training on redox signaling in cardiovascular diseases. Food and chemical toxicology : an international journal published for the British Industrial Biological Research Association. 2013;62:107-19.

28. Rajendrasozhan S, Yang SR, Edirisinghe I, Yao H, Adenuga D, Rahman I. Deacetylases and NF-kappaB in redox regulation of cigarette smoke-induced lung inflammation: epigenetics in pathogenesis of COPD. Antioxidants \& redox signaling. 2008;10(4):799-811.

29. Gutteridge JM, Halliwell B. Free radicals and antioxidants in the year 2000. A historical look to the future. Annals of the New York Academy of Sciences. 2000;899:136-47.

30. Bowler RP, Crapo JD. Oxidative stress in airways: is there a role for extracellular superoxide dismutase? American journal of respiratory and critical care medicine. 2002;166(12 Pt 2):S38-43.

31. Kostikas K, Papatheodorou G, Psathakis K, Panagou P, Loukides S. Oxidative stress in expired breath condensate of patients with COPD. Chest. 2003;124(4):1373-80. 
32. Paredi P, Kharitonov SA, Barnes PJ. Analysis of expired air for oxidation products. American journal of respiratory and critical care medicine. 2002;166(12 Pt 2):S31-7.

33. Kharitonov SA, Barnes PJ. Biomarkers of some pulmonary diseases in exhaled breath. Biomarkers : biochemical indicators of exposure, response, and susceptibility to chemicals. 2002;7(1):1-32.

34. Montuschi P, Collins JV, Ciabattoni G, Lazzeri N, Corradi M, Kharitonov SA, et al. Exhaled 8-isoprostane as an in vivo biomarker of lung oxidative stress in patients with COPD and healthy smokers. American journal of respiratory and critical care medicine. 2000;162(3 Pt 1):1175-7.

35. Barnes PJ. New treatments for chronic obstructive pulmonary disease. Annali dell'Istituto superiore di sanita. 2003;39(4):573-82.

36. Gan WQ, Man SF, Senthilselvan A, Sin DD. Association between chronic obstructive pulmonary disease and systemic inflammation: a systematic review and a meta-analysis. Thorax. 2004;59(7):574-80.

37. Morrison D, Rahman I, Lannan S, MacNee W. Epithelial permeability, inflammation, and oxidant stress in the air spaces of smokers. American journal of respiratory and critical care medicine. 1999;159(2):473-9.

38. Barnes PJ, Celli BR. Systemic manifestations and comorbidities of COPD. The European respiratory journal. 2009;33(5):1165-85.

39. Aaron SD, Angel JB, Lunau M, Wright K, Fex C, Le Saux N, et al. Granulocyte inflammatory markers and airway infection during acute exacerbation of chronic obstructive pulmonary disease. American journal of respiratory and critical care medicine. 2001;163(2):349-55.

40. Tuder RM, Yoshida T, Arap W, Pasqualini R, Petrache I. State of the art. Cellular and molecular mechanisms of alveolar destruction in emphysema: an evolutionary perspective. Proceedings of the American Thoracic Society. 2006;3(6):503-10.

41. Park JW, Ryter SW, Choi AM. Functional significance of apoptosis in chronic obstructive pulmonary disease. Copd. 2007;4(4):347-53.

42. Walsh GM. Defective apoptotic cell clearance in asthma and COPD--a new drug target for statins? Trends in pharmacological sciences. 2008;29(1):6-11.

43. Kasahara Y, Tuder RM, Taraseviciene-Stewart L, Le Cras TD, Abman S, Hirth $\mathrm{PK}$, et al. Inhibition of VEGF receptors causes lung cell apoptosis and emphysema. The Journal of clinical investigation. 2000;106(11):1311-9.

44. Majo J, Ghezzo H, Cosio MG. Lymphocyte population and apoptosis in the lungs of smokers and their relation to emphysema. The European respiratory journal. 2001;17(5):946-53.

45. Gadgil A, Duncan SR. Role of T-lymphocytes and pro-inflammatory mediators in the pathogenesis of chronic obstructive pulmonary disease. International journal of chronic obstructive pulmonary disease. 2008;3(4):531-41.

46. Morissette MC, Parent J, Milot J. The emphysematous lung is abnormally sensitive to TRAIL-mediated apoptosis. Respiratory research. 2011;12:105.

47. Segura-Valdez L, Pardo A, Gaxiola M, Uhal BD, Becerril C, Selman M. Upregulation of gelatinases $\mathrm{A}$ and $\mathrm{B}$, collagenases 1 and 2, and increased parenchymal cell death in COPD. Chest. 2000;117(3):684-94.

48. Aoshiba K, Yokohori N, Nagai A. Alveolar wall apoptosis causes lung destruction and emphysematous changes. American journal of respiratory cell and molecular biology. 2003;28(5):555-62. 
49. Cosio MG, Saetta M, Agusti A. Immunologic aspects of chronic obstructive pulmonary disease. The New England journal of medicine. 2009;360(23):2445-54.

50. Lee SH, Goswami S, Grudo A, Song LZ, Bandi V, Goodnight-White S, et al. Antielastin autoimmunity in tobacco smoking-induced emphysema. Nature medicine. 2007;13(5):567-9.

51. Lane N, Robins RA, Corne J, Fairclough L. Regulation in chronic obstructive pulmonary disease: the role of regulatory T-cells and Th17 cells. Clinical science. 2010;119(2):75-86.

52. Barnes PJ, Cosio MG. Characterization of $\mathrm{T}$ Lymphocytes in Chronic Obstructive Pulmonary Disease. 2004;1.

53. Costa CH, Rufino R, Lapa ESJR. [Inflammatory cells and their mediators in COPD pathogenesis]. Revista da Associacao Medica Brasileira. 2009;55(3):347-54.

54. Chung KF. Cytokines in chronic obstructive pulmonary disease. The European respiratory journal Supplement. 2001;34:50s-9s.

55. Chung KF, Barnes PJ. Cytokines in asthma. Thorax. 1999;54(9):825-57.

56. Abbas AK LA, Pober JS. Effector mechanisms of cell-mediated immunity. In: Abbas AK, Lichtman AH, Pober JS, eds. Cellular and molecular immunology. 4th ed. New York: W.B. Saunders, 2000;291-308.

57. Brusselle GG, Joos GF, Bracke KR. New insights into the immunology of chronic obstructive pulmonary disease. Lancet. 2011;378(9795):1015-26.

58. Rovina N, Koutsoukou A, Koulouris NG. Inflammation and immune response in COPD: where do we stand? Mediators of inflammation. 2013;2013:413735.

59. Mills PR, Davies RJ, Devalia JL. Airway epithelial cells, cytokines, and pollutants. American journal of respiratory and critical care medicine. 1999;160(5 Pt 2):S38-43.

60. Kolaczkowska E, Kubes P. Neutrophil recruitment and function in health and inflammation. Nature reviews Immunology. 2013;13(3):159-75.

61. De Filippo K, Henderson RB, Laschinger M, Hogg N. Neutrophil chemokines $\mathrm{KC}$ and macrophage-inflammatory protein- 2 are newly synthesized by tissue macrophages using distinct TLR signaling pathways. Journal of immunology. 2008;180(6):4308-15.

62. Lee J, Cacalano G, Camerato T, Toy K, Moore MW, Wood WI. Chemokine binding and activities mediated by the mouse IL-8 receptor. Journal of immunology. 1995;155(4):2158-64.

63. Lacoste JY, Bousquet J, Chanez P, Van Vyve T, Simony-Lafontaine J, Lequeu $\mathrm{N}$, et al. Eosinophilic and neutrophilic inflammation in asthma, chronic bronchitis, and chronic obstructive pulmonary disease. The Journal of allergy and clinical immunology. 1993;92(4):537-48.

64. Keatings VM, Collins PD, Scott DM, Barnes PJ. Differences in interleukin-8 and tumor necrosis factor-alpha in induced sputum from patients with chronic obstructive pulmonary disease or asthma. American journal of respiratory and critical care medicine. 1996;153(2):530-4.

65. Elhelu MA. The role of macrophages in immunology. Journal of the National Medical Association. 1983;75(3):314-7.

66. Retamales I, Elliott WM, Meshi B, Coxson HO, Pare PD, Sciurba FC, et al. Amplification of inflammation in emphysema and its association with latent adenoviral infection. American journal of respiratory and critical care medicine. 2001;164(3):46973. 
67. Barnes PJ. New concepts in chronic obstructive pulmonary disease. Annual review of medicine. 2003;54:113-29.

68. Stockley RA, Mannino D, Barnes PJ. Burden and pathogenesis of chronic obstructive pulmonary disease. Proceedings of the American Thoracic Society. 2009;6(6):524-6.

69. Slominski JM, Kedziora K. [Is COPD an autoimmune disease caused by smoking?]. Przeglad lekarski. 2006;63(10):1138-9.

70. Lambrecht BN, Hammad H. The role of dendritic and epithelial cells as master regulators of allergic airway inflammation. Lancet. 2010;376(9743):835-43.

71. Tsoumakidou M, Elston W, Zhu J, Wang Z, Gamble E, Siafakas NM, et al. Cigarette smoking alters bronchial mucosal immunity in asthma. American journal of respiratory and critical care medicine. 2007;175(9):919-25.

72. Lambrecht BN, Prins JB, Hoogsteden HC. Lung dendritic cells and host immunity to infection. The European respiratory journal. 2001;18(4):692-704.

73. Korn S, Wiewrodt R, Walz YC, Becker K, Mayer E, Krummenauer F, et al. Characterization of the interstitial lung and peripheral blood $\mathrm{T}$ cell receptor repertoire in cigarette smokers. American journal of respiratory cell and molecular biology. 2005;32(2):142-8.

74. Motz GT, Eppert BL, Sun G, Wesselkamper SC, Linke MJ, Deka R, et al. Persistence of lung CD8 $\mathrm{T}$ cell oligoclonal expansions upon smoking cessation in a mouse model of cigarette smoke-induced emphysema. Journal of immunology. 2008;181(11):8036-43.

75. O'Shaughnessy TC, Ansari TW, Barnes NC, Jeffery PK. Inflammation in bronchial biopsies of subjects with chronic bronchitis: inverse relationship of CD8+ T lymphocytes with FEV1. American journal of respiratory and critical care medicine. 1997;155(3):852-7.

76. Saetta M, Di Stefano A, Turato G, Facchini FM, Corbino L, Mapp CE, et al. CD8+ T-lymphocytes in peripheral airways of smokers with chronic obstructive pulmonary disease. American journal of respiratory and critical care medicine. 1998;157(3 Pt 1):822-6.

77. Zhao MQ, Stoler MH, Liu AN, Wei B, Soguero C, Hahn YS, et al. Alveolar epithelial cell chemokine expression triggered by antigen-specific cytolytic CD8(+) T cell recognition. The Journal of clinical investigation. 2000;106(6):R49-58.

78. Saetta M, Baraldo S, Corbino L, Turato G, Braccioni F, Rea F, et al. CD8+ve cells in the lungs of smokers with chronic obstructive pulmonary disease. American journal of respiratory and critical care medicine. 1999;160(2):711-7.

79. Finkelstein R, Fraser RS, Ghezzo H, Cosio MG. Alveolar inflammation and its relation to emphysema in smokers. American journal of respiratory and critical care medicine. 1995;152(5 Pt 1):1666-72.

80. Barnes PJ. Immunology of asthma and chronic obstructive pulmonary disease. Nature reviews Immunology. 2008;8(3):183-92.

81. Yoshimura A, Suzuki M, Sakaguchi R, Hanada T, Yasukawa H. SOCS, Inflammation, and Autoimmunity. Frontiers in immunology. 2012;3:20.

82. Miossec P, Korn T, Kuchroo VK. Interleukin-17 and type 17 helper T cells. The New England journal of medicine. 2009;361(9):888-98.

83. Di Stefano A, Caramori G, Gnemmi I, Contoli M, Vicari C, Capelli A, et al. T helper type 17-related cytokine expression is increased in the bronchial mucosa of stable chronic obstructive pulmonary disease patients. Clinical and experimental immunology. 2009;157(2):316-24. 
84. Campbell DJ, Ziegler SF. FOXP3 modifies the phenotypic and functional properties of regulatory T cells. Nature reviews Immunology. 2007;7(4):305-10.

85. Bilate AM, Lafaille JJ. Induced CD4+Foxp3+ regulatory $\mathrm{T}$ cells in immune tolerance. Annual review of immunology. 2012;30:733-58.

86. Rudensky AY. Regulatory $\mathrm{T}$ cells and Foxp3. Immunological reviews. 2011;241(1):260-8.

87. Plumb J, Smyth LJ, Adams HR, Vestbo J, Bentley A, Singh SD. Increased Tregulatory cells within lymphocyte follicles in moderate COPD. The European respiratory journal. 2009;34(1):89-94.

88. Sales DS, Ito JT, Zanchetta IA, Annoni R, Aun MV, Ferraz LFS, et al. Regulatory T-Cell Distribution within Lung Compartments in COPD. Copd. 2017:1-10. 89. Wei J, Xiong XF, Lin YH, Zheng BX, Cheng DY. Association between serum interleukin-6 concentrations and chronic obstructive pulmonary disease: a systematic review and meta-analysis. PeerJ. 2015;3:e1199.

90. Geraghty P, Wyman AE, Garcia-Arcos I, Dabo AJ, Gadhvi S, Foronjy R. STAT3 modulates cigarette smoke-induced inflammation and protease expression. Frontiers in physiology. 2013;4:267.

91. Saleh A, Shan L, Halayko AJ, Kung S, Gounni AS. Critical role for STAT3 in IL-17A-mediated CCL11 expression in human airway smooth muscle cells. Journal of immunology. 2009;182(6):3357-65.

92. Qu P, Roberts J, Li Y, Albrecht M, Cummings OW, Eble JN, et al. Stat3 downstream genes serve as biomarkers in human lung carcinomas and chronic obstructive pulmonary disease. Lung cancer. 2009;63(3):341-7.

93. Kimura A, Kishimoto T. IL-6: regulator of Treg/Th17 balance. European journal of immunology. 2010;40(7):1830-5.

94. McGeachy MJ, Cua DJ. The link between IL-23 and Th17 cell-mediated immune pathologies. Seminars in immunology. 2007;19(6):372-6.

95. O'Shea JJ, Paul WE. Mechanisms underlying lineage commitment and plasticity of helper CD4+ T cells. Science. 2010;327(5969):1098-102.

96. Sheng W, Yang F, Zhou Y, Yang H, Low PY, Kemeny DM, et al. STAT5 programs a distinct subset of GM-CSF-producing $\mathrm{T}$ helper cells that is essential for autoimmune neuroinflammation. Cell research. 2014;24(12):1387-402.

97. Ruwanpura SM, McLeod L, Brooks GD, Bozinovski S, Vlahos R, Longano A, et al. IL-6/Stat3-driven pulmonary inflammation, but not emphysema, is dependent on interleukin-17A in mice. Respirology. 2014;19(3):419-27.

98. Rodrigues Brandao-Rangel MA, Bachi ALL, Oliveira-Junior MC, Abbasi A, Silva-Renno A, Aparecida de Brito A, et al. Exercise Inhibits the Effects of SmokeInduced COPD Involving Modulation of STAT3. Oxidative medicine and cellular longevity. 2017;2017:6572714.

99. Barnes PJ. IL-10: a key regulator of allergic disease. Clinical and experimental allergy : journal of the British Society for Allergy and Clinical Immunology. 2001;31(5):667-9.

100. Zhao P, Li J, Tian Y, Mao J, Liu X, Feng S, et al. Restoring Th17/Treg balance via modulation of STAT3 and STAT5 activation contributes to the amelioration of chronic obstructive pulmonary disease by Bufei Yishen formula. Journal of ethnopharmacology. 2018;217:152-62.

101. GOLD. Global Strategy for the Diagnosis, Management and Prevention of Chronic Obstructive Pulmonary Disease 2017 [cited 201726 jun]. Available from: http://goldcopd.org/gold-2017-global-strategy-diagnosis-management-prevention-copd/. 
102. Aaron SD, Donaldson GC, Whitmore GA, Hurst JR, Ramsay T, Wedzicha JA. Time course and pattern of COPD exacerbation onset. Thorax. 2012;67(3):238-43.

103. Celli BR, Barnes PJ. Exacerbations of chronic obstructive pulmonary disease. The European respiratory journal. 2007;29(6):1224-38.

104. Hardaker EL, Freeman MS, Dale N, Bahra P, Raza F, Banner KH, et al. Exposing rodents to a combination of tobacco smoke and lipopolysaccharide results in an exaggerated inflammatory response in the lung. British journal of pharmacology. 2010;160(8):1985-96.

105. Soler-Cataluna JJ, Martinez-Garcia MA, Roman Sanchez P, Salcedo E, Navarro M, Ochando R. Severe acute exacerbations and mortality in patients with chronic obstructive pulmonary disease. Thorax. 2005;60(11):925-31.

106. Tanabe N, Muro S, Hirai T, Oguma T, Terada K, Marumo S, et al. Impact of exacerbations on emphysema progression in chronic obstructive pulmonary disease. American journal of respiratory and critical care medicine. 2011;183(12):1653-9.

107. Mercer PF, Shute JK, Bhowmik A, Donaldson GC, Wedzicha JA, Warner JA. MMP-9, TIMP-1 and inflammatory cells in sputum from COPD patients during exacerbation. Respiratory research. 2005;6:151.

108. Higashimoto Y, Yamagata Y, Iwata T, Okada M, Ishiguchi T, Sato H, et al. Increased serum concentrations of tissue inhibitor of metalloproteinase-1 in COPD patients. The European respiratory journal. 2005;25(5):885-90.

109. Seemungal TA, Donaldson GC, Paul EA, Bestall JC, Jeffries DJ, Wedzicha JA. Effect of exacerbation on quality of life in patients with chronic obstructive pulmonary disease. American journal of respiratory and critical care medicine. 1998;157(5 Pt 1):1418-22.

110. Seemungal TA, Donaldson GC, Bhowmik A, Jeffries DJ, Wedzicha JA. Time course and recovery of exacerbations in patients with chronic obstructive pulmonary disease. American journal of respiratory and critical care medicine. 2000;161(5):160813.

111. Sethi S, Murphy TF. Infection in the pathogenesis and course of chronic obstructive pulmonary disease. The New England journal of medicine. 2008;359(22):2355-65.

112. Taylor JD. COPD and the response of the lung to tobacco smoke exposure. Pulmonary pharmacology \& therapeutics. 2010;23(5):376-83.

113. Kobayashi S, Fujinawa R, Ota F, Kobayashi S, Angata T, Ueno M, et al. A single dose of lipopolysaccharide into mice with emphysema mimics human chronic obstructive pulmonary disease exacerbation as assessed by micro-computed tomography. American journal of respiratory cell and molecular biology. 2013;49(6):971-7.

114. Crooks SW, Bayley DL, Hill SL, Stockley RA. Bronchial inflammation in acute bacterial exacerbations of chronic bronchitis: the role of leukotriene B4. The European respiratory journal. 2000;15(2):274-80.

115. Bhowmik A, Seemungal TA, Sapsford RJ, Wedzicha JA. Relation of sputum inflammatory markers to symptoms and lung function changes in COPD exacerbations. Thorax. 2000;55(2):114-20.

116. Gompertz S, Bayley DL, Hill SL, Stockley RA. Relationship between airway inflammation and the frequency of exacerbations in patients with smoking related COPD. Thorax. 2001;56(1):36-41. 
117. Caramori G, Romagnoli M, Casolari P, Bellettato C, Casoni G, Boschetto P, et al. Nuclear localisation of p65 in sputum macrophages but not in sputum neutrophils during COPD exacerbations. Thorax. 2003;58(4):348-51.

118. Murphy TF. The role of bacteria in airway inflammation in exacerbations of chronic obstructive pulmonary disease. Current opinion in infectious diseases. 2006;19(3):225-30.

119. Dancer R, Sansom DM. Regulatory $\mathrm{T}$ cells and COPD. Thorax. 2013;68(12):1176-8.

120. Oliveira MV, Silva PL, Rocco PRM. Animal Models of Chronic Obstructive Pulmonary Disease Exacerbations: A Review of the Current Status. Journal of Biomedical Sciences. 2016;5(1):1:8.

121. Hasday JD, Bascom R, Costa JJ, Fitzgerald T, Dubin W. Bacterial endotoxin is an active component of cigarette smoke. Chest. 1999;115(3):829-35.

122. Larsson L, Szponar B, Pehrson C. Tobacco smoking increases dramatically air concentrations of endotoxin. Indoor air. 2004;14(6):421-4.

123. Sebastian A, Pehrson C, Larsson L. Elevated concentrations of endotoxin in indoor air due to cigarette smoking. Journal of environmental monitoring : JEM. 2006;8(5):519-22.

124. Vernooy JH, Dentener MA, van Suylen RJ, Buurman WA, Wouters EF. Longterm intratracheal lipopolysaccharide exposure in mice results in chronic lung inflammation and persistent pathology. American journal of respiratory cell and molecular biology. 2002;26(1):152-9.

125. Churg A, Wright JL. Animal models of cigarette smoke-induced chronic obstructive lung disease. Contributions to microbiology. 2007;14:113-25.

126. Toledo AC, Magalhaes RM, Hizume DC, Vieira RP, Biselli PJ, Moriya HT, et al. Aerobic exercise attenuates pulmonary injury induced by exposure to cigarette smoke. The European respiratory journal. 2012;39(2):254-64.

127. Biselli PJ, Lopes FD, Moriya HT, Rivero DH, Toledo AC, Saldiva PH, et al. Short-term exposure of mice to cigarette smoke and/or residual oil fly ash produces proximal airspace enlargements and airway epithelium remodeling. Brazilian journal of medical and biological research $=$ Revista brasileira de pesquisas medicas e biologicas $/$ Sociedade Brasileira de Biofisica [et al]. 2011;44(5):460-8.

128. Hantos Z, Daroczy B, Suki B, Nagy S, Fredberg JJ. Input impedance and peripheral inhomogeneity of dog lungs. Journal of applied physiology. 1992;72(1):16878.

129. Weibel ER. Morphometry: stereological theory and practical methods, In: GIL, J. (Ed.). Models of lung disease-microscopy and structural methods. New York: Marcel Dekker, 1990. p. 199-247.

130. Margraf LR, Tomashefski JF, Jr., Bruce MC, Dahms BB. Morphometric analysis of the lung in bronchopulmonary dysplasia. The American review of respiratory disease. 1991;143(2):391-400.

131. Evans MJ, Cox RA, Shami SG, Wilson B, Plopper CG. The role of basal cells in attachment of columnar cells to the basal lamina of the trachea. American journal of respiratory cell and molecular biology. 1989;1(6):463-9.

132. Papi A, Luppi F, Franco F, Fabbri LM. Pathophysiology of exacerbations of chronic obstructive pulmonary disease. Proceedings of the American Thoracic Society. 2006;3(3):245-51.

133. Makris D, Lazarou S, Alexandrakis M, Kourelis TV, Tzanakis N, Kyriakou D, et al. Tc2 response at the onset of COPD exacerbations. Chest. 2008;134(3):483-8. 
134. Groneberg DA, Chung KF. Models of chronic obstructive pulmonary disease. Respiratory research. 2004;5:18.

135. Lopes FD, Toledo AC, Olivo CR, Prado CM, Leick EA, Medeiros MC, et al. A comparative study of extracellular matrix remodeling in two murine models of emphysema. Histology and histopathology. 2013;28(2):269-76.

136. Vlahos R, Bozinovski S, Gualano RC, Ernst M, Anderson GP. Modelling COPD in mice. Pulmonary pharmacology \& therapeutics. 2006;19(1):12-7.

137. Nie YC, Wu H, Li PB, Luo YL, Zhang CC, Shen JG, et al. Characteristic comparison of three rat models induced by cigarette smoke or combined with LPS: to establish a suitable model for study of airway mucus hypersecretion in chronic obstructive pulmonary disease. Pulmonary pharmacology \& therapeutics. 2012;25(5):349-56.

138. Anciaes AM, Olivo CR, Prado CM, Kagohara KH, Pinto Tda S, Moriya HT, et al. Respiratory mechanics do not always mirror pulmonary histological changes in emphysema. Clinics. 2011;66(10):1797-803.

139. D'Hulst A I, Vermaelen KY, Brusselle GG, Joos GF, Pauwels RA. Time course of cigarette smoke-induced pulmonary inflammation in mice. The European respiratory journal. 2005;26(2):204-13.

140. Stefanska AM, Walsh PT. Chronic obstructive pulmonary disease: evidence for an autoimmune component. Cellular \& molecular immunology. 2009;6(2):81-6.

141. Tanino M, Betsuyaku T, Takeyabu K, Tanino Y, Yamaguchi E, Miyamoto K, et al. Increased levels of interleukin-8 in BAL fluid from smokers susceptible to pulmonary emphysema. Thorax. 2002;57(5):405-11.

142. O'Donnell RA, Peebles C, Ward JA, Daraker A, Angco G, Broberg P, et al. Relationship between peripheral airway dysfunction, airway obstruction, and neutrophilic inflammation in COPD. Thorax. 2004;59(10):837-42.

143. Fuke S, Betsuyaku T, Nasuhara Y, Morikawa T, Katoh H, Nishimura M. Chemokines in bronchiolar epithelium in the development of chronic obstructive pulmonary disease. American journal of respiratory cell and molecular biology. 2004;31(4):405-12.

144. van der Strate BW, Postma DS, Brandsma CA, Melgert BN, Luinge MA, Geerlings M, et al. Cigarette smoke-induced emphysema: A role for the B cell? American journal of respiratory and critical care medicine. 2006;173(7):751-8.

145. Singanayagam A, Glanville N, Walton RP, Aniscenko J, Pearson RM, Pinkerton JW, et al. A short-term mouse model that reproduces the immunopathological features of rhinovirus-induced exacerbation of COPD. Clinical science. 2015;129(3):245-58.

146. Kobayashi Y. Neutrophil infiltration and chemokines. Critical reviews in immunology. 2006;26(4):307-16.

147. Lee WL, Harrison RE, Grinstein S. Phagocytosis by neutrophils. Microbes and infection. 2003;5(14):1299-306.

148. Thatcher TH, McHugh NA, Egan RW, Chapman RW, Hey JA, Turner CK, et al. Role of CXCR2 in cigarette smoke-induced lung inflammation. American journal of physiology Lung cellular and molecular physiology. 2005;289(2):L322-8.

149. Dallegri F, Ottonello L. Tissue injury in neutrophilic inflammation. Inflammation research : official journal of the European Histamine Research Society [et al]. 1997;46(10):382-91.

150. Shapiro SD, Goldstein NM, Houghton AM, Kobayashi DK, Kelley D, Belaaouaj A. Neutrophil elastase contributes to cigarette smoke-induced emphysema in mice. The American journal of pathology. 2003;163(6):2329-35. 
151. Kang MJ, Lee CG, Lee JY, Dela Cruz CS, Chen ZJ, Enelow R, et al. Cigarette smoke selectively enhances viral PAMP- and virus-induced pulmonary innate immune and remodeling responses in mice. The Journal of clinical investigation. 2008;118(8):2771-84.

152. Monaco C, Andreakos E, Kiriakidis S, Feldmann M, Paleolog E. T-cellmediated signalling in immune, inflammatory and angiogenic processes: the cascade of events leading to inflammatory diseases. Current drug targets Inflammation and allergy. 2004;3(1):35-42.

153. Hogg JC, Chu F, Utokaparch S, Woods R, Elliott WM, Buzatu L, et al. The nature of small-airway obstruction in chronic obstructive pulmonary disease. The New England journal of medicine. 2004;350(26):2645-53.

154. Maeno T, Houghton AM, Quintero PA, Grumelli S, Owen CA, Shapiro SD. CD8+ T Cells are required for inflammation and destruction in cigarette smoke-induced emphysema in mice. Journal of immunology. 2007;178(12):8090-6.

155. Zhu J, Yamane H, Paul WE. Differentiation of effector CD4 T cell populations (*). Annual review of immunology. 2010;28:445-89.

156. Zhu J, Paul WE. CD4 T cells: fates, functions, and faults. Blood. 2008;112(5):1557-69.

157. Zhang J, Chu S, Zhong X, Lao Q, He Z, Liang Y. Increased expression of CD4+IL-17+ cells in the lung tissue of patients with stable chronic obstructive pulmonary disease (COPD) and smokers. International immunopharmacology. 2013;15(1):58-66.

158. Vieira PL, Christensen JR, Minaee S, O'Neill EJ, Barrat FJ, Boonstra A, et al. IL-10-secreting regulatory $\mathrm{T}$ cells do not express Foxp3 but have comparable regulatory function to naturally occurring CD4+CD25+ regulatory T cells. Journal of immunology. 2004;172(10):5986-93.

159. Couper KN, Blount DG, Riley EM. IL-10: the master regulator of immunity to infection. Journal of immunology. 2008;180(9):5771-7.

160. Suvas S, Azkur AK, Kim BS, Kumaraguru U, Rouse BT. CD4+CD25+ regulatory $\mathrm{T}$ cells control the severity of viral immunoinflammatory lesions. Journal of immunology. 2004;172(7):4123-32.

161. Groux H, Cottrez F, Rouleau M, Mauze S, Antonenko S, Hurst S, et al. A transgenic model to analyze the immunoregulatory role of IL-10 secreted by antigenpresenting cells. Journal of immunology. 1999;162(3):1723-9.

162. Netea MG, Sutmuller R, Hermann C, Van der Graaf CA, Van der Meer JW, van Krieken JH, et al. Toll-like receptor 2 suppresses immunity against Candida albicans through induction of $\mathrm{IL}-10$ and regulatory $\mathrm{T}$ cells. Journal of immunology. 2004;172(6):3712-8.

163. Kullberg MC, Jankovic D, Gorelick PL, Caspar P, Letterio JJ, Cheever AW, et al. Bacteria-triggered CD4(+) $\mathrm{T}$ regulatory cells suppress Helicobacter hepaticusinduced colitis. The Journal of experimental medicine. 2002;196(4):505-15.

164. Anderson CF, Oukka M, Kuchroo VJ, Sacks D. CD4(+)CD25(-)Foxp3(-) Th1 cells are the source of IL-10-mediated immune suppression in chronic cutaneous leishmaniasis. The Journal of experimental medicine. 2007;204(2):285-97.

165. Takanashi S, Hasegawa Y, Kanehira Y, Yamamoto K, Fujimoto K, Satoh K, et al. Interleukin-10 level in sputum is reduced in bronchial asthma, COPD and in smokers. The European respiratory journal. 1999;14(2):309-14.

166. Jin Y, Wan Y, Chen G, Chen L, Zhang MQ, Deng L, et al. Treg/IL-17 ratio and Treg differentiation in patients with COPD. PloS one. 2014;9(10):e111044. 